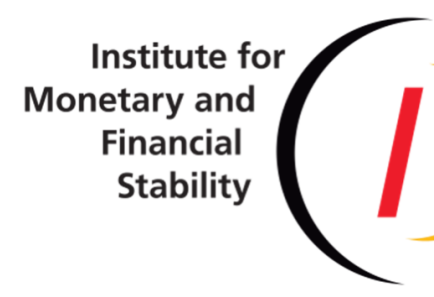

GREGOR BOEHL, FELIX STROBEL

US Business Cycle Dynamics at the Zero Lower Bound

Institute for Monetary and Financial Stability

GOETHE UNIVERSITY FRANKFURT

Working PAPER Series No. 143 (2020) 
This Working Paper is issued under the auspices of the Institute for Monetary and Financial Stability (IMFS). Any opinions expressed here are those of the author(s) and not those of the IMFS. Research disseminated by the IMFS may include views on policy, but the IMFS itself takes no institutional policy positions.

The IMFS aims at raising public awareness of the importance of monetary and financial stability. Its main objective is the implementation of the "Project Monetary and Financial Stability" that is supported by the Foundation of Monetary and Financial Stability. The foundation was established on January 1, 2002 by federal law. Its endowment funds come from the sale of 1 DM gold coins in 2001 that were issued at the occasion of the euro cash introduction in memory of the D-Mark.

The IMFS Working Papers often represent preliminary or incomplete work, circulated to encourage discussion and comment. Citation and use of such a paper should take account of its provisional character.

\section{Institute for Monetary and Financial Stability}

Goethe University Frankfurt

House of Finance

Theodor-W.-Adorno-Platz 3

D-60629 Frankfurt am Main

www.imfs-frankfurt.de | info@imfs-frankfurt.de 


\title{
US Business Cycle Dynamics at the Zero Lower Bound
}

Latest version at http://gregorboehl.com/live/bczlb_BS.pdf

\author{
Gregor Boehl $^{\mathrm{a}, *}$, Felix Strobel ${ }^{\mathrm{b}}$ \\ ${ }^{a}$ University of Bonn \\ ${ }^{b}$ Deutsche Bundesbank
}

June 23, 2020

\begin{abstract}
Using a nonlinear Bayesian likelihood approach that fully accounts for the zero lower bound on nominal interest rates, we analyze US post-crisis business cycle dynamics and provide reference parameter estimates. Contradicting the gist of the literature, we find that neither the inclusion of financial frictions nor that of household heterogeneity improve the empirical fit of the standard model, or its ability to provide a joint explanation for the post-2007 dynamics. Associated financial shocks mis-predict an increase in consumption. The common practice of omitting the ZLB period in the estimation severely distorts the analysis of the more recent economic dynamics.
\end{abstract}

Keywords: Zero Lower Bound, Bayesian Estimation, Great Recession, Business Cycles JEL: C11, C63, E31, E32, E44

\section{Introduction}

More than a decade ago, the Financial Crisis and the subsequent Great Recession did not only wreak havoc on the US economy, but it also shook the macroeconomic profession to the core. As a consequence, a plethora of approaches has been developed to enrich dynamic macroeconomic models with features conceived to enhance our understanding of the dynamics during and after the Great Recession. While progress flourished on the front of theoretical modeling, very few attempts have been made to test these models empirically on the period including and following the Great Recession. This is primarily due to the long-lasting binding zero-lower bound on nominal interest rates (ZLB) ${ }^{1}$, which renders conventional econometric methods unsuitable.

\footnotetext{
${ }^{\star}$ We are grateful to Alex Clymo, Gavin Goy, Alexander Meyer-Gohde, Alexander Richter, Mathias Trabandt, Carlos Zarazaga and participants of the 2018 Stanford MMCI Conference, the 2018 EEA Annual Congress and the 2018 VfS Jahrestagung for discussions and helpful comments on the contents of this paper. The views expressed in this paper are solely the responsibility of the authors and should not be interpreted as reflecting the views of Deutsche Bundesbank. Part of the research leading to the results in this paper has received financial support from the Alfred P. Sloan Foundation under the grant agreement G-2016-7176 for the Macroeconomic Model Comparison Initiative (MMCI) at the Institute for Monetary and Financial Stability.

${ }^{*}$ Corresponding author

Email addresses: gboehl@uni-bonn.de, felix.strobel@bundesbank.de

${ }^{1}$ Given the recent European and Japanese experience with slightly negative rates, the term "effective lower bound" is more precise. Nevertheless we employ the term "zero lower bound" throughout this text as it is used more frequently in the literature.
} 
In this paper, we make a step towards closing this gap by providing an account of the last two decades based on a set of models, which are estimated on data from this period. Our sample extends to 2019, thereby including the exit from the ZLB. Using a set of novel methods developed in Boehl (2020b) allows us to estimate large macroeconomic models while fully accounting for the effects of the ZLB. We take the standard medium-scale representative agent new Keynesian model (RANK) of Christiano et al. (2005) and Smets and Wouters (2007) as the baseline model. Motivated by the importance of the interlinkages between the financial sector and the real economy during the Great Recession, we consider the extension of the framework developed by Christiano et al. (2014); Del Negro et al. (2015b), who add financial frictions as in Bernanke et al. (1999). Motivated by the rising interest in the effects of household heterogeneity on the macroeconomy we further include the effects of hand-tomouth agents into our analysis. The two agent new Keynesian (TANK) model can be seen as a shortcut to the more thorough heterogeneous agent new Keynesian (HANK) model while incorporating important additional channels in our investigation. ${ }^{2}$

Our first key contribution is to demonstrate that neither the inclusion of financial frictions nor hand-to-mouth consumers enhance the standard model's empirical fit or its ability to provide a parsimonious account of the crisis. Second, we illustrate how an omission of the Great Recession and the ZLB period in the empirical analysis may result in misleading conclusions regarding the drivers of macroeconomic dynamics in the last decades. Third, we provide reference estimations for the crisis sample, which we compare across models and with estimation results for a pre-crisis sample.

With the Financial Crisis being one, admittedly complex, event, a good model should be able to allot the bulk of the persistent effects of the crisis to a common source within the model (Angeletos et al., 2018). ${ }^{3}$ However, we find that all models that we consider fall short in accounting for the joint dynamics of investment, consumption and inflation following 2008. Instead - in the extreme case of the models with financial frictions - the downturns of consumption and investment during the recession are almost entirely driven by disparate exogenous forces. Strictly speaking, these models attribute the behavior of these variables to two different crisis events instead of providing a joint propagation mechanism that points towards a parsimonious interpretation of the Great Recession.

We demonstrate that the economic question of a joint propagation mechanism is closely linked to the empirical fit of the model. To some degree this is intuitive as a joint driver that moves the macroeconomic system as a whole reduces the need for several separate large shocks to generate the extreme dynamics in different variables observed during the recession, thereby improving the likelihood of the model.

The simple RANK model outperforms its extended counterparts in terms of empirical fit. In this model, an exogenous increase in the risk premium on households' borrowing rate is the main driver of macroeconomic dynamics following the Great Recession. Risk premium shocks account for the drop in consumption and are responsible for the long duration of the ZLB. However, they can only provide a partial explanation for the behavior of investment and inflation during the recession. To generate the extent of the collapse in investment, an extra driver, here shocks to the marginal efficiency of investment (MEI), is needed. Similarly,

\footnotetext{
${ }^{2}$ See, e.g., McKay and Reis, 2016; Kaplan et al., 2018; Auclert, 2019 on the current stand of this literature.

${ }^{3}$ Angeletos et al. (2018) go even further and search for one shock as a main driver of business cycles over a longer time-span. In their paper, they list, for instance, the TFP shock in Kydland and Prescott (1982), the marginal efficiency of investment shock by Justiniano et al. (2010) and the risk shock by Christiano et al. (2014) as examples for similar endeavors.
} 
the dip of inflation in that period is associated with additional shocks to the price markup. Hence, albeit to a lesser extent than other models, RANK also attributes the dynamics in consumption, investment and inflation in that event to distinct drivers which hit the economy in different sectors.

Financial frictions à la Bernanke et al. (1999) do not improve upon the RANK model's ability to provide a parsimonious explanation for the dynamics during and after the Great Recession, nor do they enhance the empirical fit of the model. ${ }^{4}$ The reason for this is that the response of investment to risk premium shocks is attenuated by the presence of financial frictions. Recessionary shocks only trigger a short-lived contraction in entrepreneurial net worth, but a more persistent decline in the capital stock. This implies that the entrepreneurial leverage decreases in the medium run, lowering the credit spread and hence the cost of investment. The outlook of a favorable future investment climate actually dampens the decrease in investment from the onset and impairs the ability of the shock to generate the sharp drop of investment observed in the Recession. The financial sector attenuates the effect of MEI shocks on investment in a similar fashion.

While MEI shocks and shocks that target investment financing can account for the collapse of investment during the Great Recession, they do not contribute to the substantial decline of consumption in that episode. We illustrate this for the case of risk shocks in the spirit of Christiano et al. (2014). Our estimates suggest that these shocks trigger a negative co-movement of household spending and investment, which is at odds with observed dynamics. Consequently, we find that these shocks only play a very minor role for macroeconomic dynamics in and after the Great Recession. This somewhat inconvenient finding has implications for other financial shocks as well, that have been proposed in the literature and do not lower consumption on impact, such as the credit shock and the investment shock in Carlstrom et al. (2017) or the wealth shock proposed in Carlstrom and Fuerst (1997). ${ }^{5}$ On a more general note, it appears that a shock that affects borrowing rates of households and firms alike is a more promising candidate for providing an account of the Great Recession.

The inclusion of hand-to-mouth agents hardly affects aforementioned results. Parameter estimates, the empirical fit and the transmission of risk premium shocks are very similar for TANK and RANK models. Given our parameter estimates, the direct effects and indirect effects of hand-to-mouth agents in response to a risk premium shock roughly chancel out. A weakening link between consumption and the risk premium is offset by a stronger connection between consumption and movements in real activity. For a pre-crisis sample in which other shocks such as MEI shocks and wage markup shocks play a more prominent role, we demonstrate that the inclusion of hand-to-mouth agents actually lowers the models empirical fit as they suggest a negative correlation of wages and investment in response to a wage markup shock. This is hard to reconcile with the empirical evidence. We conclude that in the context of the standard medium-scale model, which already contains a host of bells and whistles, our analysis suggests that hand-to-mouth agents are a non-essential feature for

\footnotetext{
${ }^{4} \mathrm{By}$ considering the role of financial friction for the US economy in the Great Recession, we touch upon an active literature. Meh and Moran, 2010; Gerali et al., 2010; Cúrdia and Woodford, 2011; Gertler and Karadi, 2011; Brunnermeier and Sannikov, 2014; Christiano et al., 2014; Del Negro et al., 2017. Our analysis provides an argument for the benefits of testing these models empirically on the period of the Great Recession and the ZLB.

${ }^{5}$ An exception is the capital quality shock proposed by Gertler and Kiyotaki (2010). This shock hits the economy at very different points simultaneously to capture key features of the crisis. However, Boehl et al. (2020) document a low explanatory power to this shock as its macroeconomic effects much depends on the actual calibration.
} 
explaining business cycle dynamics. However, this does not preclude that a more thorough modeling of microeconomic heterogeneity as pursued by the HANK literature could improve upon the empirical performance. ${ }^{6}$

It has become a common practice to analyze the Great Recession and the ZLB period through the lens of models that have been calibrated to or estimated on pre-crisis data only (see, e.g., Gertler and Karadi, 2011; Christiano et al., 2014, 2015; Del Negro et al., 2015b; Carlstrom et al., 2017). This approach has generated prominent results that shape our profession's understanding of the Great Recession, the role of financial frictions, and the effect of unconventional monetary policy measures. However, we document that this practice can generate misleading conclusions. We illustrate this by comparing the results from above with a decomposition of the US post-crisis dynamics using a RANK model estimated based on pre-crisis data. In this exercise, MEI shocks, which play an important role in the pre-crisis sample, now substantially gain importance in accounting for the drop in real activity during the Great Recession. They substantially weigh on consumption and fully explain the collapse of investment. This exercise illustrates why previous studies that employed pre-crisis data for their empirical analysis focused on disturbances to investment financing as a driver of the crisis. It furthermore clarifies that the dominant role of the risk premium shock in our interpretation of the last decades is not hardwired into the model, but rather it is the interpretation of the dynamics of the US economy, that is favored by the data. ${ }^{7}$

Across all models considered, the episode of missing disinflation is reflected by an estimate of a flat Phillips curve. ${ }^{8}$ However, conducting estimates on a pre-crisis sample that starts in the Great Moderation we find that the structural relationship between nominal and real aggregates already weakens before the crisis. Our observation suggests that the link between inflation and economic activity is not well captured in the workhorse models of contemporary monetary theory. Recently, several paper have attempted to resuscitate the Phillips Curve by including financial frictions. In Christiano et al. (2015) and Gilchrist et al. (2017), increased refinancing costs drive firms to raise their prices and prevented a severe disinflation. While in our models, recessionary MEI and risk shocks can in principle generate inflationary pressure, their weight in the estimation of the crisis sample is not sufficient to address the missing disinflation puzzle. Thus, the inclusion of financial frictions does not revive the Phillips curve, nor does accounting for a binding ZLB.

A small number of papers has recently analyzed the Great Recession through the lens of estimated macroeconomic models with an endogenously binding ZLB. The estimation of DSGE models with a binding ZLB was pioneered by work on small-scale NK models. ${ }^{9}$ Gust et al. (2017) estimate a reduced version of the RANK model that is solved via global methods. In addition to this work, using the set of methods described in Boehl (2020b) allows us to consider the full version of the RANK model with the usual bells and whistles, and to extend the analysis to the role of the model extensions. Kulish et al. (2017) estimate

\footnotetext{
${ }^{6}$ For instance, Bayer et al. (2019) recently estimate a HANK model on US data and stress the importance of idiosyncratic income risk and portfolio liquidity for macroeconomic dynamics. Our TANK model naturally cannot capture these effects. However, in contrast to Bayer et al. (2019), we include the ZLB into our estimation, thereby capturing a different key factor for macroeconomic dynamics in our analysis.

${ }^{7}$ The finding of the importance of risk premium shocks is in line with results by Kulish et al. (2017) and Gust et al. (2017).

${ }^{8}$ This observation fueled a literature on the Missing Deflation Puzzle. See, e.g., Hall (2011), King and Watson (2012).

${ }^{9}$ See, e.g., Keen et al. (2017), Borağan Aruoba et al. (2018), Plante et al. (2018).
} 
a similar RANK-type model than we do, and focus on the role of forward guidance effects. Our analysis touches a different domain as we study the business cycle implications and the empirical performance of various model extensions. Fratto and Uhlig (2020) provide for a counterexample and deliberately ignore the ZLB constraint in their analysis of the last decades. The authors acknowledge that their approach may provide misleading results for the historical shock decomposition. As such, the ZLB may not only change the size but also potentially the direction of economic effects.

Lastly, a highly policy relevant issue is the macroeconomic effect of the massive interventions of the Federal Reserve in asset markets in response to the financial crisis. However, a structural investigation on the role of unconventional monetary policy requires a much more focussed analysis. Boehl et al. (2020) study the empirical effects of quantitative easing policies within the context of an estimated large-scale model with financial frictions and several channels for the real effects of asset purchases. They find that quantitative easing moderately indeed stimulated real activity via investment, but lasted negatively on aggregate consumption and had mildly deflationary effects.

The rest of the paper is as follows: Section 2 sketches the model and the employed extensions. Section 3 briefly lays out the numerical methods and our choices on data and priors. Section 4 presents the results of our estimations. Section 5 presents the interpretation of business dynamics within RANK and discusses the role of the financial frictions and handto-mouth consumers as extensions to the benchmark framework. Section 7 concludes.

\section{Models}

We employ the canonical medium-scale framework by Smets and Wouters (2007) as a baseline and allow for two model extensions: hand-to-mouth consumers, that are unable to save and only consume their current-period wage income, and financial frictions in the vein of Bernanke et al. (1999). We dub the model with only a representative agent the RANK model to distinguish it from our two-agent new Keynesian (TANK) model. The model vintage including financial frictions will be referred to as financial representative agent NK model - FRANK. ${ }^{10}$ The full set of linearized equilibrium conditions is delegated to the Appendix.

\subsection{The TANK extension}

The TANK model therefore features Ricardian and hand-to-mouth households. We assume that, for any given reason, a share $\lambda$ of households does not have any savings technology at its disposal and therefore consumes whatever it earns from its labor services provided. ${ }^{11}$ The linearized budget constraint of hand-to-mouth consumers simply reads

$$
c_{t}^{H}=w_{t}+l_{t}^{H},
$$

with $c_{t}^{H}$ and $l_{t}^{H}$ denoting hand-to-mouth agents' consumption and labor supply, and $w_{t}$ being the real wage. We assume that Ricardian and hand-to-mouth consumers share the same

\footnotetext{
${ }^{10}$ In Appendix Appendix A we additionally, we present estimation results for FTANK, a two-agent version of FRANK.

${ }^{11}$ In contrast to HANK, the TANK model does not capture uncertainty effects or time-variations of the share of constrained agents on consumption.
} 
preferences and are represented by the same labor unions in the wage formation process. Aggregate consumption and labor hours can be obtained in the linearized form as

$$
\begin{aligned}
& c_{t}=\lambda c_{t}^{H}+(1-\lambda) c_{t}^{R}, \\
& l_{t}=\lambda l_{t}^{H}+(1-\lambda) l_{t}^{R},
\end{aligned}
$$

where $c_{t}$ and $l_{t}$ are aggregate consumption and labor, and the superscript $R$ denotes the Ricardian type.

\subsection{Financial Frictions}

The second extension that we consider is the inclusion of frictions in financial markets. Here, we adopt the modeling choices by Del Negro et al. (2015b), who build on the work of Bernanke et al. (1999), De Graeve (2008) and Christiano et al. (2014). In this model, entrepreneurs obtain loans from frictionless intermediaries, which in turn receive their funds from household at the riskless interest rate. In addition to the loans, entrepreneurs use their own net worth to finance the purchase of physical capital, that they rent out to intermediate good producers. Entrepreneurs are subject to idiosyncratic shocks to their success in managing capital. As a consequence, their revenue might fall short of the amount needed to repay the loan, in which case they will default on their loan. In anticipation of the risk of entrepreneurs' default, financial intermediates pool their loans and charge a spread on the riskless rate to cover the expected losses arising from defaulting entrepreneurs. Crucially, the spread of the loan rate $\widetilde{r}_{t}^{k}$ over the risk free nominal interest rate, $r_{t}$, depends on the entrepreneurial leverage and can be written as

$$
E_{t}\left[\widetilde{r}_{t+1}^{k}-r_{t}\right]=u_{t}+\zeta_{s p, b}\left(q_{t}+\bar{k}_{t}-n_{t}\right)+\widetilde{\sigma}_{\omega, t} .
$$

Here, $u_{t}$ is the risk premium shock on the housholds borrrowing rate, $q_{t}$ is the price of capital, $\bar{k}_{t}$ is the capital stock and $n_{t}$ denotes entrepreneurial net worth. $\widetilde{\sigma}_{\omega, t}$ is a shock to the entrepreneurs' riskiness and follows an $\operatorname{AR}(1)$ process - the risk shock introduced by Christiano et al. (2014). Thus, the loan spread is defined as a function of the entrepreneurs' leverage and their riskiness, which is determined by the dispersion of the idiosyncratic shocks to entrepreneurs. Note that if the elasticity of the loan rate to the entrepreneurs' leverage, $\zeta_{s p, b}$, is set to zero, we are back to the case without financial frictions.

The evolution of aggregate entrepreneurial net worth is described by

$$
n_{t}=\zeta_{n, \widetilde{r}^{k}}\left(\widetilde{r}_{t}^{k}-\pi_{t}\right)-\zeta_{n, r}\left(r_{t-1}-\pi_{t}\right)+\zeta_{n, q k}\left(q_{t-1}+\bar{k}_{t-1}\right)+\zeta_{n, n} n_{t-1}-\frac{\zeta_{n, \sigma_{\omega}}}{\zeta_{s p, \sigma_{\omega}}} \widetilde{\sigma}_{\omega, t-1} .
$$

where $\pi_{t}$ is the inflation rate. Equation (5) links the accumulated stock of entrepreneurial net worth to the real return of renting out capital to firms, the riskless real rate, its capital holdings, its past net worth and variations in riskiness. The coefficients $\zeta_{n, \widetilde{r}^{k}}, \zeta_{n, r}, \zeta_{n, q k}$, $\zeta_{n, \sigma_{\omega}}$, and $\zeta_{s p, \sigma_{\omega}}$ are derived as in Del Negro et al. (2015b).

\section{Methodology and Data}

When including episodes of a binding ZLB in the sample, the estimation of DSGE models poses a host of different technical challenges. These are related to the solution, likelihood inference, and estimation of the model in the presence of an occasionally binding constraint 
(OBC). While methods to solve models with OBCs exists, and likewise nonlinear filters are available, the combination of both is computationally very expensive for medium-scale models. Before we turn to our estimation results, we briefly summarize the set of novel methods that allow us to conduct an estimation of medium-scale models, that we consider, in the presence of a binding ZLB. Secondly, this section describes our choices with regard to the data, calibrated parameters, and priors used in the empirical analysis.

\subsection{Solution method}

Throughout this paper we use the solution method for OBCs presented in Boehl (2020b). This section sketches the overall idea of this method. We refer to the original paper for details. First, the piecewise linear model must be cast in the form

$$
\mathbf{N}\left|\begin{array}{l}
\mathbf{x}_{t} \\
\mathbf{w}_{t}
\end{array}\right|+\mathbf{c} \max \left\{\mathbf{b}\left|\begin{array}{l}
\mathbf{x}_{t} \\
\mathbf{w}_{t}
\end{array}\right|, \bar{r}\right\}=E_{t}\left|\begin{array}{c}
\mathbf{x}_{t+1} \\
\mathbf{v}_{t}
\end{array}\right|,
$$

where $\mathbf{v}_{t}$ is an $(n \times 1)$ vector at the end of period $t$ that contains all the (latent) state variables, $\mathbf{w}_{t}=\mathbf{v}_{t-1}+\boldsymbol{\Xi} \varepsilon_{t}$ the state from last period augmented by the vector of current shocks, and $\mathbf{x}_{t}$ is an $(m \times 1)$ vector containing all forward looking variables. $N$ is the system matrix with dimension $(n+m) \times(n+m) . \bar{r}$ is the minimum value of the constrained variable $r_{t}$, which in our case is the nominal interest rate. $b$ is a row vector of dimension $1 \times(n+m)$, which determines $r_{t}$ in terms of $\left(\mathbf{x}_{t}, \mathbf{w}_{t}\right)^{\top}$. In this paper this is the monetary policy rule). The $(n+m) \times 1$ vector $\mathbf{c}$ contains the effects of $r_{t}$ onto all other variables. Further, denote by the two integer values $k$ and $l$ the expected numbers of periods that the system will remain at the ZLB and, respectively, the expected number of periods before the ZLB binds.

It can be shown that given the above specification of the system, the rational expectations solution for the system state $\mathbf{v}$ in period $t+s$, depending on the state $\mathbf{w}_{t}$ at the beginning of period $t$ and the expectations on $k$ and $l$ can be expressed in closed form as

$$
\begin{aligned}
L_{s}\left(l, k, \mathbf{w}_{t}\right)= & \mathbf{N}^{\max \{s-l, 0\}}(\mathbf{N}+\mathbf{c b})^{\min \{l, s\}} S\left(l, k, \mathbf{w}_{t}\right) \\
& +(\mathbf{I}-\mathbf{N})^{-1}\left(\mathbf{I}-\mathbf{N}^{\max \{s-l, 0\}}\right) \mathbf{c} \bar{r} \\
= & \left|\begin{array}{c}
\mathbf{x}_{t+1+s} \\
\mathbf{v}_{t+s}
\end{array}\right|
\end{aligned}
$$

where

$$
S\left(l, k, \mathbf{w}_{t}\right)=\left\{\left|\begin{array}{c}
\mathbf{x}_{t} \\
\mathbf{w}_{t}
\end{array}\right|: \mathbf{Q N}^{k}(\mathbf{N}+\mathbf{c b})^{l}\left|\begin{array}{c}
\mathbf{x}_{t} \\
\mathbf{w}_{t}
\end{array}\right|=-\mathbf{Q}(\mathbf{I}-\mathbf{N})^{-1}\left(\mathbf{I}-\mathbf{N}^{k}\right) \mathbf{c} \bar{r}\right\} .
$$

$\mathbf{Q}=\left|\begin{array}{ll}\mathbf{I} & -\boldsymbol{\Omega}\end{array}\right|$ for $\mathbf{x}_{t}=\boldsymbol{\Omega} \mathbf{w}_{t}$ represents the linear rational expectations solution of the unconstrained system as it can be obtained e.g. by the method of Klein (2000).

Search for the equilibrium values of $\{l, k\}$ must be done numerically. A crucial advantage of the above representation is that the simulation of anticipated equilibrium paths can be avoided when iterating over $\{l, k\} .^{12}$ Boehl (2020b) provides further methodological details such as equilibrium conditions and numerical routines.

\footnotetext{
${ }^{12}$ This gain in computational efficiency marks an advantage over the prominent Occbin-Toolbox developed by Guerrieri and Iacoviello (2015), which makes its use attractive for model estimation.
} 
The resulting transition function is linear for the region where the ZLB does not bind and (increasingly) nonlinear when it binds. For the model presented here, the implementation in the pydsge package (Boehl, 2020c). will find the state-space representation for about 80.000 particles draws per second and CPU.

\subsection{Filtering and Estimation Method}

Proper estimation and identification of the parameters of the model requires a Bayesian filter, i.e. a filter that approximates the state of the system given uncertainty about initial states and about potential measurement errors. For this purpose, we use the transposedensemble Kalman filter (TEnKF) also introduced in Boehl (2020b). This filter is a hybrid of the particle filter and Kalman filter technology. Similar to the particle filter, a set of points (the ensemble) is sent through the transition function during the prediction step. However, instead of re-sampling (as with the particle filter), the TEnKF approximates a state-dependent system matrix which can be used within a Kalman-like updating step. The TEnKF allows to efficiently approximate the state distribution of large-scale nonlinear systems with only a few hundred particles. The paper also suggests a nonlinear pathadjustment smoother (NPAS) to calculate the smoothed/historic shock innovations. ${ }^{13}$

TEnKF and NPAS are implemented in the econsieve package (Boehl, 2020a). Compared with the particle filter, the TEnKF also works with very small measurement errors. Importantly, it also works with a small number of particles thereby reducing computational costs. ${ }^{14}$ In contrast to the inversion filter used in Guerrieri and Iacoviello (2017), the TEnKF is a full Bayesian filter. The inversion filter does not allow for uncertainty on the initial states, which has the drawback that bad initial values can result in large approximation errors. $^{15}$

For posterior sampling we apply differential evolution Monte Carlo Markov chain methods (Ter Braak, 2006; ter Braak and Vrugt, 2008, DE-MCMC). The DE-MCMC method is a class of ensemble MCMC methods which, instead of using a single or small number of state-dependent chains (as e.g. in the Metropolis algorithm), relies on a large number of chains (the "ensemble"). Similar ensemble methods have been extensively applied in particular in astrophysics. The main advantage of these methods is that they are self-tuning, easy to parallelize, robust against local maxima, which allows to use them to sample from oddly-shaped and potential multimodal distributions. This is of particular importance as we use quite short data samples with potential systemic breaks. For each estimation, we initialize an ensemble of 200 particles with the prior distribution and run 2500 iterations. Of these, we keep 500 as a representation of the posterior distribution.

\subsection{Data and Priors}

For the quantitative analysis of the Great Recession and its aftermath, our baseline sample ranges from 1998:I to 2019:III. To our best knowledge, we are the first to include the late 2010's in the sample, which also contains the exit from the ZLB at the end of 2015. Our

\footnotetext{
${ }^{13}$ The NPAS builds two steps on top of the TEnKF: the first step is an ensemble version of the RauchTung-Striebel smoother (Rauch et al., 1965). For the second step, iterative global optimization methods are used to recover the shock innovations that fully respect the nonlinear transition function while taking the approximated distribution of smoothed states into account.

${ }^{14}$ For all estimations and for the numerical analysis we use an ensemble of 400 particles.

${ }^{15}$ A learning period will not change this property as, in the absence of potential measurement errors, the course of the dynamics is deterministic.
} 
benchmark sample is shorter than, e.g., in Gust et al. (2017), or Fratto and Uhlig (2020), who as well analyze the Great Recession in estimated models. The reason is that we want our estimation to capture idiosyncrasies of the episode in which the effective lower bound was binding, in particular the persistence of endogenous and exogenous variables, the role of policy, and the slope of the Phillips Curve. For this purpose, using a longer sample bears the risk of misspecification. ${ }^{16}$ Throughout our analysis we also refer to alternative data vintages.

We conduct estimations with seven and eight observables. The seven observables that are used throughout all estimations in the paper are real GDP growth, real consumption growth, real investment growth, labor hours, the log change of the GDP deflator, real wage growth, and the Federal Funds Rate. Additionally, we present results for estimations in which we add the Gilchrist and Zakrajšek (2012) spread (GZ-spread, henceforth). ${ }^{17}$

The measurement equations that relate the model variables to our data series are

$$
\begin{aligned}
\text { Real GDP growth } & =\bar{\gamma}+\left(y_{t}-y_{t-1}\right), \\
\text { Real consumption growth } & =\bar{\gamma}+\left(c_{t}-c_{t-1}\right), \\
\text { Real investment growth } & =\bar{\gamma}+\left(i_{t}-i_{t-1}\right), \\
\text { Real wage growth } & =\bar{\gamma}+\left(w_{t}-w_{t-1}\right), \\
\text { Labor hours } & =\bar{l}+l_{t}, \\
\text { Inflation } & =\bar{\pi}+\pi_{t}, \\
\text { Federal funds rate } & =\left(\frac{\bar{\pi}}{\beta \gamma^{-\sigma_{c}}}-1\right) * 100+r_{t} .
\end{aligned}
$$

When we also add the spread as an observable, we specify

$$
\text { GZ-spread }=\overline{\text { spread }}+E_{t}\left[\widehat{r}_{t+1}^{k}-r_{t}\right] .
$$

The construction of the observables is mostly standard and delegated to Appendix B. Three aspects are worth mentioning. First, for our benchmark estimations, we follow Justiniano et al. (2010) and include durable consumption in our investment series. As observed by Erceg and Levin (2006), durable consumption resembles investment in its behaviour over the business cycle. We find that including this choice generally improves the ability of the model to explain the data.

As a consequence, the strong fall in durable consumption during the Great Recession contributes to the sharp decrease in the investment series, whereas the decline in the consumption series at that time is somewhat dampened.Secondly, as in Boehl et al. (2020), we use a trailing $\mathrm{MA}(5)$ of the civilian non-institutional population index to normalize real quantities. This helps us to purge our observables of jumps in the index that reflect artifacts in its construction rather than the underlying economic fundamentals. Lastly, we set the empirical lower bound of the nominal interest rate within the model to $0.05 \%$ quarterly.

\footnotetext{
${ }^{16}$ Naturally, using a shorter sample yields less data observations. Yet, our sample is still larger than e.g. in Smets and Wouters (2003).

${ }^{17}$ For the computation of the spread, Gilchrist and Zakrajšek (2012) consider a broad set of loans to firms with different credit risk and compare the interest rate paid on each individual loan with the costs that the government would have had to pay on a loan with a comparable maturity. The GZ-spread is the average over these individual credit spreads.
} 
Setting it exactly to zero would imply that the ZLB never binds in our estimations, as the observed series for the FFR stays strictly above zero. Our choice maintains that the ZLB is considered binding throughout the period from 2009:Q1 to 2015:Q4. For the observable Federal Funds Rate we cut off any value below 0.05. This maintains that any observable value is also reachable for the model. Formally, we set the lower bound for the quarterly nominal rate $\bar{r}=-100\left(\frac{\bar{\pi}}{\beta \gamma^{-\sigma_{c}}}-1\right)+0.05$, where $\bar{\pi}$ is gross inflation and the parameters $\gamma$ and $\sigma_{c}$ denote the steady state growth rate and the coefficient of relative risk aversion, respectively.

We assume small measurement errors for all variables with a variance that is 0.01 times the variance of the respective series. Since the Federal Funds rate is perfectly observable (though on a higher frequency) we divide the measurement error variance here again by 100 . Hence, the observables are de facto matched perfectly.

In the calibration of some parameters and the choice of the priors for the estimation of the others we stick as closely as possible to the previous literature. For the parameters of RANK we rely on the choices of Smets and Wouters (2007). For the parameters associated with the extension of the financial sector we use the priors employed by Del Negro et al. (2015b). The TANK model only requires one additional prior for $\lambda$. Here, we choose for the prior a beta distribution with a mean of 0.3 and a standard deviation of 0.1 . Our prior mean is close to the roughly $31 \%$ reported by Kaplan et al. (2014) as the combined share of poor and wealthy hand-to-mouth agents in the US. This is also within close range to estimates by Coenen and Straub (2005) and Fève and Sahuc (2017), but slightly higher than the value estimated by Coenen et al. (2013).

In the estimations on the crisis sample, we follow Kulish et al. (2017) in the choice of our prior for $\bar{\gamma}$. Importantly, they opt for a tighter prior for this parameter than Smets and Wouters (2007). Arguably the economy deviated strongly and persistently from its steady state during the Great Recession. In order to dampen the data's pull of the parameter down to the sample mean, we therefore prefer the tight prior as well. ${ }^{18}$

\section{Estimation Results}

Our main focus is on estimations on the crisis sample from 1998:I to 2019:III. We compare parameter estimates across models and contrast them with the estimates for a pre-crisis sample from 1983:I to 2008:IV. This pre-crisis sample is a good candidate because it is quite frequently used in the literature for two reasons: it avoids the Great Inflation as well as the methodological challenge of accounting for a binding ZLB after 2008. Table A.5 summarize the posterior for model parameters for the crisis sample. The three main models we consider are RANK, TANK, and FRANK. Parameter estimates for the pre-crisis sample across models are reported in Table A.6. ${ }^{19}$ Overall we find that parameter estimates are quite robust to the model extensions, however there are meaningful systematic differences between the pre-crisis and the crisis estimates.

Across models, we find that the coefficient of relative risk aversion $\sigma_{c}$ has decreased from means between 1.260 and 1.469 in the pre-crisis sample to slightly less then unity in the crisis sample. Similarly, Kulish et al. (2017), who also include the last decade in their estimation,

\footnotetext{
${ }^{18}$ For wider priors we confirm unrealistically low estimates of the trend growth rate.

${ }^{19}$ We provide additional parameter estimates for FTANK and other variations of the financial friction models, as well as for samples from 1983-2019 in Table A.9.
} 
Sample from 1998 to 2019

Prior

Posterior

RANK

TANK

FRANK

\begin{tabular}{|c|c|c|c|c|c|c|c|c|c|c|c|c|c|}
\hline & & dist. & mean & $\mathrm{sd} / \mathrm{df}$ & mean & $\mathrm{sd}$ & mode & mean & $\mathrm{sd}$ & mode & mean & sd & mode \\
\hline$\sigma_{c}$ & CRRA & normal & 1.500 & 0.375 & 0.930 & 0.081 & 0.882 & 0.891 & 0.046 & 0.871 & 0.980 & 0.114 & 1.161 \\
\hline$\sigma_{l}$ & Labor supply & normal & 2.000 & 0.750 & 1.753 & 0.459 & 1.315 & 1.518 & 0.431 & 1.276 & 1.764 & 0.409 & 1.454 \\
\hline$\beta_{t p r}$ & Discount factor & gamma & 0.250 & 0.100 & 0.158 & 0.055 & 0.141 & 0.154 & 0.055 & 0.118 & 0.138 & 0.045 & 0.137 \\
\hline$h$ & Habit & beta & 0.700 & 0.100 & 0.833 & 0.027 & 0.839 & 0.839 & 0.025 & 0.849 & 0.755 & 0.048 & 0.666 \\
\hline$S^{\prime \prime}$ & Inv. adj. cost & normal & 4.000 & 1.500 & 5.287 & 0.914 & 4.926 & 5.420 & 0.928 & 4.971 & 4.996 & 1.007 & 3.713 \\
\hline$\iota_{p}$ & Price indexaation & beta & 0.500 & 0.150 & 0.192 & 0.066 & 0.166 & 0.180 & 0.062 & 0.190 & 0.218 & 0.077 & 0.288 \\
\hline$\iota_{w}$ & Wage indexation & beta & 0.500 & 0.150 & 0.371 & 0.112 & 0.426 & 0.398 & 0.123 & 0.429 & 0.309 & 0.101 & 0.344 \\
\hline$\alpha$ & Capital share & normal & 0.300 & 0.050 & 0.168 & 0.013 & 0.175 & 0.167 & 0.012 & 0.171 & 0.173 & 0.013 & 0.179 \\
\hline$\zeta_{p}$ & Price Calvo & beta & 0.500 & 0.100 & 0.852 & 0.033 & 0.840 & 0.850 & 0.033 & 0.861 & 0.920 & 0.027 & 0.927 \\
\hline$\zeta_{w}$ & Wage Calvo & beta & 0.500 & 0.100 & 0.710 & 0.044 & 0.678 & 0.691 & 0.047 & 0.681 & 0.766 & 0.050 & 0.771 \\
\hline$\Phi_{p}$ & Fixed cost & normal & 1.250 & 0.125 & 1.254 & 0.076 & 1.249 & 1.251 & 0.079 & 1.254 & 1.303 & 0.074 & 1.411 \\
\hline$\psi$ & Capital Utilization & beta & 0.500 & 0.150 & 0.757 & 0.080 & 0.802 & 0.759 & 0.079 & 0.751 & 0.763 & 0.071 & 0.749 \\
\hline$\phi_{\pi}$ & Mon. policy: inflation & normal & 1.500 & 0.250 & 1.353 & 0.218 & 1.512 & 1.361 & 0.218 & 1.386 & 1.101 & 0.196 & 0.900 \\
\hline$\phi_{y}$ & Mon. policy: gap & normal & 0.125 & 0.050 & 0.207 & 0.029 & 0.190 & 0.196 & 0.027 & 0.174 & 0.237 & 0.027 & 0.220 \\
\hline$\phi_{d y}$ & Mon. policy: growth & normal & 0.125 & 0.050 & 0.170 & 0.040 & 0.165 & 0.172 & 0.041 & 0.174 & 0.163 & 0.042 & 0.170 \\
\hline$\rho$ & Mon. policy: smoothing & beta & 0.750 & 0.100 & 0.816 & 0.042 & 0.833 & 0.818 & 0.040 & 0.809 & 0.751 & 0.039 & 0.711 \\
\hline$\zeta_{s p b}$ & Leverage elast. of spread & beta & 0.050 & 0.005 & & & & & & & 0.050 & 0.004 & 0.050 \\
\hline$\lambda$ & Share of $\mathrm{h} 2 \mathrm{~m}$ agents & beta & 0.300 & 0.100 & & & & 0.227 & 0.075 & 0.286 & & & \\
\hline$\rho_{r}$ & $\mathrm{AR}(1)$ monetary & beta & 0.500 & 0.200 & 0.754 & 0.088 & 0.710 & 0.737 & 0.090 & 0.760 & 0.493 & 0.079 & 0.452 \\
\hline$\rho_{g}$ & $\mathrm{AR}(1)$ fiscal & beta & 0.500 & 0.200 & 0.918 & 0.019 & 0.915 & 0.916 & 0.019 & 0.902 & 0.941 & 0.016 & 0.959 \\
\hline$\rho_{z}$ & $\mathrm{AR}(1)$ technology & beta & 0.500 & 0.200 & 0.979 & 0.013 & 0.982 & 0.982 & 0.012 & 0.986 & 0.964 & 0.025 & 0.977 \\
\hline$\rho_{u}$ & $\mathrm{AR}(1)$ risk premium & beta & 0.500 & 0.200 & 0.866 & 0.022 & 0.871 & 0.867 & 0.022 & 0.881 & 0.890 & 0.023 & 0.891 \\
\hline$\rho_{i}$ & $\operatorname{AR}(1) \mathrm{MEI}$ & beta & 0.500 & 0.200 & 0.602 & 0.127 & 0.528 & 0.572 & 0.100 & 0.573 & 0.916 & 0.024 & 0.938 \\
\hline$\rho_{p}$ & $\mathrm{AR}(1)$ price Markup & beta & 0.500 & 0.200 & 0.639 & 0.090 & 0.679 & 0.622 & 0.103 & 0.617 & 0.441 & 0.199 & 0.666 \\
\hline$\rho_{w}$ & AR(1) wage Markup & beta & 0.500 & 0.200 & 0.455 & 0.097 & 0.369 & 0.449 & 0.091 & 0.476 & 0.499 & 0.093 & 0.417 \\
\hline$\mu_{p}$ & MA price markup & beta & 0.500 & 0.200 & 0.315 & 0.121 & 0.300 & 0.345 & 0.141 & 0.257 & 0.403 & 0.149 & 0.391 \\
\hline$\mu_{w}$ & MA wage markup & beta & 0.500 & 0.200 & 0.255 & 0.090 & 0.166 & 0.246 & 0.081 & 0.259 & 0.316 & 0.093 & 0.236 \\
\hline$\rho_{g z}$ & Fiscal technology & normal & 0.500 & 0.250 & 0.607 & 0.085 & 0.646 & 0.615 & 0.089 & 0.672 & 0.479 & 0.101 & 0.340 \\
\hline$\sigma_{r}$ & Std. dev. monetary & $\mathrm{IG}$ & 0.100 & 2.000 & 0.106 & 0.017 & 0.122 & 0.110 & 0.021 & 0.112 & 0.173 & 0.045 & 0.189 \\
\hline$\sigma_{g}$ & Std. dev. fiscal & IG & 0.100 & 2.000 & 0.222 & 0.025 & 0.208 & 0.220 & 0.024 & 0.214 & 0.255 & 0.024 & 0.287 \\
\hline$\sigma_{z}$ & Std. dev. technology & IG & 0.100 & 2.000 & 0.399 & 0.043 & 0.412 & 0.396 & 0.038 & 0.399 & 0.378 & 0.042 & 0.424 \\
\hline$\sigma_{u}$ & Std. dev. risk premium & IG & 0.100 & 2.000 & 0.681 & 0.148 & 0.626 & 0.688 & 0.161 & 0.588 & 0.432 & 0.104 & 0.339 \\
\hline$\sigma_{i}$ & Std. dev. MEI & $\mathrm{IG}$ & 0.100 & 2.000 & 0.881 & 0.276 & 1.041 & 0.940 & 0.257 & 0.876 & 0.533 & 0.059 & 0.618 \\
\hline$\sigma_{p}$ & Std. dev. price Markup & $\mathrm{IG}$ & 0.100 & 2.000 & 0.184 & 0.058 & 0.139 & 0.204 & 0.078 & 0.173 & 0.411 & 0.152 & 0.182 \\
\hline$\sigma_{w}$ & Std. dev. wage Markup & $\mathrm{IG}$ & 0.100 & 2.000 & 1.272 & 0.294 & 1.487 & 1.287 & 0.279 & 1.176 & 1.133 & 0.222 & 1.289 \\
\hline $\bar{\gamma}$ & Trend growth & normal & 0.440 & 0.050 & 0.382 & 0.036 & 0.386 & 0.379 & 0.038 & 0.392 & 0.391 & 0.033 & 0.393 \\
\hline $\bar{l}$ & ME constant: labor & normal & 0.000 & 2.000 & 0.997 & 0.634 & 1.099 & 1.179 & 0.651 & 1.356 & 1.395 & 0.643 & 2.243 \\
\hline $\bar{\pi}$ & ME constant: inflation & gamma & 0.625 & 0.100 & 0.632 & 0.059 & 0.659 & 0.645 & 0.057 & 0.688 & 0.603 & 0.060 & 0.581 \\
\hline & ME constant: spread & normal & 0.500 & 0.100 & & & & & & & 0.331 & 0.064 & 0.322 \\
\hline
\end{tabular}

Table 1: Comparison of estimation results across models for the crisis sample (1998-2019). 
Sample from 1983 to 2008

Prior

Posterior

RANK

TANK

FRANK

\begin{tabular}{|c|c|c|c|c|c|c|c|c|c|c|c|c|c|}
\hline & & dist. & mean & $\mathrm{sd} / \mathrm{df}$ & mean & $\mathrm{sd}$ & mode & mean & $\mathrm{sd}$ & mode & mean & sd & mode \\
\hline$\sigma_{c}$ & CRRA & normal & 1.500 & 0.375 & 1.469 & 0.147 & 1.468 & 1.388 & 0.133 & 1.298 & 1.424 & 0.126 & 1.444 \\
\hline$\sigma_{l}$ & Labour supply & normal & 2.000 & 0.750 & 2.361 & 0.539 & 2.555 & 2.062 & 0.513 & 1.849 & 2.519 & 0.507 & 2.786 \\
\hline$\beta_{t p r}$ & Discount Factor & gamma & 0.250 & 0.100 & 0.147 & 0.046 & 0.146 & 0.147 & 0.049 & 0.142 & 0.143 & 0.048 & 0.123 \\
\hline$h$ & Habit & beta & 0.700 & 0.100 & 0.689 & 0.048 & 0.699 & 0.710 & 0.040 & 0.688 & 0.669 & 0.042 & 0.670 \\
\hline$S^{\prime \prime}$ & Inv. adj. cost & normal & 4.000 & 1.500 & 5.622 & 1.035 & 6.023 & 5.727 & 1.029 & 4.939 & 6.176 & 0.982 & 5.926 \\
\hline$\iota_{p}$ & Price indexation & beta & 0.500 & 0.150 & 0.309 & 0.100 & 0.311 & 0.344 & 0.106 & 0.323 & 0.355 & 0.130 & 0.385 \\
\hline$\iota_{w}$ & Wage indexation & beta & 0.500 & 0.150 & 0.424 & 0.127 & 0.476 & 0.414 & 0.129 & 0.371 & 0.373 & 0.121 & 0.600 \\
\hline$\alpha$ & Capital share & normal & 0.300 & 0.050 & 0.214 & 0.011 & 0.218 & 0.213 & 0.011 & 0.210 & 0.226 & 0.011 & 0.226 \\
\hline$\zeta_{p}$ & Price Calvo & beta & 0.500 & 0.100 & 0.845 & 0.032 & 0.832 & 0.858 & 0.033 & 0.855 & 0.847 & 0.031 & 0.841 \\
\hline$\zeta_{w}$ & Wage Calvo & beta & 0.500 & 0.100 & 0.783 & 0.047 & 0.769 & 0.792 & 0.045 & 0.797 & 0.833 & 0.038 & 0.859 \\
\hline$\Phi_{p}$ & Fixed Cost & normal & 1.250 & 0.125 & 1.531 & 0.072 & 1.603 & 1.551 & 0.070 & 1.554 & 1.525 & 0.063 & 1.521 \\
\hline$\psi$ & Capital utilization & beta & 0.500 & 0.150 & 0.631 & 0.089 & 0.643 & 0.625 & 0.091 & 0.685 & 0.545 & 0.069 & 0.485 \\
\hline$\phi_{\pi}$ & Mon. policy: inflation & normal & 1.500 & 0.250 & 1.294 & 0.245 & 1.436 & 1.319 & 0.235 & 1.067 & 1.311 & 0.217 & 1.273 \\
\hline$\phi_{y}$ & Mon. policy: gap & normal & 0.125 & 0.050 & 0.222 & 0.040 & 0.216 & 0.212 & 0.038 & 0.235 & 0.196 & 0.033 & 0.206 \\
\hline$\phi_{d y}$ & Mon. policy: growth & normal & 0.125 & 0.050 & 0.203 & 0.040 & 0.199 & 0.205 & 0.041 & 0.214 & 0.198 & 0.038 & 0.216 \\
\hline$\rho$ & Mon. policy: smoothing & beta & 0.750 & 0.100 & 0.710 & 0.044 & 0.752 & 0.713 & 0.041 & 0.638 & 0.734 & 0.036 & 0.744 \\
\hline$\zeta_{s p b}$ & Leverage elast. of spread & beta & 0.050 & 0.005 & & & & & & & 0.051 & 0.004 & 0.048 \\
\hline$\lambda$ & Share of $\mathrm{h} 2 \mathrm{~m}$ agents & beta & 0.300 & 0.100 & & & & 0.176 & 0.052 & 0.151 & & & \\
\hline$\rho_{r}$ & $\mathrm{AR}(1)$ monetary & beta & 0.500 & 0.200 & 0.813 & 0.061 & 0.771 & 0.813 & 0.061 & 0.855 & 0.696 & 0.070 & 0.715 \\
\hline$\rho_{g}$ & AR(1) Ffscal & beta & 0.500 & 0.200 & 0.972 & 0.013 & 0.975 & 0.972 & 0.013 & 0.981 & & 0.031 & 0.948 \\
\hline$\rho_{z}$ & $\mathrm{AR}(1)$ technology & beta & 0.500 & 0.200 & 0.955 & 0.015 & 0.940 & 0.947 & 0.017 & 0.950 & 0.941 & 0.021 & 0.963 \\
\hline$\rho_{u}$ & $\mathrm{AR}(1)$ risk premium & beta & 0.500 & 0.200 & 0.736 & 0.090 & 0.754 & 0.700 & 0.083 & 0.797 & 0.691 & 0.076 & 0.785 \\
\hline$\rho_{i}$ & $\mathrm{AR}(1) \mathrm{MEI}$ & beta & 0.500 & 0.200 & 0.767 & 0.061 & 0.806 & 0.807 & 0.048 & 0.793 & 0.868 & 0.028 & 0.883 \\
\hline$\rho_{p}$ & $\mathrm{AR}(1)$ price markup & beta & 0.500 & 0.200 & 0.764 & 0.082 & 0.827 & 0.749 & 0.100 & 0.821 & 0.728 & 0.106 & 0.801 \\
\hline$\rho_{w}$ & $\mathrm{AR}(1)$ wage markup & beta & 0.500 & 0.200 & 0.673 & 0.109 & 0.688 & 0.642 & 0.121 & 0.694 & 0.588 & 0.110 & 0.650 \\
\hline$\mu_{p}$ & MA price markup & beta & 0.500 & 0.200 & 0.611 & 0.144 & 0.603 & 0.642 & 0.115 & 0.601 & 0.514 & 0.140 & 0.557 \\
\hline$\mu_{w}$ & MA wage markup & beta & 0.500 & 0.200 & 0.393 & 0.152 & 0.396 & 0.423 & 0.158 & 0.443 & 0.391 & 0.156 & 0.386 \\
\hline$\rho_{g z}$ & Fiscal technology & normal & 0.500 & 0.250 & 0.352 & 0.078 & 0.423 & 0.351 & 0.079 & 0.324 & 0.389 & 0.079 & 0.382 \\
\hline$\sigma_{r}$ & Std. dev. monetary & $\mathrm{IG}$ & 0.100 & 2.000 & 0.130 & 0.015 & 0.141 & 0.131 & 0.015 & 0.123 & 0.151 & 0.021 & 0.138 \\
\hline$\sigma_{g}$ & Std. dev. fiscal & IG & 0.100 & 2.000 & 0.237 & 0.017 & 0.233 & 0.238 & 0.018 & 0.228 & 0.242 & 0.018 & 0.230 \\
\hline$\sigma_{z}$ & Std. dev. technology & IG & 0.100 & 2.000 & 0.308 & 0.028 & 0.316 & 0.309 & 0.027 & 0.285 & 0.316 & 0.027 & 0.300 \\
\hline$\sigma_{u}$ & Std. dev. risk premium & IG & 0.100 & 2.000 & 0.958 & 0.397 & 0.853 & 1.138 & 0.412 & 0.619 & 0.954 & 0.314 & 0.625 \\
\hline$\sigma_{i}$ & Std. dev. MEI & $\mathrm{IG}$ & 0.100 & 2.000 & 0.639 & 0.114 & 0.590 & 0.576 & 0.083 & 0.582 & 0.641 & 0.059 & 0.587 \\
\hline$\sigma_{p}$ & Std. ev. price markup & $\mathrm{IG}$ & 0.100 & 2.000 & 0.140 & 0.045 & 0.098 & 0.158 & 0.047 & 0.101 & 0.138 & 0.054 & 0.090 \\
\hline$\sigma_{w}$ & Std. dev. wage markup & $\mathrm{IG}$ & 0.100 & 2.000 & 0.457 & 0.100 & 0.420 & 0.523 & 0.153 & 0.459 & 0.591 & 0.148 & 0.511 \\
\hline $\bar{\gamma}$ & Trend growth & normal & 0.440 & 0.050 & 0.463 & 0.025 & 0.460 & 0.466 & 0.024 & 0.473 & 0.412 & 0.027 & 0.427 \\
\hline $\bar{l}$ & ME constant: labor & normal & 0.000 & 2.000 & 2.297 & 0.587 & 2.497 & 2.187 & 0.559 & 2.832 & 1.532 & 0.501 & 1.791 \\
\hline $\bar{\pi}$ & ME constant: inflation & gamma & 0.625 & 0.100 & 0.703 & 0.065 & 0.704 & 0.693 & 0.065 & 0.706 & 0.599 & 0.065 & 0.613 \\
\hline$\overline{s p r}$ & ME constant: spread & normal & 0.500 & 0.100 & & & & & & & 0.472 & 0.064 & 0.438 \\
\hline
\end{tabular}

Table 2: Comparison of estimation results across models for the sample before the crisis (1983-2008). 
Slope of the Phillips Curve

\begin{tabular}{l||rrrr}
\hline Sample & RANK & TANK & FRANK & FTANK \\
\hline $1998-2019$ & $0.007(0.004)$ & $0.007(0.003)$ & $0.002(0.002)$ & $0.001(0.0)$ \\
$1983-2008$ & $0.004(0.002)$ & $0.003(0.002)$ & $0.004(0.002)$ & $0.003(0.001)$ \\
$1983-2019$ & $0.002(0.001)$ & $0.002(0.001)$ & $0.002(0.001)$ & $0.002(0.001)$ \\
& & & & \\
Sample & FRANK-R & FTANK-R & FRANK-Spread & FTANK-Spread \\
\hline $1998-2019$ & $0.01(0.003)$ & $0.011(0.003)$ & $0.001(0.003)$ & $0.001(0.001)$ \\
$1983-2008$ & $0.004(0.003)$ & $0.004(0.005)$ & $0.099(0.09)$ & $0.004(0.088)$
\end{tabular}

Table 3: Comparison of the slopes of estimated Phillips Curves of the different models. Posterior means with standard deviations in parenthesis. The short crisis sample (1998-2019) is the benchmark we focus on in the main body.

find $\sigma_{c}$ to be close to unity. A value of $\sigma_{c}$ close to one mutes the effect of variations in labor hours on consumption via the Euler equation, which is introduced through the nonseperabilites in preferences. The reduction of this channel prevents the strong drop in labor hours during the crisis to exert an excessive downwards pull on consumption.

The posterior mean values for habit formation, $h$, vary from from 0.755 (FRANK) to 0.839 (TANK) in the crisis sample. Across models, this is roughly 0.1 higher than in the pre-crisis sample. In contrast, investment adjustment costs are lower for each model in the crisis sample (between 4.996 and 5.287) than in the pre-crisis sample (between 5.612 and 6.176). This reflects the high volatility of investment relative to consumption observed in the Great Recession.

The estimates of labor market parameters imply more flexibility of both labor and wages in the Great Recession and at the ZLB than in prior decades. The posterior mean for the inverse of the Frisch elasticity, $\sigma_{l}$, lies between 1.764 (FRANK) and 1.518 (TANK) in the crisis sample, which is somewhat lower than in the pre-crisis sample, where it is estimated to be slightly higher than 2 in all models. This implies a higher elasticity of labor supply during the crisis and therefore a higher responsiveness to demand shocks. This allows for a quicker decline in labor hours and labor income in the Great Recession. Additionally, in crisis times, and in particular in models without financial frictions, the parameter governing wage rigidities, $\zeta_{w}$, is estimated to be lower than in the pre-crisis sample. Mean values here range from 0.691 (TANK) to 0.766 (FRANK), allowing wages to respond faster to developments in the economy. Our estimates of $\zeta_{w}$ come close to the value in Kulish et al. (2017), but stand in contrast to the estimates of Gust et al. (2017) who obtain an wage adjustment cost parameter of 4420 in a Rotemberg setting, which implies a virtually inexistent wage Phillips curve.

The RANK estimates for the Calvo parameter of $\zeta_{p}=0.852$ and the gross price markup of $\Phi_{p}=1.254$ support the general notion that the Phillips Curve has been flat in the last decades. Table 3 summarizes the estimated slopes of the Phillips across different samples and model vintages. At the mean, the slope of the Phillips Curve of RANK is estimated to be 0.007 . This is substantially lower than the estimate by Smets and Wouters (2007), who find a slope coefficient of roughly 0.02. Our estimates provide evidence that the Phillips curve has already been flattening out during the Great Moderation and has stayed flat at the ZLB. This finding is robust to all model considered, including estimates of FRANK in which we include a risk shock á la Christiano et al. (2014)(FRANK-R) and the GZ-spread 
(FRANK-Spread), and corroborated by estimates of Kulish et al. (2017), who start their sample in the 80 s and include the crisis period in their estimation.

The persistence parameter of the risk premium shock lies roughly in the range of 0.866 to 0.890 in the crisis sample. This is substantially higher than the estimates for the pre-crisis sample, which vary around $0.7 .{ }^{20}$ This is not surprising as this shock plays a larger role for the Great Recession and the ZLB period than for an analysis of the pre-crisis period. The persistence parameter for MEI shocks displays substantial differences between models with and without financial frictions. In RANK, its posterior mean value is 0.602 , whereas for FRANK it is at 0.916 . This points at the more important role of MEI shocks in financial friction models in the crisis, which we discuss in Subsection 5.2.

The share of hand-to-mouth agents, $\lambda$, is estimated to be around 0.227 in TANK. The share of hand-to-mouth agents is a tad higher in the crisis sample, than in the pre-crisis sample. This squares with the notion that credit constraints played a larger role for households in the Great Recession and its aftermath than in the previous decades. However the posterior mean is below its prior, which, motivated by the estimates by Kaplan et al. (2014), is set to 0.3. Our results suggest that high ad-hoc calibrations of the share at, e.g., 0.5, which are often applied in the literature ${ }^{21}$, overstate the weight of hand-to-mouth consumers in macroeconomic models.

\section{Business Cycle Dynamics at the ZLB}

The mortgage crisis, which culminated in the default of Lehman Brothers in September 2008 , sent the US economy into a deep recession. Output, consumption, investment and employment plummeted in 2009. The drop in investment was particularly sharp in comparison to the decline in consumption. However, while real activity collapsed, price dynamics did not follow suit. The drop in inflation in the Great Recession was mild and short-lived, sparking a lively debate on the missing deflation puzzle. ${ }^{22}$ As argued above, with the financial crisis marking one, albeit complex, event, a good model should provide a parsimonious account of this event in terms of a common causal driver of the occurrences during this period. Any shock that can serve as such a common driver must therefore generate a pronounced drop differential of investment and consumption, as well as the modest decline in inflation. In this section we lay out that none of our models meets the challenge of attributing these key features to a common source. At the end of the section, we discuss how the presence of a joint propagation mechanism or the lack thereof in the model affects its empirical fit. We show that against the gist of the literature, neither household heterogeneity nor financial frictions improve upon the simple RANK model in terms of empirical fit.

\subsection{The Great Recession through the lens of RANK}

We start our discussion of business cycle dynamics at the ZLB by summarizing the main implications, which result from the estimation of RANK on the crisis sample.

In the context of the estimated RANK model, risk premiums shocks are the most prominent driver of the joint dynamics of key variables following the financial crisis. Figure 1

\footnotetext{
${ }^{20}$ For comparison in their estimate from 1966-2004, Smets and Wouters (2007) report a persistence parameter of 0.22 for the risk premium shock. Kulish et al. (2017), who include the recent decades in their sample, report a persistence parameter of 0.95 for the shock.

${ }^{21}$ See, e.g., Galí et al. (2007).

${ }^{22}$ See, e.g., Christiano et al. (2015), Del Negro et al. (2015b), Gilchrist et al. (2017).
} 


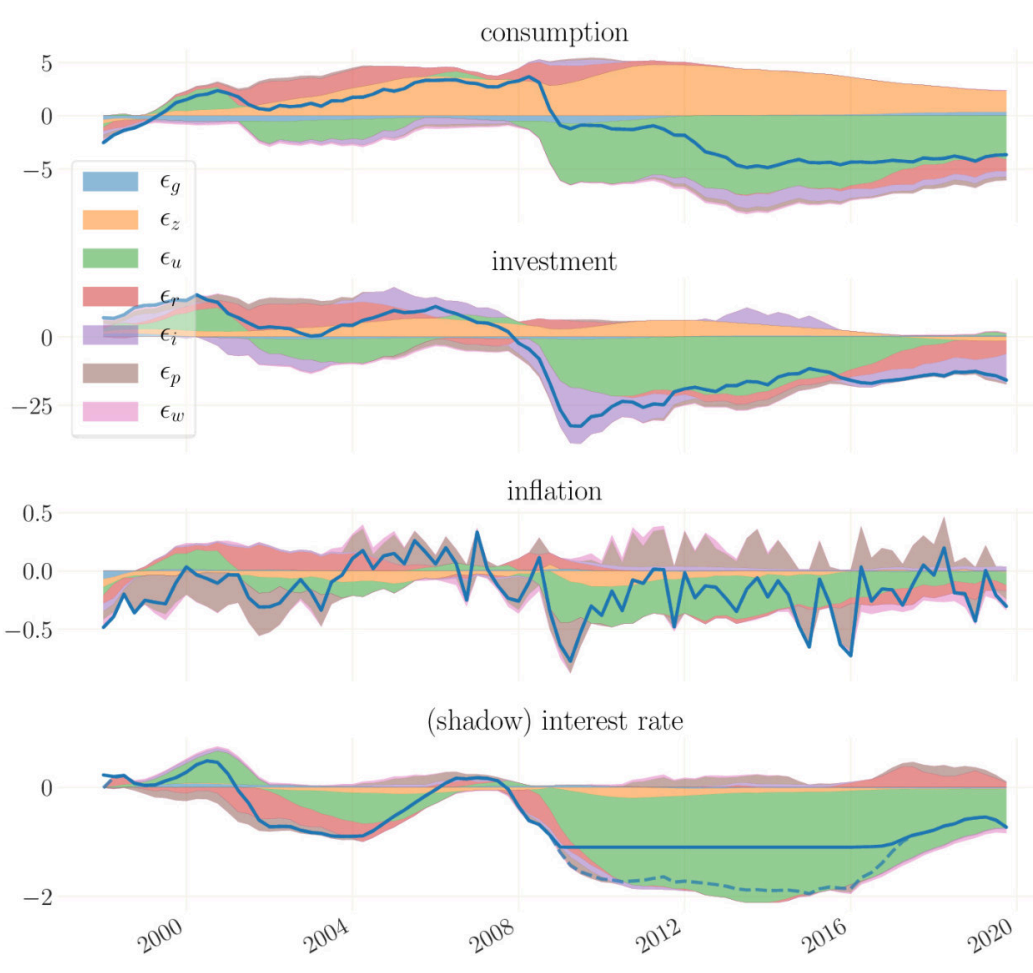

Figure 1: RANK Model estimated to 1998-2019. Decomposition of the smoothed time series into the contribution of the different shocks. Note: Means over 250 simulations drawn from the posterior. The contribution of each shock is normalized as in Appendix E.

illustrates the dominant role of risk premium shocks on the households' borrowing rate, $\epsilon_{t}^{u}$, for macroeconomic dynamics following the Great Recession. ${ }^{23}$ It presents the historical shock decompositions of key variables for the crisis sample. From 2009 on, persistently elevated risk premiums account for almost the entire drop of aggregate consumption, weigh on aggregate investment and inflation, and consequently are responsible for the long duration of the ZLB spell for the nominal interest rate.

However, high risk premiums cannot fully account for the sharp drop in investment during the Great Recession. While recessionary risk premium shocks do trigger a simultaneous downturn of consumption and investment, they fail to match the drop differential of these components, creating the need for an extra driver to make up for the missing decline in investment. In the case at hand, the initial decline of investment is triggered by recessionary MEI shocks, $\epsilon_{t}^{i}$, which at the trough account for roughly half of the collapse in investment.

Similarly, the decline of inflation during the Great Recession can only partly be attributed to the increase in risk premiums. The estimated flat Phillips Curve prevents the decline in real activity from generating substantial deflation, which requires price markup shocks, $\epsilon_{t}^{p}$, to account for the inflation dynamics. These shocks govern the high-frequency

\footnotetext{
${ }^{23}$ The dominant role of risk premium shocks is corroborated by the generalized forecast error variance decomposition, reported in Table D.11 in the appendix.
} 

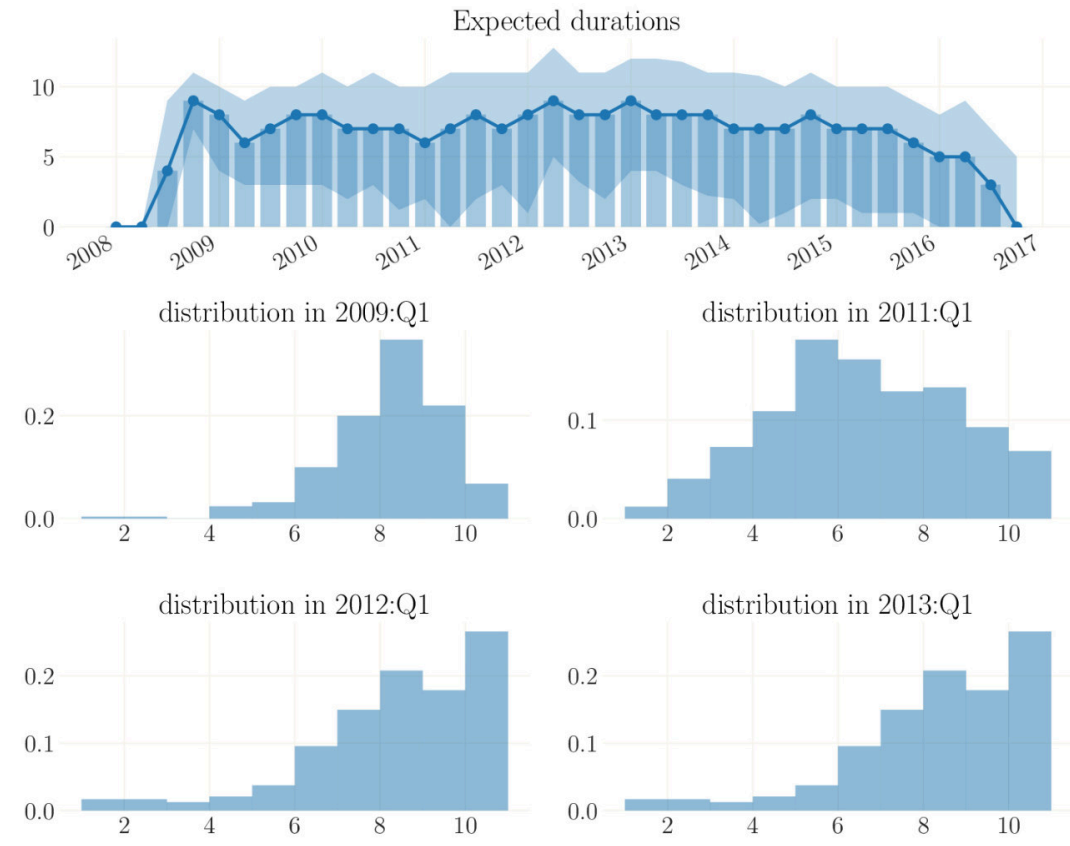

Figure 2: Expected ZLB durations for RANK. The shaded area in the top panel represent $90 \%$ credible sets. In the lower panels, the last bar to the right marks the probability of a duration of 10 or more quarters.

movements of inflation in the sample and account for the dip in inflation during the Great Recession. ${ }^{24}$ The only modest decrease in inflation triggered a debate on the missing disinflation puzzle. Christiano et al. (2015) attribute some inflationary pressure to a persistent decline in productivity relative to its pre-recession trend. In contrast, in our estimation, which abstracts from a TFP-specific trend, the technology process, $z_{t}$, is consistently measured to be positive. In addition, Christiano et al. (2015) as well as Gilchrist et al. (2017) ascribe the missing inflation to higher refinancing costs of firms. We confirm that within the RANK model, MEI shocks raise inflation by increasing the firms' cost of investments. However, the size of this effect is negligible according to our estimation. In our analysis, similar to Del Negro et al. (2015b), the estimate of a flat Phillips Curve is responsible for the lack of a steep decline in inflation. We view the reliance on MEI shocks and price markup shocks as disparate exogenous drivers for the explanation of the dynamics of investment and inflation in the years of the Great Recession constitutes a shortcoming of the RANK model. $^{25}$

The long duration of the ZLB is largely interpreted by our estimation as an endogenous response of the central bank to the deterioration of fundamentals via the Taylor rule, rather than to an active lower-for-longer policy. ${ }^{26}$ Figure 2 shows the dynamics and the distribution

\footnotetext{
${ }^{24}$ The relatively low estimate of $\phi_{\pi}$ in the Taylor rule moderates the transmission of the volatile short-lived effects of price markup shocks on inflation to the nominal interest rate, and in turn to economic activity.

${ }^{25}$ For an illustration of the exogenous shock process, see Figure K.22 in the appendix.

${ }^{26}$ In principle, our model allows for forward guidance shocks at the ZLB. However, as discussed in Appendix $\mathrm{G}$, we find that, in the absence of additional data input such as, e.g., term premia, nonlinear filters do not
} 
of the expected duration of the ZLB spell over the sample. ${ }^{27}$ The mean expected durations vary between six and ten quarters throughout the ZLB years. Although we do not target, nor use any prior information on the actual expectations of market participants on the duration of the ZLB, for the most part they come remarkably close to the average expected durations reported by the Blue Chip Financial Forecast and the Federal Reserve Bank of New York's Survey of Primary Dealers. In the first years of the ZLB, our mean estimates somewhat overestimate expected durations, and around 2012, they are slightly too low. However, the results of these surveys lie within the $90 \%$ confidence intervals of our estimation for almost all quarters. The lower panels of Figure 2 show the distributions of expected ZLB durations at different points in time. In 2009:Q1, most of the probability mass lies on durations of, or higher than, 8 quarters. The same holds for the first quarters of 2012 and 2013, for which survey data shows high expected durations as well. In contrast, for 2011:Q1 when our mean expected duration of seven quarters slightly exceeds the mean implied by the Primary Dealer Survey, the distribution shows that considerable probability mass is allocated to lower expected durations and the survey mean is within the confidence interval of the RANK estimation.

The resulting estimated average expected durations are higher than those by Gust et al. (2017), who obtain an average ZLB spell of merely 3.5 quarters. Like us they do not incorporate survey data on duration expectation in the estimation of their model, which is in several respects similar to ours, although smaller. A potential reason for the difference in the resulting expected durations might be the treatment of the ZLB in the estimation. As mentioned in Section 3.3, we set the empirical ZLB to $0.05 \%$ quarterly, whereas Gust et al. (2017) choose exactly zero percent. This may be problematic as the Federal Funds Rate never actually went all the way down to zero. In theory, their model is hence capable of matching the observables without forcing the model to the zero lower bound. From this angle it is surprising that in their smoothed state estimates, they hit the ZLB at all. We suspect that this is due to the assumption of relatively large observation errors, which is often necessary when employing the particle filter (see e.g. Atkinson et al., 2019). ${ }^{28}$

Kulish et al. (2017) use survey data to construct priors on expected durations, which they estimate directly. While this procedure poses a challenge for parameter identification by substantially extending the dimensionality of the parameter space, it eases matching the observed dynamics of the expectations over the years at the ZLB. In contrast to the aforementioned papers, our sample also covers the takeoff from the ZLB. The mean of the smoothed nominal interest rate series leaves the ZLB a year after the actual ZLB period ended. The model therefore interprets the very low federal fund rate in 2016 to have the same effects on equilibrium dynamics as a binding ZLB. This might capture uncertainty effects that could not explicitly included in our modelling approach.

\subsection{FRANK: Challenges for financial friction modeling}

We start this section by showing that the inclusion of the financial sector impairs the ability of non-financial shocks to generate the observed collapse in investment during the

\footnotetext{
perform reliably well in identify forward guidance shocks at the ZLB. For a discussion of the effects of unconventional monetary policy, see Boehl et al. (2020).

${ }^{27}$ For a discussion of the economic cost of a binding ZLB, see Appendix F. Closely related to the cost of the binding ZLB is the decline in the natural rate, which is discussed in Appendix H.

${ }^{28}$ Their measurement errors variances are assumed to at least $10 \%$ of the variance of data sample, which is a full magnitude higher than our assumed measurement errors (3 magnitudes for the Federal Funds Rate).
} 

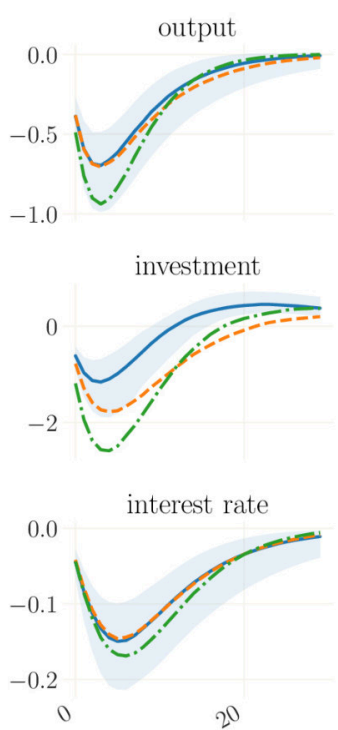

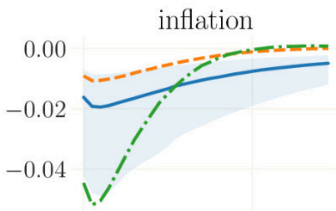

price of capital
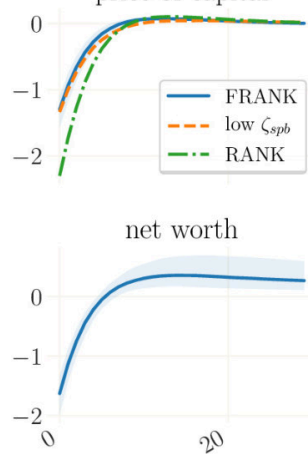

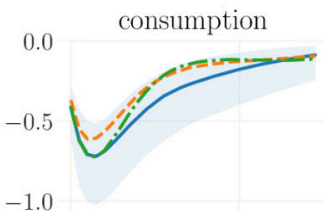

capital stock

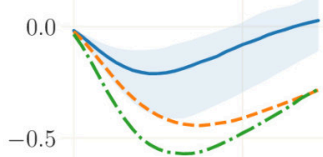

leverage

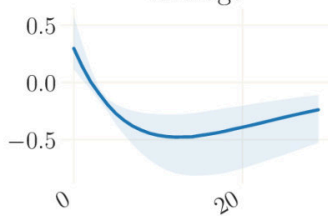

Figure 3: IRFs to a risk premium shock in FRANK estimated for 1998-2019. In orange: estimated FRANK with $\zeta_{s p b} \approx 0$. In green: RANK. Note: Medians over 250 simulations drawn from the posterior. $90 \%$ credible set for FRANK. Shock size is the posterior mean standard deviation for each model.

Great Recession. Subsequently, we show that financial shocks cannot fill in as main drivers of the recessions, due to their inability to generate a substantial decline in consumption in the estimated models. As a consequence, the models with financial frictions do not offer a joint propagation mechanism for the behaviour of the components of aggregate demand. This stands in contrast to the large theoretical literature that highlights the importance of the inter-linkages between the real economy and the financial sector for the macroeconomic dynamics following the financial crisis.

\subsubsection{The role of the financial sector for the transmission of shocks}

The inclusion of financial frictions alters the transmission of shocks in important ways. Figure 3 shows the dynamic response of key variables to a risk premium shock. The difference between 'FRANK' and 'low $\zeta_{s p b}$ ' isolates the effect of the financial accelerator on the transmission of the shock in an estimated FRANK model, whereas the difference between 'RANK' and 'FRANK' also includes the effect of changes in all parameter estimates. ${ }^{29}$ In all cases, an exogenous increase of the risk premium on the households' borrowing rate induces a contraction in aggregate demand. The presence of financial frictions, however, amplifies the drop in consumption and attenuates the drop in investment in response to the shock. This worsens the shock's ability to account for the observed drop differential of consumption and investment in the Great Recession.

Why is that so? On impact, a risk premium shock reduces the price of capital and net worth of entrepreneurs. As a consequence, their leverage increases and - accordingly - the

\footnotetext{
${ }^{29}$ In our discussion of financial frictions we focus on FRANK and omit the FTANK model as the role of hand-to-mouth agents does not alter the key results.
} 


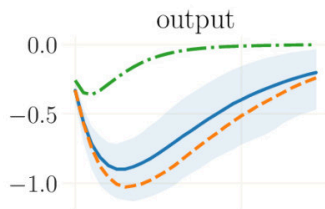

investment

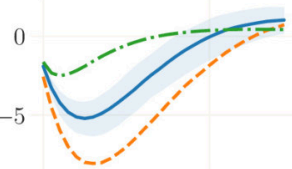

interest rate

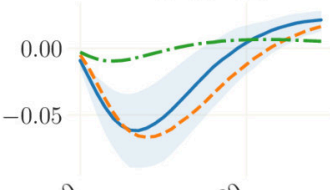

20

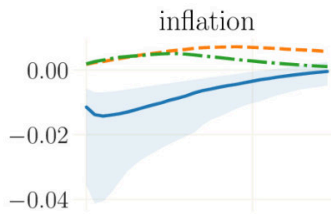

price of capital
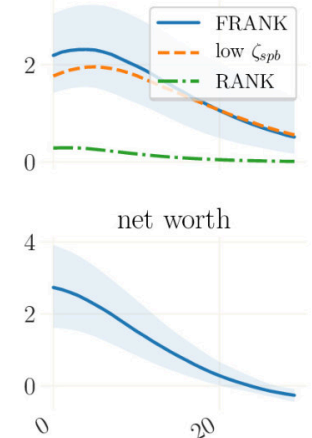

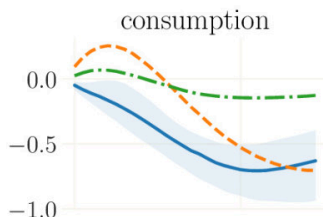

$-1.0$

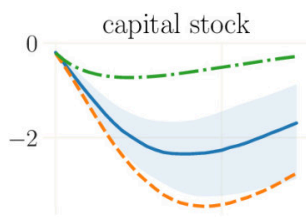

leverage

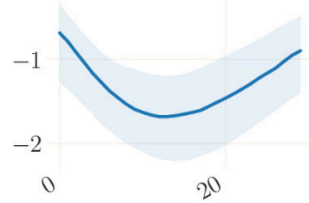

Figure 4: IRFs to a MEI shock in FRANK estimated for 1998-2019. In orange: estimated FRANK with $\zeta_{s p b} \approx 0$. In green: RANK. Note: Medians over 250 simulations drawn from the posterior. $90 \%$ credible set for FRANK. Shock size is the posterior mean standard deviation for each model.

return on capital demanded by creditors. However, in the context of the estimated FRANK model, the high return on capital induces a quick recovery of net worth (c.f. Equation 5). In contrast, the decline in the capital stock is more persistent. Hence, the increase in leverage is short-lived and reverses after a few periods, while in the medium-run, the low leverage reduces the required return on capital, and improves the investment climate. As the investment decision is forward looking and rash adjustments of the capital stock are costly, the outlook of a future investment boom already attenuates the fall of investment from the onset. The attenuating role of financial frictions impairs the ability of the risk premium shock to account for the dramatic fall of investment observed in the Great Recession without simultaneously generating an excess decline in consumption. Thus, less weight is assigned to these shocks, and more weight to MEI shocks, which must fill in to generate the strong fall in investment.

As is shown in Figure 4, the estimated financial friction has a similar effect on the transmission of recessionary MEI shocks: they increase the price of capital and raise entrepreneurial net worth, thereby lowering the spread. Again, the direct effect of the financial sector is to dampen the decline in investment. Despite the financial attenuator, the decline in investment is far stronger in the estimated FRANK model than in the estimated RANK model due to shifts in other parameter estimates. Importantly, the estimate for the persistence parameter $\rho_{i}$ is higher in FRANK (0.916) than in RANK (0.602). In equilibrium, the higher value of $\rho_{i}$ implies a more persistent and substantial decline in investment, which triggers a stronger drop in output and labor hours. The sharper decline in labor weighs on consumption, which decreases directly on impact. The negative co-movement between investment and consumption is therefore removed. However, the fall in consumption is far too modest to enable MEI shocks in FRANK to match the drop differential between investment 

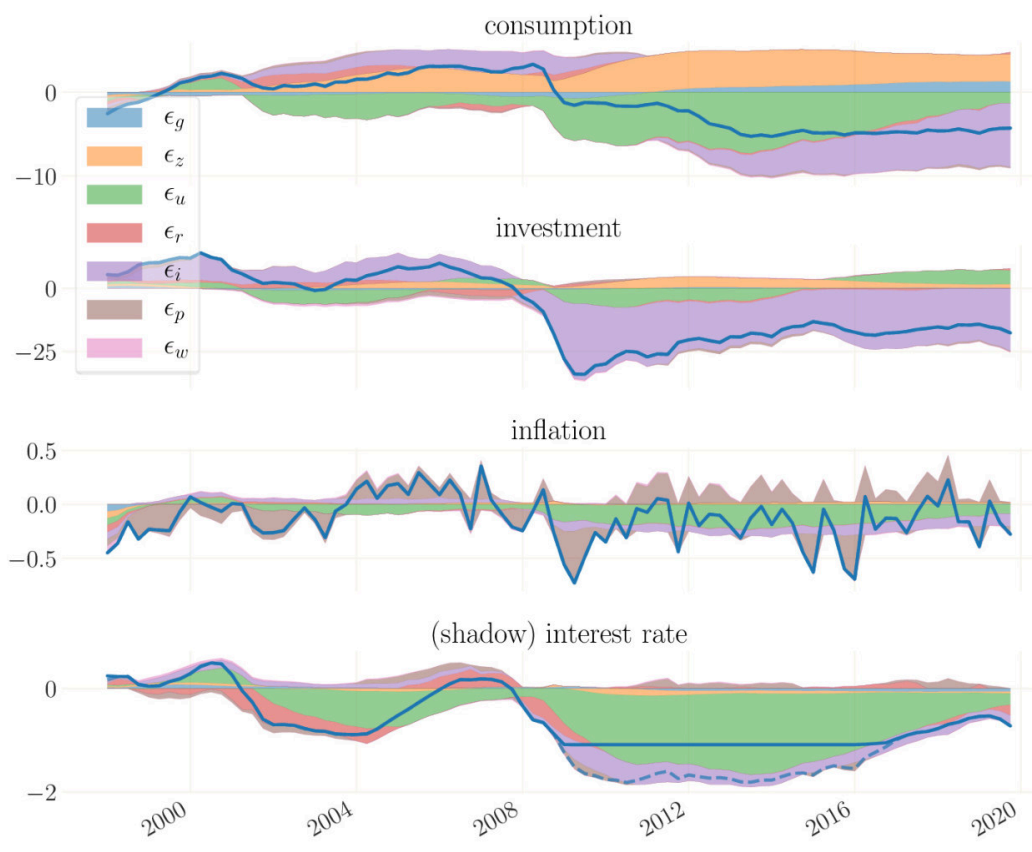

Figure 5: FRANK Model estimated to 1998-2019. Decomposition of the smoothed time series into the contribution of the different shocks. Note: Means over 250 simulations drawn from the posterior. The contribution of each shock is normalized as in Appendix E.

and consumption.

Figure 5 shows that as a result, the dynamics of consumption and investment are driven by two disparate sources of shocks. This represents a severe drawback for the FRANK model's appeal, as it moves farther away from providing a unifying account of macroeconomic dynamics in the Great Recession than RANK. While the financial sector itself acts as an attenuator for output and investment dynamics, the higher persistence in MEI shocks in FRANK supports a more pronounced decline in aggregate demand thereby creating deflationary pressure. As with RANK, this pressure is too weak to cause the dip in inflation during the Great Recession. Again, the inability of the model to account for the inflation dynamics is associated with a flat Phillips Curve and variations in inflation are largely attributed to exogenous fluctuations in the price markup.

\subsubsection{Can risk shocks explain the Great Recession?}

The difficulties of the MEI shock to generate one of the Great Recession's key features - a substantial, simultaneous drop of consumption and investment - is shared by a wide range of financial shocks, that have been proposed in the literature. Like the MEI shock, they present a disturbance to the intertemporal investment decision, or as labelled in Christiano et al. (2015), the financial wedge. At odds with observed dynamics in the Recession, these shocks stimulate consumption. This holds for instance by the contractionary credit shock, which Carlstrom et al. (2017) employ in their analysis of the effects of unconventional monetary policy. Similarly, recessionary wealth shocks raise households consumption in Carlstrom 


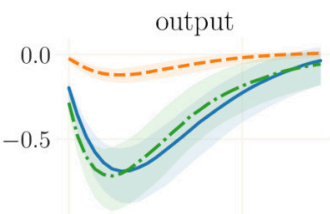

investment

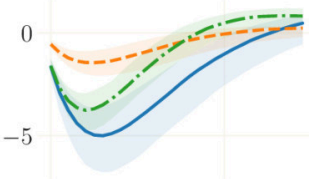

interest rate

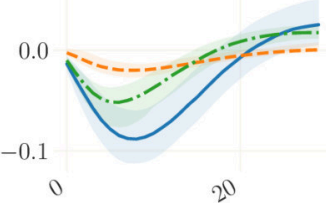

inflation

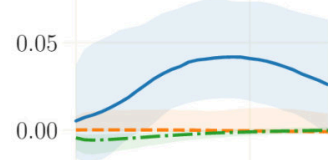

price of capital$$
2
$$$$
0
$$

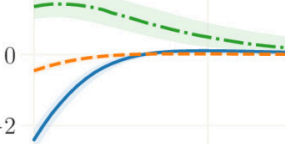

spread

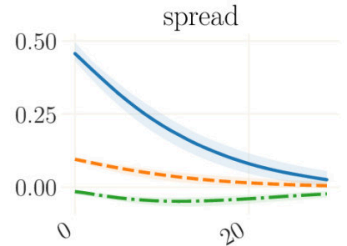

consumption

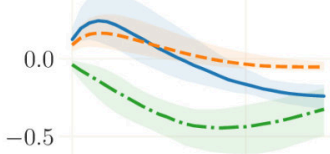

capital stock

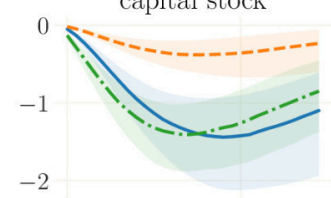

net worth

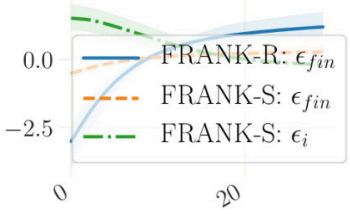

Figure 6: IRFs to a risk shock in FRANK-R and FRANK-S estimated for 1998-2019. Additionally the IRFS to an MEI shock in the same FRANK-S estimate. Note: Medians over 250 simulations drawn from the posterior with $90 \%$ credible sets. Shock size is the posterior mean standard deviation for each model.

and Fuerst (1997). ${ }^{30}$

Figure 6 displays this unappealing feature of a financial shock in our estimates, where it triggers a negative co-movement of consumption and investment. For this illustration we employ the risk shock, which was developed by Christiano et al. (2014). The risk shock is an exogenous process driving changes in the volatility of cross-sectional idiosyncratic uncertainty of entrepreneurs. The Figure results from two exercises, that we conduct in order to investigate on the ability of this shock to improve our understanding of the Great Recession and the ZLB period. First, we exchange the MEI shock in FRANK for the risk shock and estimate the resulting model as before (FRANK-R). Secondly, we use FRANK with both shocks and add the GZ spread as an additional observable in our estimation (FRANK-S). ${ }^{31}$

An increase in entrepreneurial risk raises the spread and makes external funding less affordable for entrepreneurs. Aggregate investment and the price of capital therefore both drop, jointly with entrepreneurial net worth. In contrast to the MEI shock, which drives Tobin's $Q$ and investment in opposite directions, the risk shock is therefore a demand shock in the market for investment goods. The drop in investment demand lowers output and hence labor hours. However, the latter are sufficiently stable so that the decline in the

\footnotetext{
${ }^{30} \mathrm{~A}$ prominent exception is the capital quality shock developed by Gertler and Kiyotaki (2010). This shock was engineered to capture key features of the crisis and hits the economy at multiple distinct points simultaneously.

${ }^{31}$ For details on the estimated parameters, interested readers are relegated to Table A.7 in Appendix A. For completeness, we additionally conduct analogous estimations with our two-agent extension. The results of the parameter estimates are reported in the same Table A.7 as well. Adding hand-to-mouth agents however does not alter the main results of this section.
} 

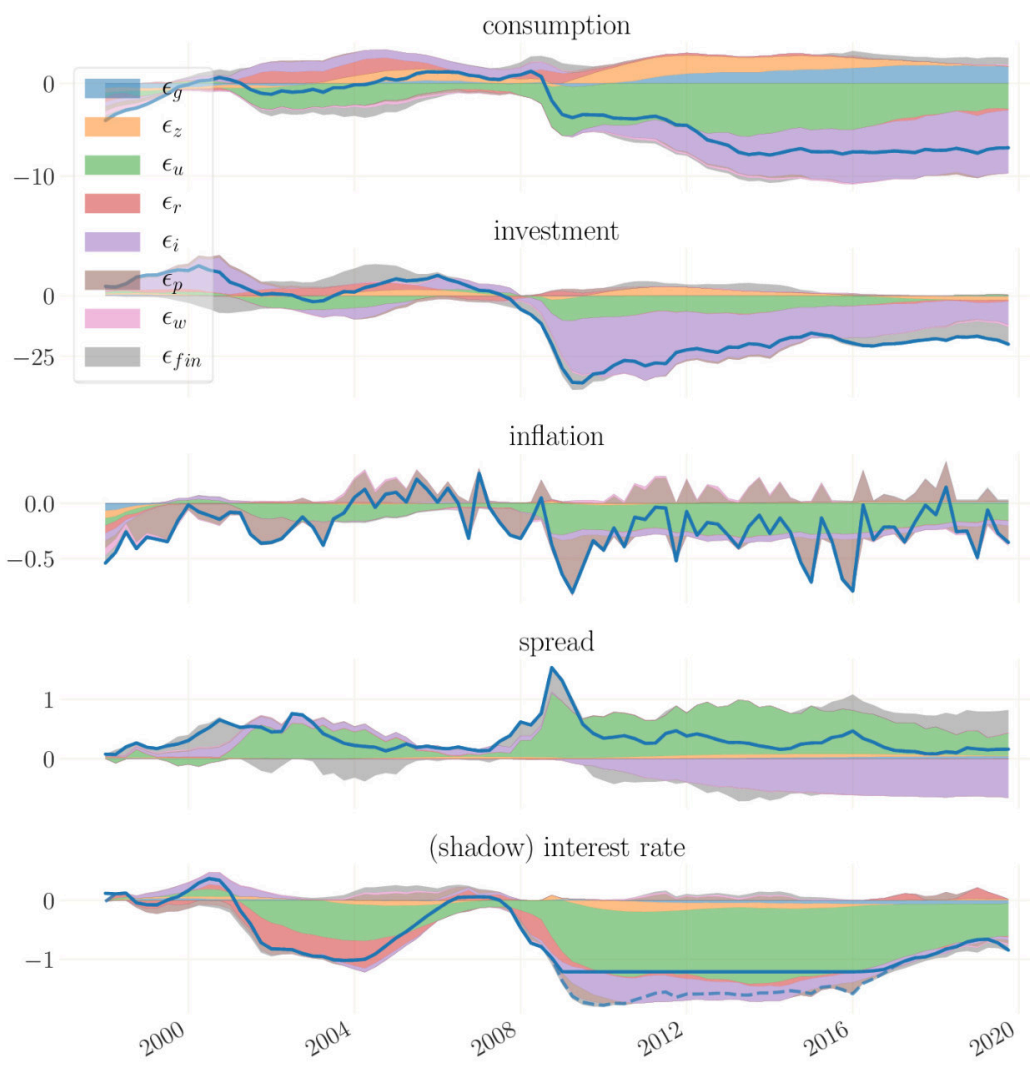

Figure 7: FRANK-S Model - estimated including the GZ spread as observable - estimated to 1998-2019. Decomposition of the smoothed time series into the contribution of the different shocks. Note: Means over 250 simulations drawn from the posterior. The contribution of each shock is normalized as in Appendix E. The shock size is the posterior mean standard deviation for each model.

real rate dominates the consumption response in the short run in both estimations. With regard of the post-2008 course of inflation, an appealing feature of the risk shock is that, by raising the costs of capital, it increases marginal cost and thereby creates inflationary pressure. This effect is particularly pronounced in FRANK-R. However, whereas the risk shock speaks to the missing deflation puzzle, its implications for consumption dynamics are at odds with the data.

For both, FRANK-R and in FRANK-S, the problem persists that consumption and investment dynamics following the Great Recession are explained by disparate sources within the model. For FRANK-S this is illustrated in Figure 7, whereas the historical shock decompositions for FRANK-R are relegated to Figure I.19 in Appendix I. In both cases, the risk premium shock remains the main source of movements in consumption. Notwithstanding, for reasons discussed in Section 5.2.1, the financial accelerator undermines the risk premium shock's ability to account for investment dynamics and creates additional need for financial wedge type of shocks.

Crucially, the role of risk shocks for macroeconomic dynamics in FRANK-S is negligible. Of the risk shock and the MEI shock, the latter produces a response of consumption that 
is more in line with observations in the crisis. Consequently, MEI shocks take a more prominent role in the explanation of investment dynamics than risk shocks. Increases in entrepreneurial risk only play a notable role for the credit spread. In conjunction with increasing risk premiums on households borrowing rates, they are responsible for the spike of the credit spread in the financial crisis. Other than MEI shocks, recessionary risk shocks increase the spread, which renders them unable to reconcile the very moderate spreads after 2010 with the continuing depression of investment. The decomposition of inflation and interest rate dynamics is almost the same as in FRANK. ${ }^{32}$ Adding the risk shock and the spread as an observable therefore does not improve upon the explanation of macroeconomic dynamics as given by RANK. As the risk shock in our exercise stands in for a range of financial shocks that fail to trigger a fall in consumption, it appears that in general the financial wedge may not be an excellent candidate for providing a parsimonious narrative of the Great Recession.

\subsection{The role of hand-to-mouth agents}

The recent years have also seen a surge of interest into the interaction of microeconomic heterogeneity and macroeconomic dynamics. While a full-fledged HANK model exceeds the scope of our analysis, we introduce hand-to-mouth consumers, thereby extending our RANK to a TANK model. Hand-to-mouth consumers capture the fact that financial constraints affected the dynamics of households consumption spending. As their income is determined solely by the labor market, the introduction of these agents ties aggregate demand closer to labor market outcomes. ${ }^{33}$ A contraction in investment therefore should exert a stronger downward pull on consumption via the decline in labor income of households.

However, our analysis implies that the effect of hand-to-mouth agents on the results for the crisis sample is rather small. Parameter estimates as well as the historical shock decomposition of the crisis for TANK (see Figure I.18 in Appendix I) are very similar to the results for RANK. ${ }^{34}$ The low relevance of hand-to-mouth consumers is mainly due to the presence of other frictions in our model that make it difficult to identify the effects of hand-to-mouth agants on business cycle dynamics: non-separable preferences create an additional link between labor hours and consumption via the Euler equation of Ricardian agents; sticky wages prevent sharp movement in the income of hand-to-mouth consumers and hence their spending; lastly, habit formation strongly attenuates swings in the consumption of constrained agents during the crisis.

Figure 8 illustrates that the transmission of the risk premium shock, which again dominates macroeconomic dynamics in the crisis, is hardly altered. In RANK, the reaction of consumption, a key component of aggregate demand, is determined by the intertemporal substitution of current for future spending, the price of which is determined by the households savings (or borrowing) rate. Adding hand-to-mouth consumers to the model dampens the direct effect of risk premium shocks on aggregate consumption, as a lower share of households can adjust its consumption decision to changes in the interest rate. At the same time, hand-to-mouth consumers add an indirect effect to the transmission of risk premium

\footnotetext{
${ }^{32}$ In FRANK-R the slope of the Phillips curve is steeper and real shocks play a larger role for inflation dynamics. As displayed in Figure I.19 in Appendix I, the inflationary impact of risk shocks becomes notable.

${ }^{33}$ In our framework, we keep the labor market simple. For a full-fledged account of its dynamics during the Great Recession., see Christiano et al. (2015).

${ }^{34}$ We confine our discussion in the main body to the results of TANK, as the results with regards to the role of hand-to-mouth consumers hold with FTANK as well.
} 

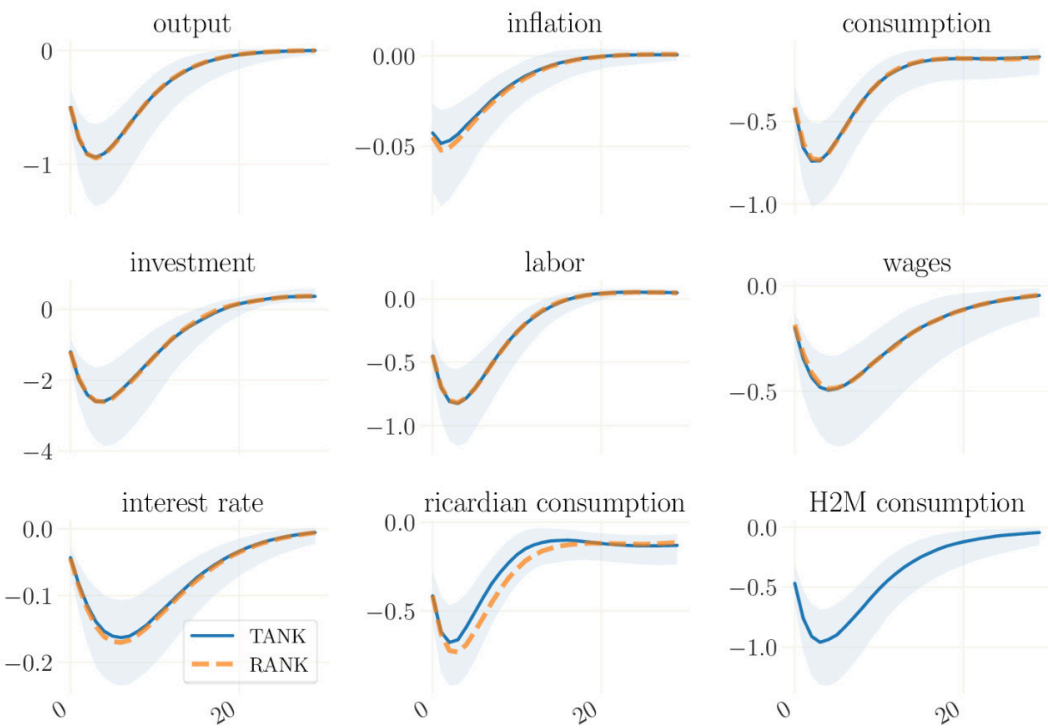

Figure 8: IRFs to a risk premium shock in TANK estimated for 1998-2019. Compared with mean IRFs to RANK. Note: Medians over 250 simulations drawn from the posterior with $90 \%$ credible set for TANK. Shock size is the posterior mean standard deviation for each model.

shocks, because their spending is tied to current income, which closely tracks the fluctuations in real activity, that are caused by risk premium shocks as well. If the amplification and attenuation via the indirect and direct effect cancel out, hand-to-mouth consumers have no effects on the transmission of this shock. ${ }^{35}$

Whether the indirect effect outweighs the direct effect mainly depends on the estimates of labor market parameters. The estimated value of the Calvo parameter for wage setting, $\zeta_{w}$, implies a substantial wage rigidity, that attenuates the reaction of real wages to aggregate demand and therefore fluctuations in hand-to-mouth agents' spending. This substantially reduces the indirect effect. Another important parameter is $\sigma_{l}$. In the extreme case of $\sigma_{l}=0$, the consumption of Ricardian and hand-to-mouth agents move closely together since, due to the assumption of identical preferences, they are tied together via the same labor supply curve. All else equal, the higher $\sigma_{l}$ - the less elastic the labor supply - the more $c_{h, t}$ differs from $c_{r, t}$, and the stronger the fall in wages when labor hours drop. Lower wages in turn further reduce hand-to-mouths agents' budget and hence their consumption. For the posterior estimate of $\sigma_{l}$ of TANK in the crisis sample, the fall in $c_{h}$ is only a tad more pronounced than that of $c_{r}$. In equilibrium this slightly lowers the policy rate, which dampens the fall of $c_{r}$, and increases the wedge between the consumption of both types of agents. ${ }^{36}$ However, combined with their low share in households, the diverging spending

\footnotetext{
${ }^{35} \mathrm{~A}$ related intuition has been discussed by Bilbiie (2019) in the context of monetary policy shocks, which affect the households saving (borrowing) rate in a similar manner.

${ }^{36}$ This type of externality imposed by hand-to-mouth consumers on Ricardian households, which arises due to the feedback effects of hand-to-mouth spending on aggregate demand and the interest rate is discussed in Bilbiie (2019).
} 

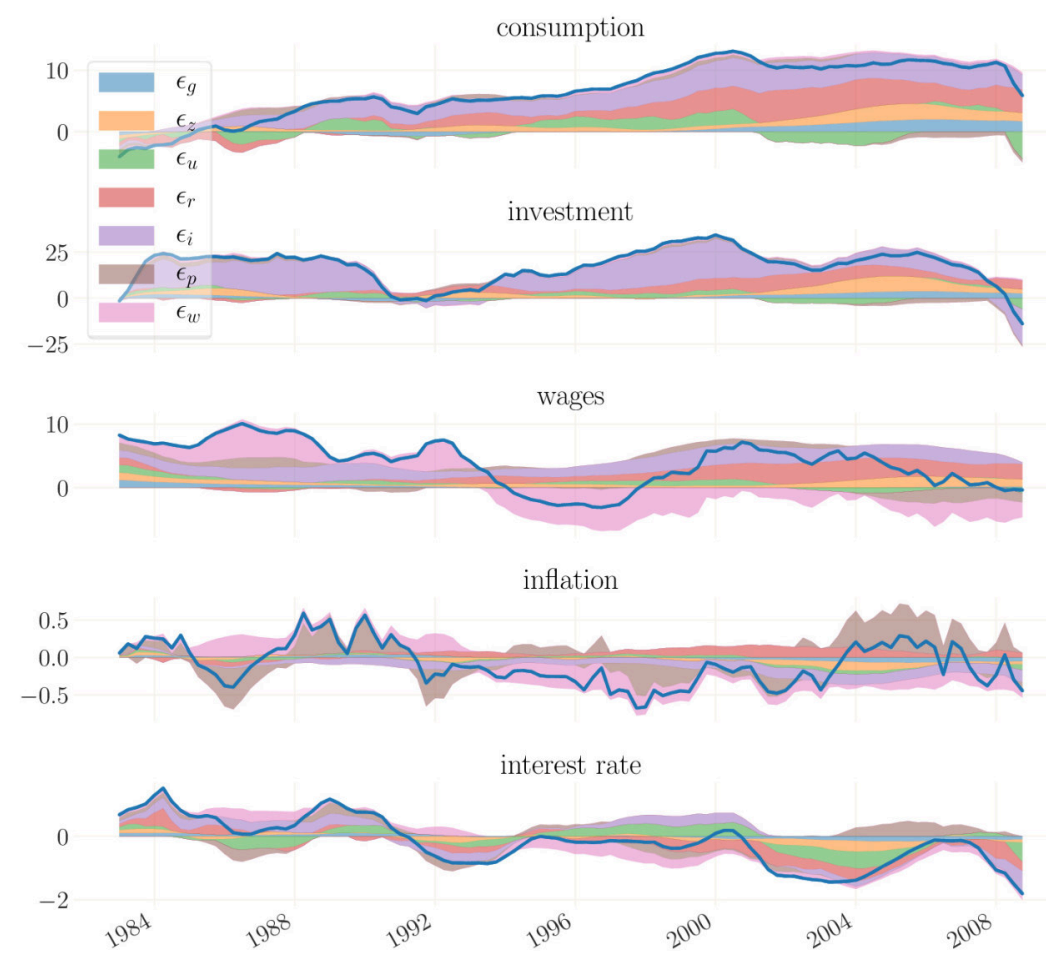

Figure 9: TANK Model estimated to 1983-2008. Decomposition of time series into the contribution of the different shocks. Note: Means over 250 simulations drawn from the posterior. The contribution of each shock is normalized as in Appendix E.

behavior of hand-to-mouth consumers is not sufficient to have a substantial impact on aggregate dynamics in the crisis sample. ${ }^{37}$

While the irrelevance of hand-to-mouth consumers for the crisis sample is largely due to the prominence of the risk premium shock, other exogenous driving forces can induce a stronger divergence of the behavior of household types. A case in point are wage markup shocks. These shocks only play a small role in the crisis sample, but feature more prominently before the Great Recession. We illustrate this in Figure 9, which shows the historical shock decomposition of that period for TANK. Here, MEI shocks drive investment and consumption dynamics to a large extent while wage markup shocks explain a significant share of real wage and inflation dynamics. ${ }^{38}$ In the mid-80s, positive wage markup shocks raise the real wage and support a positive comovement of wages with aggregate demand compo-

\footnotetext{
${ }^{37}$ Additionally, the differences in the consumption response of household types is illustrated for the transmission of MEI shocks in RANK and TANK in Figure J.21 in Appendix J. Whereas Ricardian consumption increases in response to the shock, consumption of hand-to-mouth consumers follows labor market variables and declines. In principle, hand-to-mouth consumers could help to lower the aggregate consumption response and create co-movement of investment and consumption in response to this shock. However, as in the transmission of risk premium shocks, their impact on aggregate figures is negligible.

${ }^{38}$ For this sample, the downward trending interest rate drives the persistent upwards deviation of consumption from its trend.
} 

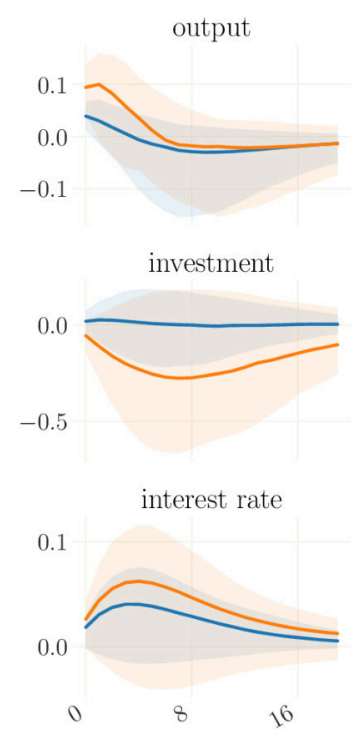

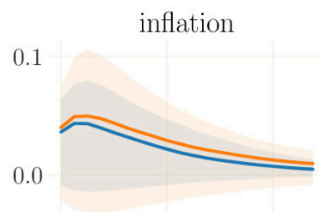

labor

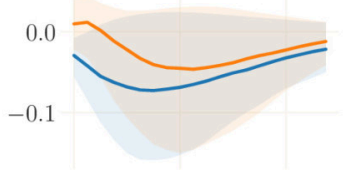

ricardian consumption

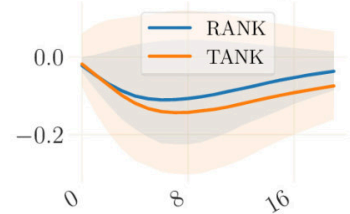

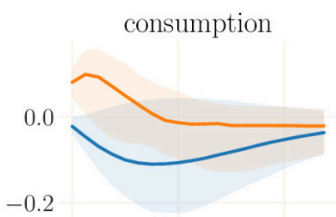

wages

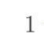

0

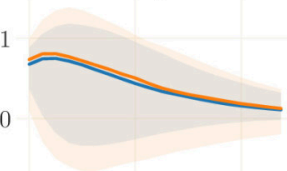

H2M consumption

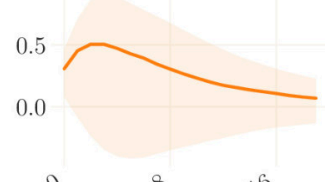

Figure 10: IRFs to a wage markup shock for RANK and TANK estimated for 1983-2008. For TANK, the share of hand-to-mouth agents $\lambda$ is increased to 0.3 (vs. 0.176 in the posterior mean) to illustrate the effect of MPC heterogeneity. Note: Medians over 250 simulations drawn from the posterior. $90 \%$ credible set for TANK. Shock size is the posterior mean standard deviation for each model

nents. In contrast, in the mid-90s, negative wage markup shocks depress wages and create a negative comovement with aggregat demand.

As shown in Figure 10, the transmission of wage markup and MEI shocks is altered by the addition of hand-to-mouth consumers. While the response of wages and inflation is practically the same in RANK and TANK, the reaction of consumption differs accross models. ${ }^{39}$ In RANK, consumption declines, whereas in TANK a boost to labor income directly feeds into increased spending by hand-to-mouth agents. This raises aggregate demand as well as labor hours, while the investment response has the opposite sign, though the effect on the latter is minuscule. Overall, TANK creates unlikely joint dynamics of the components of real activity in response to a wage markup shock. As this is not easy to reconcile with the data, it creates an inconvenient finding for TANK for the pre-crisis sample. ${ }^{40}$ Hence, the look at the pre-crisis sample underlines that the difficulty of hand-to-mouth consumers to improve upon RANK are not limited to the crisis sample.

To check whether the irrelevance of hand-to-mouth consumers for macroeconomic dynamics in our analysis is driven by our choice of the prior for $\lambda$, we conduct additional estimations, in which we assign a uniform prior to this parameter. Table A.10 in Appendix A shows the result of our robustness check. While in our benchmark estimates we obtain posterior means of roughly $22 \%$ for TANK and FTANK, the estimation with wide priors

\footnotetext{
${ }^{39}$ As wage markup shocks are most important for wages and inflation in the historical shock decomposition, the differences in the decomposition between RANK and TANK are negligible.

${ }^{40}$ In fact, the measures for the estimated MDD displayed in Table A.6 show a better empirical fit for RANK than for TANK in the pre-crisis sample.
} 
Estimated marginal data densities

\begin{tabular}{l||cc|cc}
\hline \multicolumn{1}{l||}{} & \multicolumn{2}{c}{$1998-2019$} & \multicolumn{2}{c}{$1983-2008$} \\
& Mod.HM & Laplace & Mod.HM & Laplace \\
\hline RANK & -388.522 & -393.117 & -444.460 & -448.292 \\
TANK & -393.376 & -395.718 & -451.007 & -450.096 \\
FRANK & -402.072 & -405.040 & -448.026 & -450.343 \\
FTANK & -404.826 & -408.701 & -447.142 & -450.919 \\
FRANK-R & -390.133 & -394.931 & -446.363 & -448.189 \\
FTANK-R & -391.684 & -398.029 & -449.958 & -448.847 \\
\hline FRANK-S & -362.267 & -360.621 & -393.203 & -400.407 \\
FTANK-S & -362.103 & -366.018 & -398.474 & -400.559 \\
\multicolumn{5}{c}{ Table 4: Comparison of the MDD (marginal data density) }
\end{tabular}

yield far lower estimates, namely between five and nine percent for all considered samples. We therefore conclude that the low relevance of hand-to-mouth consumers in our benchmark analysis is not the result of our informed prior. Rather it is due to the presence of other frictions in our model that make it difficult to identify their effects on business cycle dynamics.

\subsection{The empirical fit of RANK, TANK 83 Financial friction models}

Lastly, we assess how household heterogeneity à la TANK and financial frictions affect the models' empirical fit in the crisis. In Table 4, the first figure for each model marks the approximation of the estimated marginal data density (MDD) via the Modified Harmonic Mean, developed by Geweke (1999) whereas the second uses the Laplace Approximation. ${ }^{41}$

Centrally, the estimated MDDs confirm that neither financial frictions nor hand-tomouth consumers improve upon RANK in the crisis sample, as long as the same set of observables is considered. This is in line with our analysis above. The empirical fit of the model in the crisis sample is closely related to the ability of the most prominent shocks in the sample to efficiently generate the observed dynamics. The more additional shocks are needed to explain the variations of the observables, the worse is the empirical fit. As discussed above, of the shocks under consideration, the risk premium shock is the one that goes a longest way in driving joint dynamics over the crisis sample.

The empirical fit of TANK is only slightly worse than that of RANK for both measures of the estimated MDD. Its failure to improve upon RANK is largely tied to its irrelevance for the transmission of risk premium shocks. The MDD measures of FRANK, FTANK, FRANK-R and FTANK-R show that financial frictions deteriorate the empirical fit of the model. We find that this is due to the fact that the presence of financial frictions dampens the drop differential of consumption and investment in response to a risk premium shock (c.f. Section 5.2.1). This impedes the ability of risk premium shocks to generate the stark

\footnotetext{
${ }^{41}$ As the posterior distributions for the FRANK models are in parts bimodal, the Laplace estimator of the MDD is likely to be biased as it relies on the assumption of a unimodal posterior. Similarly, as noted in the original paper, the high dimensional parameter space of the models considered here potentially results in approximation errors when using the approximation via the Modified Harmonic Mean. Note that for estimations based on nonlinear filters, the estimate of the likelihood can also be subject to approximation errors due to sampling errors.
} 
collapse of investment in the Great Recession without triggering an excessive decline in consumption. As a consequence, financial friction models more heavily rely on additional shocks. MEI shocks or risk shocks need to account for the decline in investment, and price markup feature more prominently in the generation of inflation dynamics.

Notably, FRANK-R and FTANK-R, the models in which MEI shocks are replaced by risk shocks fare better in terms of empirical fit than their counterparts FRANK and FTANK. The reason is that compared to the effects of MEI shocks, the inflationary pressure induced by risk shocks is more pronounced. The support of risk shocks dampens the fall of marginal cost in the Great Recession and allows for a higher estimate of the slope coefficient of the Phillips curve without inducing strong disinflation. Consequently, the steeper Phillips curve allows a larger fraction of inflation dynamics to be explained endogenously. The reduced need for the additional price markup shocks improves the empirical fit of FRANK-R which is only slightly worse than that of RANK. Unfortunately, as discussed in Section 5.2.2, this appealing feature disappears once the set of observables is enlarged by the credit spread and MEI shocks crowd out risk shocks. Additionally, while improving upon a joint account for investment and inflation, they fail to conciliate the dynamics of consumption and investment.

The fit of FRANK-S and FTANK-S is not directly comparable to the other models. Whereas matching the path of the credit spread as an additional observable constitutes a challenge in the estimation, the joint use of MEI shocks and risk shocks creates an additional degree of freedom to match the data. These shocks have very similar effects on the model dynamics. Using both in the same analysis, allows for matching the data with smaller disturbances of two types instead of larger disturbances of one type, which would yield a lower likelihood.

The results presented in this section demonstrate that the employed extensions might not add significant value to the standard medium-scale RANK model for fitting the macroeconomic dynamics in the US around the Great Recession. This presents a potentially inconvenient finding to the disadvantage of current TANK or financial friction models. Our results highlight the challenge to find a proper modeling of these features, that enables them to improve upon the standard model. At the same time, and somewhat expectable, the RANK model itself delivers a poor story for the course of the macroeconomic dynamics since the financial crisis.

\section{Issues with a post-crisis analysis based on pre-crisis estimates}

Fully accounting for the ZLB in the estimation of a DSGE model is non-trivial (c.f. Subsections 3.1 and 3.2). It therefore has become common practice to analyze the dynamics of the US economy during the crisis based on models, that are estimated on pre-ZLB data only (see, e.g., Chen et al., 2012; Christiano et al., 2014, 2015; Del Negro et al., 2015b; Carlstrom et al., 2017). This approach has generated prominent that shape our understanding of the Great Recession, the role of financial frictions or the effects of unconventional monetary policy. In this subsection we illustrate that this practice can yield strongly misleading implications. One particular implication is, that the importance of disturbances to the investment decision is highly overtaxed. Shocks to investment cost have received heightened attention in a search for an explanation of the events of the Great Recession - Christiano et al. (2015) label it the financial wedge. In their analysis, variations in this wedge explain the bulk of variations in real activity in the Great Recession and its aftermath. In contrast to their finding, we argue that the importance of risk premium shocks, or in analogous terms, the consumption wedge, is underestimated. 

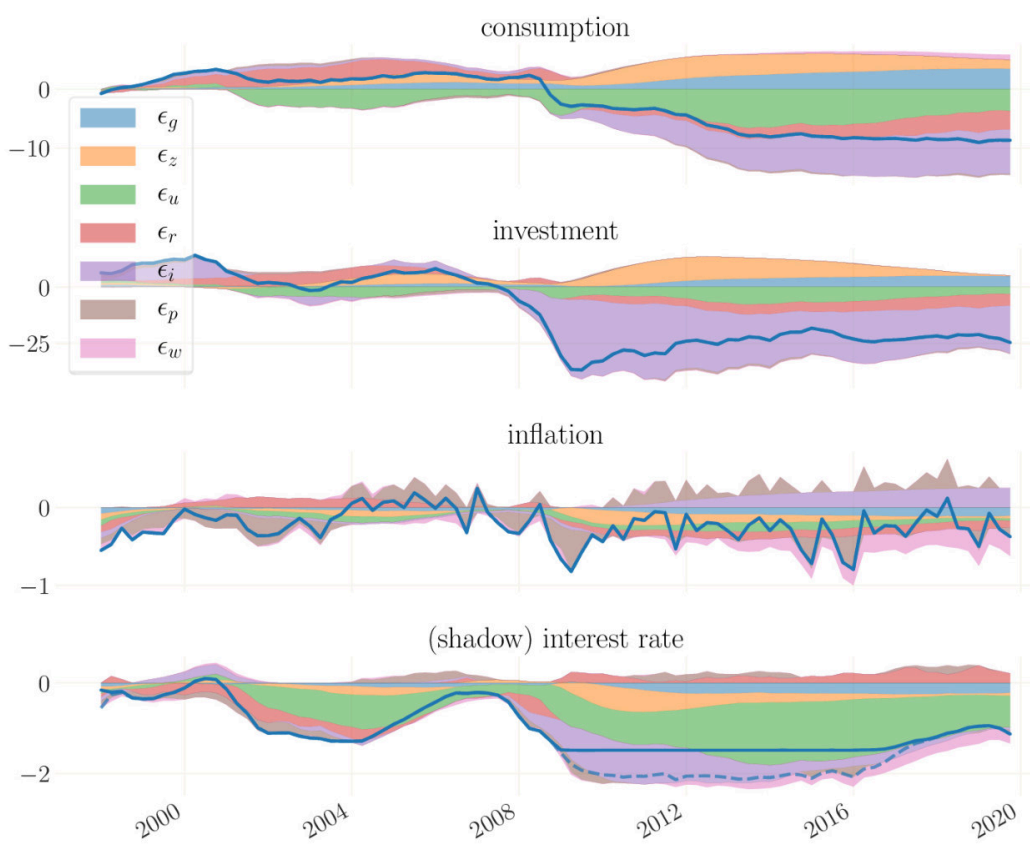

Figure 11: RANK Model estimated to 1983-2008 used for the decomposition of the sample from 1998 2019. Note: Means over 250 simulations drawn from the posterior. The contribution of each shock is normalized as in Appendix E.

We illustrate this in Figure 11, which shows the historical shock decomposition for the crisis sample using parameter estimates derived from the estimation of the RANK model on the pre-crisis sample. Relying only on pre-crisis data drastically changes the interpretation of the crisis. Importantly, as a comparison with Figure 1 shows, in this exercise the role of risk premium shocks for business cycle dynamics is dramatically reduced. The decline in consumption is now attributed to a combination of risk premium shocks and MEI shocks. Investment dynamics are almost entirely driven by MEI shocks, whereas the effect of risk premium shocks is subdued. Compared to the results from the previous section, the role of risk premiums for inflation dynamics is strongly reduced as well. In contrast, the inflationary effect of negative MEI shocks now becomes more relevant. The long ZLB period as well is explained to a mixture of recessionary risk premium shocks and MEI shocks.

The sharp difference between this interpretation of the crisis and the interpretation based on an estimation on crisis data can be attributed to the differences in the estimated parameter values displayed above in Table A.5. In particular, the estimates of $\sigma_{c}$ play an important role. In the crisis estimate, its posterior mean is at 0.930 . In the pre-crisis estimate it is at 1.469. Figure 12 shows how this alters the transmission of risk premium shocks. Already in the base case of RANK, a drawback of the risk premium shock is that it cannot match the drop differential of consumption and investment that was observed in the Great Recession. A risk premium shock that would have triggered a collapse in investment as observed in 2009, would have caused an excessive fall in consumption. For a coefficient of relative risk aversion of $\sigma_{c}=1.469$, as in this exercise, this drawback is exacerbated. For values of $\sigma_{c}$ larger than one, the decline in labor hours exerts an additional downwards 

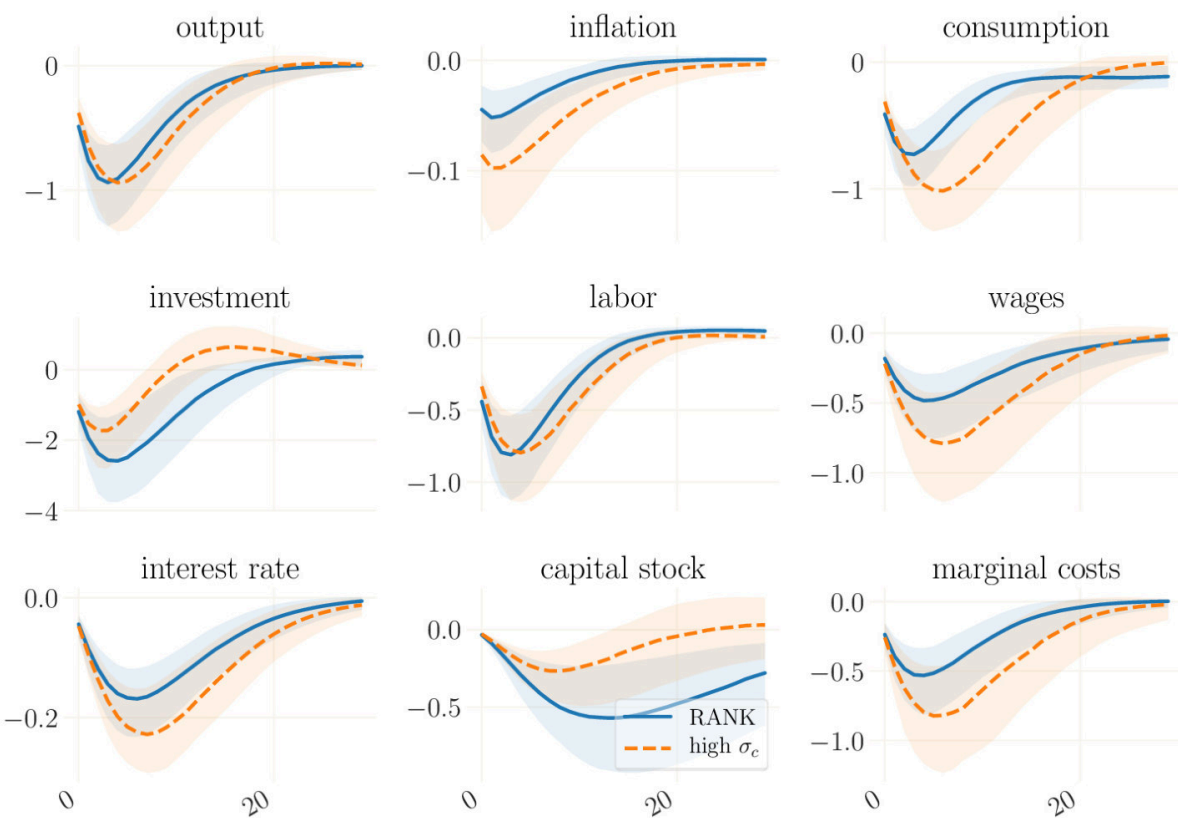

Figure 12: IRFs to a risk premium shock in RANK estimated for 1998-2019. In orange with $\sigma_{c}=1.469$, a values taken from the estimate of RANK from 1983 to 2008.

Note: Medians over 250 simulations drawn from the posterior. $90 \%$ credible set for RANK. Shock size is the posterior mean standard deviation.

pull on consumption through the non-separabilities in the utility function. In turn, the lower consumption translates into an outward shift of the labor supply curve, and a further drop in wages. Investment falls by less, since the marginal product of capital increases with the additional employment used in production. Therefore, the drop differential between investment and consumption becomes even smaller and makes it less likely that risk premium shocks can account for the Great Recession.

In contrast, Figure 13 shows that one cause of the failure of MEI shocks to be reconciled with the dynamics of the Great Recession is the low estimate of $\sigma_{c}$ derived from the estimation on crisis data. Here, a negative MEI shock increases consumption: by lowering aggregate demand, MEI shocks weigh on the policy interest rate, which in turn stimulates consumption on impact. This negative co-movement of consumption and investment is at odds with the observed dynamics in the Great Recession. In contrast, when the higher value of $\sigma_{c}$ derived from the estimate on pre-crisis data is used, the non-separabilities between labor and consumption generate a decline in consumption. In that case, the more prominent role for MEI shocks allows a stronger support for inflation which, after an initial decline in response to the shock, rebounds and puts upwards pressure on price dynamics. Hence, given the pre-crisis estimate for the coefficient of relative risk aversion, MEI shocks can address the missing deflation puzzle. However, the pre-crisis estimate of $\sigma_{c}$ is very close to the prior mean and it is hard to reject that this estimate is a matter of poor identification. On the contrary, the crisis-sample estimate of this parameter is almost two standard deviations distant from the prior mean, which suggests that the value is driven by the data. Hence we 

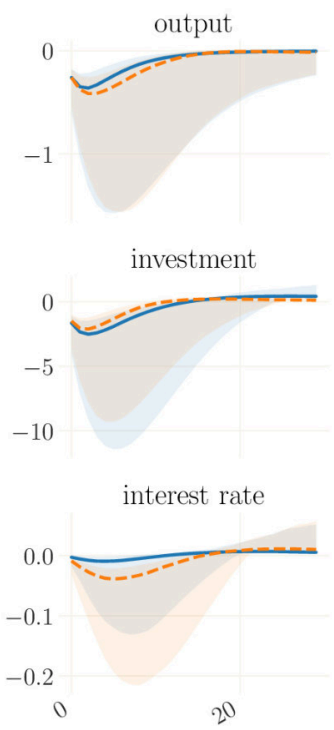
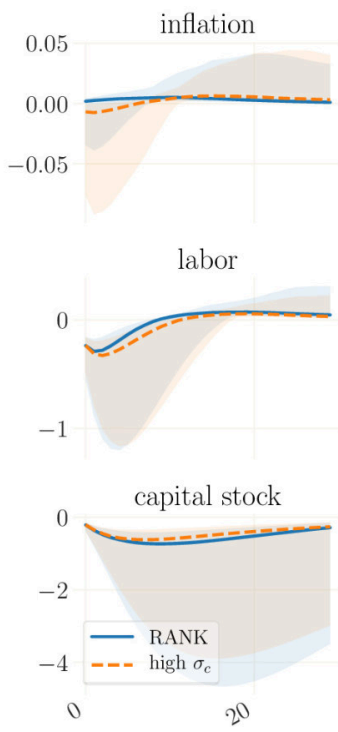
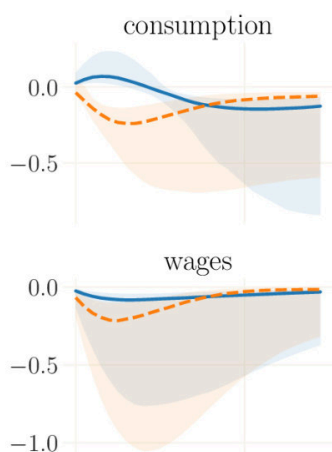

$-1.0$

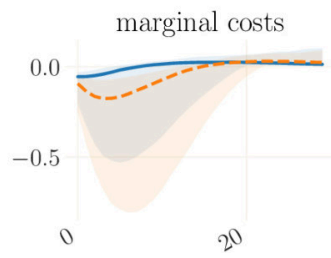

Figure 13: IRFs to a MEI shock in RANK estimated for 1998-2019. In orange with $\sigma_{c}=1.469$, a values taken from the estimate of RANK from 1983 to 2008. Note: Medians over 250 simulations drawn from the posterior. $90 \%$ credible set for RANK. Shock size is the posterior mean standard deviation.

find that through the lens of pre-crisis estimates, MEI shocks - and other financial wedge type of shocks which share similar properties - appear more attractive than they are when bringing the model to crisis data.

This account of the Great Recession offered by our exercise based on the pre-crisis sample differs sharply from the interpretation deemed most likely by the crisis data. As we see, elevated risk premiums to the households borrowing rate play a dominant role for business cycles. This can be loosely associated to increases in mortgage lending rates and calls for a more refined modeling of household finances, as well as additional modeling features that link a contraction in consumption to a strong fall in investment. ${ }^{42}$ Whatever modeling choices prove to be the best fit to capture the events of the recent decades, the exercise in this section highlights the importance of making use of the data of the last decade, when analyzing business cycle dynamics during this time.

\section{Conclusion}

In this paper we estimate a selection of models on a sample that centers around the Great Recession and includes the period of the binding ZLB thereafter. For the Bayesian inference we take this occasionally binding constraint serious. Our approach allows us to analyze US business cycles during that period and decompose the dynamics into the contribution of its causal drivers. This paper is the first to estimate models on a US data sample that

\footnotetext{
${ }^{42}$ Additional challenges highlighted by Gomme et al. (2011) is to generate a negative co-movement of the investment volume and Tobin's q, as well as to break the equivalence of the return on assets and the return on equity.
} 
ends in 2019, including the exit from the ZLB, and a rigorous model comparison. With our comprehensive assessment of parameter estimates over various time horizons, we provide for reference estimation for a set of medium-scale models that can be used to circumvent the technical complications associated with the ZLB. Additionally, we provide a discussion of how parameter estimates differ for crisis and pre-crisis samples.

Importantly, we find that although the empirical performance of the RANK model calls for improvements, neither a TANK extension nor models that include financial frictions as in Bernanke et al. (1999) meet the challenge of assigning a common causal driver to the main events in the Great Recession. Namely, these models fall short of providing the source for the collapse in investment, the decline in consumption and the only modest dip in inflation observed in the recession. Particularly in models with financial frictions, consumption and investment dynamics are dominated by independent drivers and a joint propagation mechanism is absent. The absence of a common explanation for the dynamics in the Great Recession presents a severe drawback for the considered models as a storytelling device. This is also reflected in the fact that hand-to-mouth agents and financial frictions somewhat worsen the empirical fit of the standard model.

Whereas recessionary financial shocks can in principle be inflationary, their implied consumption response is at odds with the data. Hence, they are assigned a low weight in the estimation of the crisis sample. This prevents them from contributing to an explanation of the missing disinflation puzzle. Post-crisis dynamics are dominated by elevated risk premiums on household borrowing rates, in line with the importance of increased mortgage rates in the financial crisis. In contrast, pre-crisis business cycles are to a large degree driven by shocks to the marginal efficiency of investment. Using pre-crisis estimates to analyze the post-crisis period yields the misleading conclusion that shocks to the cost of investment were a main driver for the Great Recession and the US economy's post-crisis trajectory. This result is a cautionary tale that should discourage from empirically investigating on the Great Recession with models tuned to match the pre-crisis experience.

Going forward, it is a fruitful endeavor to use more refined models that zoom in on the drivers of elevated risk premiums or to consider a more detailed modeling of labor markets. To keep the scope of the paper manageable, we abstain from a discussion of the role of the expanded set of monetary policies for post-crisis business cycles. Instead, a detailed analysis of the effects of quantitative easing policies for macroeconomic dynamics in the US in the context of a large-scale model is provided by Boehl et al. (2020).

\section{References}

Angeletos, G.-M., Collard, F., Dellas, H., 2018. Business cycle anatomy. Working Paper 24875, National Bureau of Economic Research.

Atkinson, T., Richter, A. W., Throckmorton, N. A., 2019. The zero lower bound and estimation accuracy. Journal of Monetary Economics .

Auclert, A., 2019. Monetary policy and the redistribution channel. American Economic Review 109 (6), 2333-67.

Bayer, C., Born, B., Luetticke, R., 2019. Shocks, frictions, and inequality in US business cycles. Mimeo, frankfurt school.

Bernanke, B. S., Gertler, M., Gilchrist, S., 1999. The financial accelerator in a quantitative business cycle framework. Handbook of macroeconomics 1, 1341-1393. 
Bilbiie, F. O., 2019. The new keynesian cross. Journal of Monetary Economics .

Boehl, G., 2020a. econsieve - a collection of linear and nonlinear (kalman) filters for economic models.

URL https://github.com/gboehl/econsieve

Boehl, G., 2020b. Efficient solution, filtering and estimation of models with obcs. Tech. rep., unpublished manuscript.

Boehl, G., 2020c. pydsge - a package to simulate, filter, and estimate dsge models with occasionally binding constraints.

URL https://github.com/gboehl/pydsge

Boehl, G., Goy, G., Strobel, F., 2020. A Structural Investigation of Quantitative Easing. Tech. rep., unpublished manuscript.

URL https://gregorboehl.com

Borağan Aruoba, S., Cuba-Borda, P., Schorfheide, F., 2018. Macroeconomic Dynamics Near the ZLB: A Tale of Two Countries. The Review of Economic Studies 85 (1), 87-118.

Brunnermeier, M. K., Sannikov, Y., 2014. A macroeconomic model with a financial sector. American Economic Review 104 (2), 379-421.

Calvo, G. A., 1983. Staggered prices in a utility-maximizing framework. Journal of Monetary Economics 12 (3), 383-398.

Carlstrom, C. T., Fuerst, T. S., 1997. Agency Costs, Net Worth, and Business Fluctuations: A Computable General Equilibrium Analysis. American Economic Review 87 (5), 893910 .

Carlstrom, C. T., Fuerst, T. S., Paustian, M., 2017. Targeting long rates in a model with segmented markets. American Economic Journal: Macroeconomics 9 (1), 205-42.

Chen, H., Cúrdia, V., Ferrero, A., 2012. The macroeconomic effects of large-scale asset purchase programmes. The Economic Journal 122 (564), F289-F315.

Christiano, L., Eichenbaum, M., Evans, C., 2005. Nominal rigidities and the dynamic effects of a shock to monetary policy. Journal of Political Economy 113 (1), 1-45.

Christiano, L. J., Eichenbaum, M. S., Trabandt, M., 2015. Understanding the great recession. American Economic Journal: Macroeconomics 7 (1), 110-67.

Christiano, L. J., Motto, R., Rostagno, M., 2014. Risk Shocks. American Economic Review 104 (1), 27-65.

Coenen, G., Straub, R., 2005. Does government spending crowd in private consumption? theory and empirical evidence for the euro area. International Finance 8 (3), 435-470.

Coenen, G., Straub, R., Trabandt, M., 2013. Gauging the effects of fiscal stimulus packages in the euro area. Journal of Economic Dynamics and Control 37 (2), 367-386.

Cúrdia, V., Woodford, M., 2011. The central-bank balance sheet as an instrument of monetary policy. Journal of Monetary Economics 58, 54-79. 
De Graeve, F., 2008. The external finance premium and the macroeconomy: Us post-wwii evidence. Journal of Economic Dynamics and Control 32 (11), 3415-3440.

Del Negro, M., Eggertsson, G., Ferrero, A., Kiyotaki, N., 2017. The Great Escape? A Quantitative Evaluation of the Fed's Liquidity Facilities. American Economic Review 107 (3), 824-857.

Del Negro, M., Giannoni, M., Paterson, C., 2015a. The forward guidance puzzle. Staff Report 574, Federal Reserve Bank of New York.

Del Negro, M., Giannoni, M. P., Schorfheide, F., 2015b. Inflation in the great recession and new keynesian models. American Economic Journal: Macroeconomics 7 (1), 168-96.

Edge, R. M., Kiley, M. T., Laforte, J.-P., 2008. Natural rate measures in an estimated dsge model of the u.s. economy. Journal of Economic Dynamics and Control 32 (8), 2512 2535 .

Eggertsson, G. B., Woodford, M., 2003. The zero bound on interest rates and optimal monetary policy. Brookings Papers on Economic Activity 2003 (1), 139-211.

Erceg, C., Levin, A., 2006. Optimal monetary policy with durable consumption goods. Journal of Monetary Economics 53 (7), 1341-1359.

Fratto, C., Uhlig, H., 2020. Accounting for Post-Crisis Inflation: A Retro Analysis. Review of Economic Dynamics 35, 133-153.

Fève, P., Sahuc, J., 2017. In Search of the Transmission Mechanism of Fiscal Policy in the Euro Area. Journal of Applied Econometrics 32 (3), 704-718.

Galí, J., López-Salido, J. D., Vallés, J., 2007. Understanding the effects of government spending on consumption. Journal of the European Economic Association 5 (1), 227-270.

Gerali, A., Neri, S., Sessa, L., Signoretti, F. M., 2010. Credit and banking in a dsge model of the euro area. Journal of Money, Credit and Banking 42 (s1), 107-141.

Gertler, M., Karadi, P., 2011. A model of unconventional monetary policy. Journal of Monetary Economics 58, 17-34.

Gertler, M., Kiyotaki, N., 2010. Financial intermediation and credit policy in business cycle analysis. In: Friedman, B. M., Woodford, M. (Eds.), Handbook of Monetary Economics. Vol. 3. Elsevier, Ch. 11, pp. 547-599.

Geweke, J., 1999. Using simulation methods for bayesian econometric models: inference, development,and communication. Econometric Reviews 18 (1), 1-73.

Gilchrist, S., Schoenle, R., Sim, J., Zakrajšek, E., 2017. Inflation dynamics during the financial crisis. American Economic Review 107 (3), 785-823.

Gilchrist, S., Zakrajšek, E., 2012. Credit spreads and business cycle fluctuations. American Economic Review 102 (4), 1692-1720.

Gomme, P., Ravikumar, B., Rupert, P., 2011. The return to capital and the business cycle. Review of Economic Dynamics 14 (2), 262-278. 
Guerrieri, L., Iacoviello, M., 2015. Occbin: A toolkit for solving dynamic models with occasionally binding constraints. Journal of Monetary Economics 70, 22-38.

Guerrieri, L., Iacoviello, M., 2017. Collateral constraints and macroeconomic asymmetries. Journal of Monetary Economics 90 (C), 28-49.

Gust, C., Herbst, E., López-Salido, D., Smith, M. E., 2017. The empirical implications of the interest-rate lower bound. American Economic Review 107 (7), 1971-2006.

Hall, R. E., 2011. The long slump. American Economic Review 101 (2), 431-69.

Holston, K., Laubach, T., Williams, J. C., 2017. Measuring the natural rate of interest: International trends and determinants. Journal of International Economics 108, S59 S75.

Jones, C., 2017. Unanticipated shocks and forward guidance at the zlb. Tech. rep., manuscript.

Jones, C., Kulish, M., Rees, D. M., 2018. International Spillovers of Forward Guidance Shocks. IMF Working Papers 18/114, International Monetary Fund.

Justiniano, A., Primiceri, G., Tambalotti, A., 2011. Investment Shocks and the Relative Price of Investment. Review of Economic Dynamics 14 (1), 101-121.

Justiniano, A., Primiceri, G. E., Tambalotti, A., 2010. Investment shocks and business cycles. Journal of Monetary Economics 57 (2), 132-145.

Kaplan, G., Moll, B., Violante, G. L., 2018. Monetary policy according to hank. American Economic Review 108 (3), 697-743.

Kaplan, G., Violante, G. L., Weidner, J., 2014. The wealthy hand-to-mouth. Working Paper 20073, National Bureau of Economic Research.

Keen, B. D., Richter, A. W., Throckmorton, N. A., 2017. Forward guidance and the state of the economy. Economic Inquiry 55 (4), 1593-1624.

Kimball, M. S., 1995. The Quantitative Analytics of the Basic Neomonetarist Model. NBER Working Papers 5046, National Bureau of Economic Research, Inc.

King, R. G., Watson, M. W., 2012. Inflation and unit labor cost. Journal of Money, credit and Banking 44, 111-149.

Klein, P., 2000. Using the generalized schur form to solve a multivariate linear rational expectations model. Journal of Economic Dynamics and Control 24 (10), 1405-1423.

Kulish, M., Morley, J., Robinson, T., 2017. Estimating DSGE models with zero interest rate policy. Journal of Monetary Economics 88, $35-49$.

Kydland, F. E., Prescott, E. C., 1982. Time to Build and Aggregate Fluctuations. Econometrica 50 (6), 1345-1370.

Lanne, M., Nyberg, H., 2016. Generalized Forecast Error Variance Decomposition for Linear and Nonlinear Multivariate Models. Oxford Bulletin of Economics and Statistics 78 (4), 595-603. 
Laubach, T., Williams, J. C., 2003. Measuring the Natural Rate of Interest. The Review of Economics and Statistics 85 (4), 1063-1070.

McKay, A., Reis, R., 2016. The role of automatic stabilizers in the u.s. business cycle. Econometrica 84 (1), 141-194.

Meh, C. A., Moran, K., 2010. The role of bank capital in the propagation of shocks. Journal of Economic Dynamics and Control 34 (3), 555-576.

Neri, S., Gerali, A., 2019. Natural rates across the Atlantic. Journal of Macroeconomics $62(\mathrm{C})$.

Plante, M., Richter, A. W., Throckmorton, N. A., 2018. The zero lower bound and endogenous uncertainty. The Economic Journal 128 (611), 1730-1757.

Rauch, H. E., Striebel, C., Tung, F., 1965. Maximum likelihood estimates of linear dynamic systems. AIAA journal 3 (8), 1445-1450.

Smets, F., Wouters, R., 2003. An estimated dynamic stochastic general equilibrium model of the euro area. Journal of the European economic association 1 (5), 1123-1175.

Smets, F., Wouters, R., 2007. Shocks and frictions in US business cycles: A Bayesian DSGE approach. American Economic Review 97 (3), 586-606.

Ter Braak, C. J., 2006. A markov chain monte carlo version of the genetic algorithm differential evolution: easy bayesian computing for real parameter spaces. Statistics and Computing 16 (3), 239-249.

ter Braak, C. J., Vrugt, J. A., 2008. Differential evolution markov chain with snooker updater and fewer chains. Statistics and Computing 18 (4), 435-446. 


\section{Appendix A Additional estimation results}

Sample from 1998 to 2019

Prior Posterior

\begin{tabular}{|c|c|c|c|c|c|c|}
\hline & \multicolumn{2}{|c|}{ Prior } & & \multicolumn{3}{|c|}{$\begin{array}{c}\text { Posterior } \\
\text { FTANK }\end{array}$} \\
\hline & dist. & mean & $\mathrm{sd} / \mathrm{df}$ & mean & sd & mode \\
\hline$\sigma_{c}$ & normal & 1.500 & 0.375 & 0.907 & 0.088 & 0.939 \\
\hline$\sigma_{l}$ & normal & 2.000 & 0.750 & 1.636 & 0.372 & 1.616 \\
\hline$\beta_{t p r}$ & gamma & 0.250 & 0.100 & 0.131 & 0.045 & 0.157 \\
\hline$h$ & beta & 0.700 & 0.100 & 0.779 & 0.039 & 0.793 \\
\hline$S^{\prime \prime}$ & normal & 4.000 & 1.500 & 5.078 & 0.957 & 4.326 \\
\hline$\iota_{p}$ & beta & 0.500 & 0.150 & 0.211 & 0.078 & 0.301 \\
\hline$\iota_{w}$ & beta & 0.500 & 0.150 & 0.321 & 0.113 & 0.305 \\
\hline$\alpha$ & normal & 0.300 & 0.050 & 0.174 & 0.011 & 0.173 \\
\hline$\zeta_{p}$ & beta & 0.500 & 0.100 & 0.922 & 0.014 & 0.924 \\
\hline$\zeta_{w}$ & beta & 0.500 & 0.100 & 0.751 & 0.046 & 0.776 \\
\hline$\Phi_{p}$ & normal & 1.250 & 0.125 & 1.320 & 0.070 & 1.347 \\
\hline$\psi$ & beta & 0.500 & 0.150 & 0.758 & 0.079 & 0.845 \\
\hline$\phi_{\pi}$ & normal & 1.500 & 0.250 & 1.108 & 0.132 & 0.991 \\
\hline$\phi_{y}$ & normal & 0.125 & 0.050 & 0.235 & 0.026 & 0.208 \\
\hline$\phi_{d y}$ & normal & 0.125 & 0.050 & 0.161 & 0.042 & 0.241 \\
\hline$\rho$ & beta & 0.750 & 0.100 & 0.753 & 0.031 & 0.755 \\
\hline$\zeta_{s p b}$ & beta & 0.050 & 0.005 & 0.050 & 0.004 & 0.052 \\
\hline$\lambda$ & beta & 0.300 & 0.100 & 0.223 & 0.073 & 0.193 \\
\hline$\rho_{r}$ & beta & 0.500 & 0.200 & 0.491 & 0.071 & 0.425 \\
\hline$\rho_{g}$ & beta & 0.500 & 0.200 & 0.938 & 0.018 & 0.945 \\
\hline$\rho_{z}$ & beta & 0.500 & 0.200 & 0.970 & 0.021 & 0.972 \\
\hline$\rho_{u}$ & beta & 0.500 & 0.200 & 0.886 & 0.025 & 0.891 \\
\hline$\rho_{p}$ & beta & 0.500 & 0.200 & 0.412 & 0.146 & 0.567 \\
\hline$\rho_{w}$ & beta & 0.500 & 0.200 & 0.515 & 0.086 & 0.450 \\
\hline$\rho_{i}$ & beta & 0.500 & 0.200 & 0.914 & 0.025 & 0.915 \\
\hline$\mu_{p}$ & beta & 0.500 & 0.200 & 0.357 & 0.090 & 0.301 \\
\hline$\mu_{w}$ & beta & 0.500 & 0.200 & 0.326 & 0.087 & 0.264 \\
\hline$\rho_{g z}$ & normal & 0.500 & 0.250 & 0.483 & 0.095 & 0.487 \\
\hline$\sigma_{g}$ & $\mathrm{IG}$ & 0.100 & 2.000 & 0.252 & 0.025 & 0.252 \\
\hline$\sigma_{u}$ & IG & 0.100 & 2.000 & 0.465 & 0.110 & 0.442 \\
\hline$\sigma_{z}$ & IG & 0.100 & 2.000 & 0.389 & 0.042 & 0.408 \\
\hline$\sigma_{r}$ & IG & 0.100 & 2.000 & 0.171 & 0.034 & 0.185 \\
\hline$\sigma_{p}$ & IG & 0.100 & 2.000 & 0.414 & 0.140 & 0.228 \\
\hline$\sigma_{w}$ & IG & 0.100 & 2.000 & 1.086 & 0.203 & 1.225 \\
\hline$\sigma_{i}$ & $\mathrm{IG}$ & 0.100 & 2.000 & 0.524 & 0.060 & 0.530 \\
\hline $\bar{\gamma}$ & normal & 0.440 & 0.050 & 0.392 & 0.034 & 0.390 \\
\hline $\bar{l}$ & normal & 0.000 & 2.000 & 1.364 & 0.601 & 1.285 \\
\hline $\bar{\pi}$ & gamma & 0.625 & 0.100 & 0.592 & 0.050 & 0.613 \\
\hline sprea & normal & 0.500 & 0.100 & 0.335 & 0.062 & 0.254 \\
\hline
\end{tabular}

Table A.5: Estimation results for FTANK for the crisis sample (1998-2019). 
Sample from 1983 to 2008 Prior

Posterior

FTANK

\begin{tabular}{|c|c|c|c|c|c|c|}
\hline & dist. & mean & $\mathrm{sd} / \mathrm{df}$ & mean & sd & mode \\
\hline$\sigma_{c}$ & normal & 1.500 & 0.375 & 1.260 & 0.122 & 1.255 \\
\hline$\sigma_{l}$ & normal & 2.000 & 0.750 & 2.499 & 0.510 & 2.771 \\
\hline$\beta_{t p r}$ & gamma & 0.250 & 0.100 & 0.147 & 0.047 & 0.146 \\
\hline$h$ & beta & 0.700 & 0.100 & 0.659 & 0.052 & 0.696 \\
\hline$S^{\prime \prime}$ & normal & 4.000 & 1.500 & 5.989 & 0.987 & 5.926 \\
\hline$\iota_{p}$ & beta & 0.500 & 0.150 & 0.299 & 0.103 & 0.224 \\
\hline$\iota_{w}$ & beta & 0.500 & 0.150 & 0.399 & 0.124 & 0.488 \\
\hline$\alpha$ & normal & 0.300 & 0.050 & 0.222 & 0.010 & 0.224 \\
\hline$\zeta_{p}$ & beta & 0.500 & 0.100 & 0.846 & 0.027 & 0.815 \\
\hline$\zeta_{w}$ & beta & 0.500 & 0.100 & 0.843 & 0.038 & 0.867 \\
\hline$\Phi_{p}$ & normal & 1.250 & 0.125 & 1.514 & 0.067 & 1.523 \\
\hline$\psi$ & beta & 0.500 & 0.150 & 0.545 & 0.063 & 0.519 \\
\hline$\phi_{\pi}$ & normal & 1.500 & 0.250 & 1.318 & 0.213 & 1.174 \\
\hline$\phi_{y}$ & normal & 0.125 & 0.050 & 0.213 & 0.034 & 0.196 \\
\hline$\phi_{d y}$ & normal & 0.125 & 0.050 & 0.192 & 0.039 & 0.200 \\
\hline$\rho$ & beta & 0.750 & 0.100 & 0.732 & 0.038 & 0.717 \\
\hline$\zeta_{s p b}$ & beta & 0.050 & 0.005 & 0.050 & 0.004 & 0.050 \\
\hline$\lambda$ & beta & 0.300 & 0.100 & 0.218 & 0.059 & 0.161 \\
\hline$\rho_{r}$ & beta & 0.500 & 0.200 & 0.702 & 0.068 & 0.742 \\
\hline$\rho_{g}$ & beta & 0.500 & 0.200 & 0.941 & 0.029 & 0.967 \\
\hline$\rho_{z}$ & beta & 0.500 & 0.200 & 0.936 & 0.019 & 0.944 \\
\hline$\rho_{u}$ & beta & 0.500 & 0.200 & 0.764 & 0.074 & 0.776 \\
\hline$\rho_{p}$ & beta & 0.500 & 0.200 & 0.749 & 0.085 & 0.827 \\
\hline$\rho_{w}$ & beta & 0.500 & 0.200 & 0.607 & 0.106 & 0.438 \\
\hline$\rho_{i}$ & beta & 0.500 & 0.200 & 0.875 & 0.029 & 0.885 \\
\hline$\mu_{p}$ & beta & 0.500 & 0.200 & 0.528 & 0.151 & 0.547 \\
\hline$\mu_{w}$ & beta & 0.500 & 0.200 & 0.323 & 0.131 & 0.145 \\
\hline$\rho_{g z}$ & normal & 0.500 & 0.250 & 0.405 & 0.081 & 0.400 \\
\hline$\sigma_{g}$ & $\mathrm{IG}$ & 0.100 & 2.000 & 0.238 & 0.018 & 0.224 \\
\hline$\sigma_{u}$ & IG & 0.100 & 2.000 & 0.697 & 0.252 & 0.654 \\
\hline$\sigma_{z}$ & IG & 0.100 & 2.000 & 0.314 & 0.029 & 0.325 \\
\hline$\sigma_{r}$ & IG & 0.100 & 2.000 & 0.147 & 0.019 & 0.134 \\
\hline$\sigma_{p}$ & IG & 0.100 & 2.000 & 0.130 & 0.048 & 0.087 \\
\hline$\sigma_{w}$ & IG & 0.100 & 2.000 & 0.512 & 0.116 & 0.684 \\
\hline$\sigma_{i}$ & $\mathrm{IG}$ & 0.100 & 2.000 & 0.667 & 0.073 & 0.648 \\
\hline $\bar{\gamma}$ & normal & 0.440 & 0.050 & 0.419 & 0.027 & 0.415 \\
\hline $\bar{l}$ & normal & 0.000 & 2.000 & 1.447 & 0.578 & 1.221 \\
\hline $\bar{\pi}$ & gamma & 0.625 & 0.100 & 0.600 & 0.066 & 0.598 \\
\hline$\overline{s p r}$ & normal & 0.500 & 0.100 & 0.473 & 0.064 & 0.490 \\
\hline
\end{tabular}

Table A.6: Estimation results for FTANK for the sample before the crisis (1983-2008). 


\begin{tabular}{|c|c|c|c|c|c|c|c|c|c|c|c|c|c|c|c|}
\hline & \multirow{2}{*}{\multicolumn{3}{|c|}{ Prior }} & \multicolumn{12}{|c|}{ Posterior } \\
\hline & & & & \multicolumn{3}{|c|}{ FRANK-R } & \multicolumn{3}{|c|}{ FTANK-R } & \multicolumn{3}{|c|}{ FRANK-S } & \multicolumn{3}{|c|}{ FTANK-S } \\
\hline & dist. & mean & $\mathrm{sd} / \mathrm{df}$ & mean & sd & mode & mean & sd & mode & mean & sd & mode & mean & sd & mode \\
\hline$\sigma_{c}$ & normal & 1.500 & 0.375 & 1.365 & 0.116 & 1.397 & 1.232 & 0.107 & 1.203 & 1.156 & 0.117 & 1.135 & 0.999 & 0.103 & 1.002 \\
\hline$\sigma_{l}$ & normal & 2.000 & 0.750 & 1.478 & 0.410 & 1.442 & 1.604 & 0.460 & 1.671 & 1.421 & 0.450 & 1.638 & 1.228 & 0.351 & 1.675 \\
\hline$\beta_{t p r}$ & gamma & 0.250 & 0.100 & 0.129 & 0.042 & 0.119 & 0.127 & 0.043 & 0.086 & 0.102 & 0.033 & 0.092 & 0.109 & 0.036 & 0.131 \\
\hline$h$ & beta & 0.700 & 0.100 & 0.831 & 0.029 & 0.827 & 0.843 & 0.024 & 0.872 & 0.545 & 0.051 & 0.535 & 0.554 & 0.057 & 0.583 \\
\hline$S^{\prime \prime}$ & normal & 4.000 & 1.500 & 5.773 & 0.978 & 5.367 & 5.724 & 0.897 & 5.279 & 2.964 & 0.748 & 2.155 & 2.864 & 0.754 & 2.489 \\
\hline$\iota_{p}$ & beta & 0.500 & 0.150 & 0.228 & 0.076 & 0.285 & 0.216 & 0.068 & 0.203 & 0.280 & 0.091 & 0.269 & 0.248 & 0.078 & 0.192 \\
\hline$\iota_{w}$ & beta & 0.500 & 0.150 & 0.422 & 0.125 & 0.282 & 0.421 & 0.125 & 0.436 & 0.379 & 0.114 & 0.263 & 0.379 & 0.118 & 0.456 \\
\hline$\alpha$ & normal & 0.300 & 0.050 & 0.199 & 0.013 & 0.210 & 0.197 & 0.013 & 0.198 & 0.178 & 0.012 & 0.176 & 0.179 & 0.011 & 0.190 \\
\hline$\zeta_{p}$ & beta & 0.500 & 0.100 & 0.793 & 0.030 & 0.753 & 0.784 & 0.032 & 0.761 & 0.935 & 0.028 & 0.936 & 0.932 & 0.021 & 0.939 \\
\hline$\zeta_{w}$ & beta & 0.500 & 0.100 & 0.694 & 0.045 & 0.694 & 0.705 & 0.041 & 0.716 & 0.760 & 0.066 & 0.818 & 0.767 & 0.065 & 0.818 \\
\hline$\Phi_{p}$ & normal & 1.250 & 0.125 & 1.383 & 0.095 & 1.461 & 1.375 & 0.092 & 1.315 & 1.316 & 0.060 & 1.355 & 1.317 & 0.061 & 1.326 \\
\hline$\psi$ & beta & 0.500 & 0.150 & 0.808 & 0.064 & 0.818 & 0.810 & 0.064 & 0.850 & 0.809 & 0.062 & 0.843 & 0.825 & 0.060 & 0.824 \\
\hline$\phi_{\pi}$ & normal & 1.500 & 0.250 & 1.382 & 0.197 & 1.190 & 1.391 & 0.196 & 1.439 & 0.979 & 0.181 & 0.860 & 0.982 & 0.120 & 0.967 \\
\hline$\phi_{y}$ & normal & 0.125 & 0.050 & 0.195 & 0.026 & 0.196 & 0.194 & 0.026 & 0.214 & 0.205 & 0.024 & 0.203 & 0.223 & 0.032 & 0.197 \\
\hline$\phi_{d y}$ & normal & 0.125 & 0.050 & 0.174 & 0.039 & 0.174 & 0.177 & 0.038 & 0.164 & 0.179 & 0.040 & 0.205 & 0.173 & 0.039 & 0.178 \\
\hline$\rho$ & beta & 0.750 & 0.100 & 0.790 & 0.036 & 0.772 & 0.791 & 0.035 & 0.808 & 0.725 & 0.033 & 0.701 & 0.731 & 0.033 & 0.735 \\
\hline$\rho_{r}$ & beta & 0.500 & 0.200 & 0.835 & 0.056 & 0.849 & 0.828 & 0.062 & 0.858 & 0.469 & 0.060 & 0.476 & 0.451 & 0.057 & 0.465 \\
\hline$\rho_{g}$ & beta & 0.500 & 0.200 & 0.888 & 0.033 & 0.874 & 0.890 & 0.031 & 0.912 & 0.966 & 0.013 & 0.970 & 0.966 & 0.017 & 0.971 \\
\hline$\rho_{z}$ & beta & 0.500 & 0.200 & 0.981 & 0.013 & 0.995 & 0.982 & 0.011 & 0.970 & 0.919 & 0.024 & 0.899 & 0.921 & 0.023 & 0.951 \\
\hline$\rho_{u}$ & beta & 0.500 & 0.200 & 0.739 & 0.053 & 0.756 & 0.736 & 0.049 & 0.734 & 0.968 & 0.007 & 0.959 & 0.965 & 0.007 & 0.967 \\
\hline$\rho_{p}$ & beta & 0.500 & 0.200 & 0.597 & 0.100 & 0.662 & 0.649 & 0.092 & 0.647 & 0.542 & 0.107 & 0.581 & 0.562 & 0.090 & 0.635 \\
\hline$\rho_{w}$ & beta & 0.500 & 0.200 & 0.451 & 0.089 & 0.413 & 0.450 & 0.085 & 0.415 & 0.577 & 0.103 & 0.608 & 0.526 & 0.102 & 0.485 \\
\hline$\rho_{i}$ & beta & 0.500 & 0.200 & & & & & & & 0.906 & 0.026 & 0.918 & 0.913 & 0.026 & 0.913 \\
\hline$\rho_{\text {fin }}$ & beta & 0.500 & 0.200 & 0.960 & 0.012 & 0.963 & 0.956 & 0.015 & 0.965 & 0.960 & 0.024 & 0.948 & 0.957 & 0.024 & 0.968 \\
\hline$\mu_{p}$ & beta & 0.500 & 0.200 & 0.291 & 0.141 & 0.363 & 0.309 & 0.130 & 0.254 & 0.385 & 0.119 & 0.306 & 0.278 & 0.109 & 0.343 \\
\hline$\mu_{w}$ & beta & 0.500 & 0.200 & 0.249 & 0.080 & 0.215 & 0.247 & 0.077 & 0.203 & 0.366 & 0.114 & 0.416 & 0.313 & 0.100 & 0.279 \\
\hline$\rho_{g z}$ & normal & 0.500 & 0.250 & 0.619 & 0.095 & 0.691 & 0.618 & 0.093 & 0.617 & 0.291 & 0.089 & 0.283 & 0.294 & 0.087 & 0.286 \\
\hline$\sigma_{g}$ & $\mathrm{IG}$ & 0.100 & 2.000 & 0.220 & 0.028 & 0.195 & 0.220 & 0.028 & 0.214 & 0.275 & 0.022 & 0.260 & 0.272 & 0.022 & 0.257 \\
\hline$\sigma_{u}$ & IG & 0.100 & 2.000 & 1.363 & 0.390 & 1.189 & 1.398 & 0.357 & 1.598 & 0.130 & 0.012 & 0.132 & 0.131 & 0.011 & 0.133 \\
\hline$\sigma_{z}$ & IG & 0.100 & 2.000 & 0.410 & 0.044 & 0.373 & 0.413 & 0.043 & 0.391 & 0.415 & 0.043 & 0.484 & 0.411 & 0.043 & 0.415 \\
\hline$\sigma_{r}$ & $\mathrm{IG}$ & 0.100 & 2.000 & 0.093 & 0.012 & 0.086 & 0.094 & 0.013 & 0.086 & 0.181 & 0.034 & 0.166 & 0.187 & 0.034 & 0.169 \\
\hline$\sigma_{p}$ & IG & 0.100 & 2.000 & 0.198 & 0.072 & 0.181 & 0.166 & 0.047 & 0.152 & 0.292 & 0.083 & 0.213 & 0.228 & 0.053 & 0.193 \\
\hline$\sigma_{w}$ & IG & 0.100 & 2.000 & 1.325 & 0.277 & 1.419 & 1.315 & 0.265 & 1.295 & 0.938 & 0.165 & 0.903 & 1.040 & 0.220 & 1.102 \\
\hline$\sigma_{i}$ & IG & 0.100 & 2.000 & & & & & & & 0.551 & 0.068 & 0.571 & 0.546 & 0.068 & 0.561 \\
\hline$\sigma_{f i n}$ & $\mathrm{IG}$ & 0.100 & 2.000 & 0.444 & 0.078 & 0.427 & 0.461 & 0.090 & 0.415 & 0.096 & 0.011 & 0.099 & 0.098 & 0.012 & 0.087 \\
\hline $\bar{\gamma}$ & normal & 0.440 & 0.050 & 0.313 & 0.041 & 0.284 & 0.312 & 0.044 & 0.358 & 0.403 & 0.023 & 0.394 & 0.406 & 0.023 & 0.412 \\
\hline $\bar{l}$ & normal & 0.000 & 2.000 & 1.123 & 0.793 & 1.295 & 1.085 & 0.758 & 0.661 & 1.606 & 0.567 & 1.309 & 1.390 & 0.648 & 1.475 \\
\hline $\bar{\pi}$ & gamma & 0.625 & 0.100 & 0.561 & 0.065 & 0.558 & 0.563 & 0.069 & 0.579 & 0.692 & 0.058 & 0.634 & 0.678 & 0.051 & 0.665 \\
\hline$\overline{\text { spread }}$ & normal & 0.500 & 0.100 & 0.352 & 0.075 & 0.394 & 0.365 & 0.073 & 0.413 & 0.259 & 0.062 & 0.236 & 0.263 & 0.061 & 0.316 \\
\hline$\zeta_{s p b}$ & beta & 0.050 & 0.005 & 0.051 & 0.004 & 0.053 & 0.051 & 0.004 & 0.052 & 0.051 & 0.004 & 0.051 & 0.051 & 0.004 & 0.050 \\
\hline$\lambda$ & beta & 0.300 & 0.100 & & & & 0.196 & 0.057 & 0.166 & & & & 0.139 & 0.043 & 0.105 \\
\hline MDD & & & & & ש & .931 & -391. & S & 8.029 & -362 . & 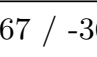 & 0.621 & -362 & $03 /-3$ & 0.018 \\
\hline
\end{tabular}

Table A.7: Comparison of estimation results across models for the crisis sample: Models with financial shock instead of MEI shock (FRANK-R and FTANK-R) and estimations including the GZ spread (FRANK-S and FTANK-S). 


\begin{tabular}{|c|c|c|c|c|c|c|c|c|c|c|c|c|c|c|c|}
\hline & \multirow{2}{*}{\multicolumn{3}{|c|}{ Prior }} & \multicolumn{12}{|c|}{ Posterior } \\
\hline & & & & \multicolumn{3}{|c|}{ FRANK-R } & \multicolumn{3}{|c|}{ FTANK-R } & \multicolumn{3}{|c|}{ FRANK-S } & \multicolumn{3}{|c|}{ FTANK-S } \\
\hline & dist. & mean & $\mathrm{sd} / \mathrm{df}$ & mean & sd & mode & mean & sd & mode & mean & $\mathrm{sd}$ & mode & mean & sd & mode \\
\hline$\sigma_{c}$ & normal & 1.500 & 0.375 & 1.572 & 0.175 & 1.652 & 1.485 & 0.164 & 1.353 & 1.537 & 0.147 & 1.504 & 1.448 & 0.139 & 1.459 \\
\hline$\sigma_{l}$ & normal & 2.000 & 0.750 & 1.773 & 0.560 & 1.819 & 1.456 & 0.589 & 1.751 & 2.628 & 0.488 & 2.669 & 2.566 & 0.536 & 1.992 \\
\hline$\beta_{t p r}$ & gamma & 0.250 & 0.100 & 0.158 & 0.052 & 0.131 & 0.166 & 0.055 & 0.121 & 0.133 & 0.044 & 0.126 & 0.133 & 0.043 & 0.135 \\
\hline$h$ & beta & 0.700 & 0.100 & 0.684 & 0.044 & 0.701 & 0.699 & 0.045 & 0.703 & 0.451 & 0.045 & 0.484 & 0.418 & 0.059 & 0.440 \\
\hline$S^{\prime \prime}$ & normal & 4.000 & 1.500 & 4.215 & 0.969 & 4.164 & 4.379 & 0.930 & 4.645 & 2.685 & 0.641 & 2.870 & 2.558 & 0.662 & 2.279 \\
\hline$\iota_{p}$ & beta & 0.500 & 0.150 & 0.331 & 0.118 & 0.417 & 0.342 & 0.125 & 0.259 & 0.322 & 0.096 & 0.394 & 0.330 & 0.101 & 0.299 \\
\hline$\iota_{w}$ & beta & 0.500 & 0.150 & 0.438 & 0.125 & 0.459 & 0.439 & 0.123 & 0.537 & 0.396 & 0.120 & 0.303 & 0.418 & 0.126 & 0.473 \\
\hline$\alpha$ & normal & 0.300 & 0.050 & 0.241 & 0.013 & 0.243 & 0.239 & 0.013 & 0.225 & 0.227 & 0.011 & 0.225 & 0.223 & 0.010 & 0.231 \\
\hline$\zeta_{p}$ & beta & 0.500 & 0.100 & 0.840 & 0.034 & 0.818 & 0.842 & 0.050 & 0.843 & 0.886 & 0.023 & 0.887 & 0.878 & 0.024 & 0.876 \\
\hline$\zeta_{w}$ & beta & 0.500 & 0.100 & 0.759 & 0.052 & 0.765 & 0.760 & 0.072 & 0.725 & 0.829 & 0.055 & 0.871 & 0.834 & 0.055 & 0.862 \\
\hline$\Phi_{p}$ & normal & 1.250 & 0.125 & 1.546 & 0.067 & 1.570 & 1.564 & 0.073 & 1.563 & 1.523 & 0.070 & 1.531 & 1.524 & 0.063 & 1.538 \\
\hline$\psi$ & beta & 0.500 & 0.150 & 0.665 & 0.087 & 0.607 & 0.655 & 0.092 & 0.679 & 0.484 & 0.109 & 0.438 & 0.435 & 0.108 & 0.490 \\
\hline$\phi_{\pi}$ & normal & 1.500 & 0.250 & 1.239 & 0.249 & 1.253 & 1.278 & 0.276 & 1.272 & 1.094 & 0.209 & 1.128 & 1.315 & 0.249 & 1.101 \\
\hline$\phi_{y}$ & normal & 0.125 & 0.050 & 0.218 & 0.036 & 0.201 & 0.216 & 0.047 & 0.232 & 0.170 & 0.035 & 0.137 & 0.163 & 0.033 & 0.173 \\
\hline$\phi_{d y}$ & normal & 0.125 & 0.050 & 0.200 & 0.039 & 0.201 & 0.195 & 0.042 & 0.166 & 0.226 & 0.039 & 0.209 & 0.234 & 0.040 & 0.242 \\
\hline$\rho$ & beta & 0.750 & 0.100 & 0.713 & 0.041 & 0.707 & 0.717 & 0.042 & 0.712 & 0.691 & 0.046 & 0.687 & 0.717 & 0.040 & 0.673 \\
\hline$\rho_{r}$ & beta & 0.500 & 0.200 & 0.807 & 0.068 & 0.831 & 0.810 & 0.079 & 0.833 & 0.633 & 0.086 & 0.627 & 0.585 & 0.082 & 0.642 \\
\hline$\rho_{g}$ & beta & 0.500 & 0.200 & 0.969 & 0.017 & 0.975 & 0.969 & 0.030 & 0.980 & 0.980 & 0.010 & 0.978 & 0.979 & 0.010 & 0.973 \\
\hline$\rho_{z}$ & beta & 0.500 & 0.200 & 0.968 & 0.014 & 0.979 & 0.963 & 0.018 & 0.961 & 0.932 & 0.023 & 0.921 & 0.928 & 0.019 & 0.936 \\
\hline$\rho_{u}$ & beta & 0.500 & 0.200 & 0.770 & 0.063 & 0.726 & 0.755 & 0.066 & 0.812 & 0.975 & 0.007 & 0.979 & 0.974 & 0.007 & 0.973 \\
\hline$\rho_{p}$ & beta & 0.500 & 0.200 & 0.708 & 0.129 & 0.830 & 0.700 & 0.143 & 0.843 & 0.770 & 0.096 & 0.838 & 0.760 & 0.100 & 0.807 \\
\hline$\rho_{w}$ & beta & 0.500 & 0.200 & 0.701 & 0.103 & 0.578 & 0.715 & 0.101 & 0.780 & 0.701 & 0.104 & 0.757 & 0.681 & 0.113 & 0.539 \\
\hline$\rho_{i}$ & beta & 0.500 & 0.200 & & & & & & & 0.776 & 0.048 & 0.734 & 0.782 & 0.049 & 0.759 \\
\hline$\rho_{\text {fin }}$ & beta & 0.500 & 0.200 & 0.837 & 0.040 & 0.871 & 0.860 & 0.041 & 0.823 & 0.982 & 0.007 & 0.981 & 0.985 & 0.008 & 0.979 \\
\hline$\mu_{p}$ & beta & 0.500 & 0.200 & 0.556 & 0.158 & 0.629 & 0.589 & 0.138 & 0.633 & 0.698 & 0.108 & 0.777 & 0.676 & 0.105 & 0.739 \\
\hline$\mu_{w}$ & beta & 0.500 & 0.200 & 0.453 & 0.161 & 0.233 & 0.419 & 0.140 & 0.492 & 0.433 & 0.149 & 0.513 & 0.400 & 0.144 & 0.216 \\
\hline$\rho_{g z}$ & normal & 0.500 & 0.250 & 0.373 & 0.081 & 0.422 & 0.391 & 0.085 & 0.362 & 0.361 & 0.083 & 0.401 & 0.383 & 0.082 & 0.397 \\
\hline$\sigma_{g}$ & IG & 0.100 & 2.000 & 0.237 & 0.017 & 0.227 & 0.236 & 0.018 & 0.226 & 0.241 & 0.016 & 0.237 & 0.243 & 0.017 & 0.238 \\
\hline$\sigma_{u}$ & $\mathrm{IG}$ & 0.100 & 2.000 & 0.742 & 0.233 & 0.913 & 0.824 & 0.266 & 0.612 & 0.100 & 0.009 & 0.092 & 0.103 & 0.009 & 0.104 \\
\hline$\sigma_{z}$ & $\mathrm{IG}$ & 0.100 & 2.000 & 0.300 & 0.027 & 0.299 & 0.298 & 0.028 & 0.314 & 0.314 & 0.030 & 0.317 & 0.315 & 0.030 & 0.309 \\
\hline$\sigma_{r}$ & $\mathrm{IG}$ & 0.100 & 2.000 & 0.126 & 0.015 & 0.126 & 0.126 & 0.021 & 0.107 & 0.180 & 0.034 & 0.176 & 0.193 & 0.034 & 0.197 \\
\hline$\sigma_{p}$ & IG & 0.100 & 2.000 & 0.160 & 0.066 & 0.095 & 0.178 & 0.071 & 0.093 & 0.164 & 0.037 & 0.137 & 0.162 & 0.044 & 0.161 \\
\hline$\sigma_{w}$ & IG & 0.100 & 2.000 & 0.455 & 0.103 & 0.511 & 0.416 & 0.078 & 0.360 & 0.423 & 0.081 & 0.368 & 0.427 & 0.114 & 0.522 \\
\hline$\sigma_{i}$ & IG & 0.100 & 2.000 & & & & & & & 0.745 & 0.101 & 0.800 & 0.756 & 0.103 & 0.786 \\
\hline$\sigma_{f i n}$ & IG & 0.100 & 2.000 & 1.053 & 0.276 & 0.828 & 0.962 & 0.256 & 1.293 & 0.080 & 0.007 & 0.081 & 0.078 & 0.008 & 0.083 \\
\hline $\bar{\gamma}$ & normal & 0.440 & 0.050 & 0.468 & 0.027 & 0.438 & 0.485 & 0.024 & 0.508 & 0.489 & 0.019 & 0.484 & 0.490 & 0.019 & 0.500 \\
\hline $\bar{l}$ & normal & 0.000 & 2.000 & 2.599 & 0.762 & 2.319 & 2.464 & 0.828 & 2.279 & 2.779 & 0.513 & 2.328 & 2.693 & 0.568 & 2.713 \\
\hline $\bar{\pi}$ & gamma & 0.625 & 0.100 & 0.638 & 0.068 & 0.632 & 0.648 & 0.071 & 0.571 & 0.727 & 0.085 & 0.678 & 0.752 & 0.094 & 0.710 \\
\hline$\overline{\text { spread }}$ & normal & 0.500 & 0.100 & 0.475 & 0.073 & 0.543 & 0.468 & 0.072 & 0.500 & 0.330 & 0.059 & 0.338 & 0.341 & 0.062 & 0.372 \\
\hline$\zeta_{s p b}$ & beta & 0.050 & 0.005 & 0.050 & 0.004 & 0.052 & 0.049 & 0.004 & 0.047 & 0.046 & 0.004 & 0.047 & 0.046 & 0.004 & 0.046 \\
\hline$\lambda$ & beta & 0.300 & 0.100 & & & & 0.236 & 0.067 & 0.307 & & & & 0.205 & 0.065 & 0.195 \\
\hline MDD & & & & & & & & & & & $03 /-4$ & 0.407 & -398 & $74 /-4$ & .559 \\
\hline
\end{tabular}

Table A.8: Comparison of estimation results across models for the pre-crisis sample from 1983-2008. Models with financial shock instead of MEI shock (FRANK-R and FTANK-R) and estimations including the GZ spread (FRANK-S and FTANK-S). 


\begin{tabular}{|c|c|c|c|c|c|c|c|c|c|c|c|c|c|c|c|}
\hline & \multirow{2}{*}{\multicolumn{4}{|c|}{ Prior }} & \multicolumn{11}{|c|}{ Posterior } \\
\hline & & & & & \multicolumn{3}{|c|}{ RANK } & \multicolumn{3}{|l|}{ TANK } & \multicolumn{3}{|c|}{ FRANK } & \multicolumn{2}{|c|}{ FTANK } \\
\hline & dist. & mean & $\mathrm{sd} / \mathrm{df}$ & mean & sd & mode & mean & $\mathrm{sd}$ & mode & mean & $\mathrm{sd}$ & mode & mean & $\mathrm{sd}$ & mode \\
\hline$\sigma_{c}$ & normal & 1.500 & 0.375 & 1.339 & 0.138 & 1.328 & 1.237 & 0.128 & 1.244 & 1.116 & 0.128 & 0.995 & 0.983 & 0.095 & 0.951 \\
\hline$\sigma_{l}$ & normal & 2.000 & 0.750 & 2.999 & 0.462 & 3.201 & 2.873 & 0.478 & 2.924 & 2.803 & 0.469 & 2.356 & 2.601 & 0.470 & 2.701 \\
\hline$\beta_{t p r}$ & gamma & 0.250 & 0.100 & 0.145 & 0.049 & 0.123 & 0.144 & 0.049 & 0.152 & 0.156 & 0.049 & 0.174 & 0.178 & 0.056 & 0.161 \\
\hline$h$ & beta & 0.700 & 0.100 & 0.676 & 0.052 & 0.665 & 0.692 & 0.047 & 0.673 & 0.713 & 0.045 & 0.717 & 0.733 & 0.045 & 0.646 \\
\hline$S^{\prime \prime}$ & normal & 4.000 & 1.500 & 5.047 & 0.960 & 4.965 & 5.181 & 1.014 & 4.503 & 5.923 & 0.962 & 5.644 & 6.104 & 1.089 & 5.145 \\
\hline$\iota_{p}$ & beta & 0.500 & 0.150 & 0.230 & 0.079 & 0.246 & 0.235 & 0.080 & 0.144 & 0.221 & 0.071 & 0.168 & 0.237 & 0.078 & 0.257 \\
\hline$\iota_{w}$ & beta & 0.500 & 0.150 & 0.380 & 0.110 & 0.377 & 0.391 & 0.116 & 0.497 & 0.357 & 0.117 & 0.288 & 0.369 & 0.121 & 0.267 \\
\hline$\alpha$ & normal & 0.300 & 0.050 & 0.185 & 0.010 & 0.179 & 0.186 & 0.009 & 0.188 & 0.202 & 0.010 & 0.194 & 0.202 & 0.009 & 0.209 \\
\hline$\zeta_{p}$ & beta & 0.500 & 0.100 & 0.914 & 0.015 & 0.922 & 0.915 & 0.013 & 0.925 & 0.917 & 0.015 & 0.906 & 0.918 & 0.015 & 0.922 \\
\hline$\zeta_{w}$ & beta & 0.500 & 0.100 & 0.827 & 0.030 & 0.839 & 0.827 & 0.031 & 0.838 & 0.873 & 0.030 & 0.900 & 0.877 & 0.028 & 0.889 \\
\hline$\Phi_{p}$ & normal & 1.250 & 0.125 & 1.335 & 0.057 & 1.358 & 1.349 & 0.059 & 1.300 & 1.308 & 0.058 & 1.305 & 1.328 & 0.056 & 1.357 \\
\hline$\psi$ & beta & 0.500 & 0.150 & 0.739 & 0.073 & 0.734 & 0.746 & 0.075 & 0.756 & 0.623 & 0.064 & 0.642 & 0.638 & 0.061 & 0.641 \\
\hline$\phi_{\pi}$ & normal & 1.500 & 0.250 & 0.911 & 0.189 & 0.850 & 0.946 & 0.157 & 0.849 & 1.114 & 0.187 & 1.080 & 1.095 & 0.165 & 0.997 \\
\hline$\phi_{y}$ & normal & 0.125 & 0.050 & 0.287 & 0.027 & 0.279 & 0.286 & 0.027 & 0.293 & 0.245 & 0.030 & 0.250 & 0.239 & 0.029 & 0.247 \\
\hline$\phi_{d y}$ & normal & 0.125 & 0.050 & 0.191 & 0.040 & 0.243 & 0.190 & 0.039 & 0.172 & 0.201 & 0.042 & 0.207 & 0.179 & 0.042 & 0.188 \\
\hline$\rho$ & beta & 0.750 & 0.100 & 0.654 & 0.050 & 0.652 & 0.661 & 0.041 & 0.641 & 0.727 & 0.035 & 0.726 & 0.718 & 0.037 & 0.685 \\
\hline$\rho_{r}$ & beta & 0.500 & 0.200 & 0.882 & 0.053 & 0.899 & 0.882 & 0.031 & 0.896 & 0.662 & 0.072 & 0.658 & 0.676 & 0.063 & 0.644 \\
\hline$\rho_{g}$ & beta & 0.500 & 0.200 & 0.985 & 0.029 & 0.987 & 0.987 & 0.023 & 0.990 & 0.929 & 0.045 & 0.915 & 0.911 & 0.045 & 0.908 \\
\hline$\rho_{z}$ & beta & 0.500 & 0.200 & 0.984 & 0.008 & 0.984 & 0.983 & 0.008 & 0.984 & 0.988 & 0.011 & 0.994 & 0.985 & 0.016 & 0.995 \\
\hline$\rho_{u}$ & beta & 0.500 & 0.200 & 0.880 & 0.035 & 0.892 & 0.872 & 0.035 & 0.884 & 0.873 & 0.031 & 0.881 & 0.870 & 0.029 & 0.897 \\
\hline$\rho_{p}$ & beta & 0.500 & 0.200 & 0.579 & 0.098 & 0.537 & 0.569 & 0.111 & 0.701 & 0.664 & 0.096 & 0.721 & 0.691 & 0.078 & 0.744 \\
\hline$\rho_{w}$ & beta & 0.500 & 0.200 & 0.718 & 0.096 & 0.680 & 0.725 & 0.084 & 0.671 & 0.640 & 0.092 & 0.433 & 0.596 & 0.090 & 0.572 \\
\hline$\rho_{i}$ & beta & 0.500 & 0.200 & 0.813 & 0.053 & 0.824 & 0.836 & 0.048 & 0.854 & 0.909 & 0.017 & 0.923 & 0.916 & 0.016 & 0.923 \\
\hline$\mu_{p}$ & beta & 0.500 & 0.200 & 0.523 & 0.084 & 0.480 & 0.508 & 0.088 & 0.640 & 0.450 & 0.161 & 0.420 & 0.452 & 0.155 & 0.498 \\
\hline$\mu_{w}$ & beta & 0.500 & 0.200 & 0.501 & 0.133 & 0.436 & 0.505 & 0.120 & 0.437 & 0.414 & 0.113 & 0.204 & 0.357 & 0.108 & 0.334 \\
\hline$\rho_{g z}$ & normal & 0.500 & 0.250 & 0.316 & 0.081 & 0.362 & 0.321 & 0.082 & 0.283 & 0.391 & 0.117 & 0.431 & 0.429 & 0.112 & 0.473 \\
\hline$\sigma_{g}$ & $\mathrm{IG}$ & 0.100 & 2.000 & 0.258 & 0.016 & 0.249 & 0.259 & 0.016 & 0.253 & 0.266 & 0.017 & 0.254 & 0.262 & 0.019 & 0.232 \\
\hline$\sigma_{u}$ & IG & 0.100 & 2.000 & 0.461 & 0.161 & 0.374 & 0.488 & 0.139 & 0.420 & 0.418 & 0.127 & 0.373 & 0.438 & 0.119 & 0.267 \\
\hline$\sigma_{z}$ & IG & 0.100 & 2.000 & 0.333 & 0.028 & 0.356 & 0.329 & 0.028 & 0.346 & 0.324 & 0.027 & 0.319 & 0.325 & 0.030 & 0.298 \\
\hline$\sigma_{r}$ & IG & 0.100 & 2.000 & 0.104 & 0.014 & 0.097 & 0.104 & 0.009 & 0.098 & 0.140 & 0.022 & 0.136 & 0.136 & 0.017 & 0.146 \\
\hline$\sigma_{p}$ & IG & 0.100 & 2.000 & 0.287 & 0.052 & 0.305 & 0.290 & 0.067 & 0.236 & 0.200 & 0.066 & 0.150 & 0.177 & 0.050 & 0.153 \\
\hline$\sigma_{w}$ & IG & 0.100 & 2.000 & 0.564 & 0.099 & 0.595 & 0.553 & 0.085 & 0.637 & 0.653 & 0.110 & 0.991 & 0.698 & 0.119 & 0.707 \\
\hline$\sigma_{i}$ & $\mathrm{IG}$ & 0.100 & 2.000 & 0.566 & 0.076 & 0.539 & 0.536 & 0.067 & 0.550 & 0.612 & 0.062 & 0.609 & 0.611 & 0.071 & 0.638 \\
\hline $\bar{\gamma}$ & normal & 0.440 & 0.050 & 0.417 & 0.037 & 0.441 & 0.424 & 0.031 & 0.431 & 0.337 & 0.041 & 0.296 & 0.329 & 0.034 & 0.301 \\
\hline $\bar{l}$ & normal & 0.000 & 2.000 & 2.433 & 0.532 & 2.308 & 2.509 & 0.580 & 2.327 & 0.656 & 0.805 & 0.321 & 0.295 & 0.837 & 0.677 \\
\hline $\bar{\pi}$ & gamma & 0.625 & 0.100 & 0.703 & 0.057 & 0.693 & 0.704 & 0.057 & 0.684 & 0.582 & 0.050 & 0.566 & 0.580 & 0.049 & 0.581 \\
\hline$\overline{\text { spread }}$ & normal & 0.500 & 0.100 & & & & & & & 0.451 & 0.059 & 0.444 & 0.447 & 0.061 & 0.487 \\
\hline$\zeta_{s p b}$ & beta & 0.050 & 0.005 & & & & & & & 0.051 & 0.004 & 0.051 & 0.050 & 0.004 & 0.046 \\
\hline$\lambda$ & beta & 0.300 & 0.100 & & & & 0.142 & 0.041 & 0.107 & & & & 0.200 & 0.063 & 0.204 \\
\hline MDD & & & & $-0 \angle 9$ & $01-0$ & 650 & -634 & $21,-0$ & .451 & -040 & $017-0$ & .910 & -64 & $7 /-$ & 182 \\
\hline
\end{tabular}

Table A.9: Comparison of estimation results across models for the full sample including the crisis (1983-2019). MDD (marginal data density) given as Modified Harmonic Mean and Laplace Approximations. 


\begin{tabular}{|c|c|c|c|c|c|c|c|c|c|c|c|c|}
\hline & \multicolumn{3}{|c|}{ Prior } & \multicolumn{9}{|c|}{$\begin{array}{c}\text { Posterior } \\
1983-2008\end{array}$} \\
\hline & dist. & mean & $\mathrm{sd} / \mathrm{df}$ & mean & sd & mode & mean & $\mathrm{sd}$ & mode & mean & sd & mode \\
\hline$\sigma_{c}$ & normal & 1.500 & 0.375 & 1.013 & 0.105 & 0.969 & 1.445 & 0.142 & 1.430 & 1.326 & 0.140 & 1.274 \\
\hline$\sigma_{l}$ & normal & 2.000 & 0.750 & 1.718 & 0.412 & 2.119 & 2.243 & 0.545 & 2.369 & 2.923 & 0.442 & 2.639 \\
\hline$\beta_{t p r}$ & gamma & 0.250 & 0.100 & 0.142 & 0.051 & 0.106 & 0.145 & 0.046 & 0.149 & 0.146 & 0.047 & 0.083 \\
\hline$h$ & beta & 0.700 & 0.100 & 0.825 & 0.027 & 0.828 & 0.698 & 0.047 & 0.737 & 0.665 & 0.046 & 0.695 \\
\hline$S^{\prime \prime}$ & normal & 4.000 & 1.500 & 5.716 & 0.915 & 5.428 & 5.528 & 1.022 & 5.768 & 4.937 & 0.931 & 5.617 \\
\hline$\iota_{p}$ & beta & 0.500 & 0.150 & 0.195 & 0.069 & 0.173 & 0.295 & 0.097 & 0.221 & 0.230 & 0.079 & 0.221 \\
\hline$\iota_{w}$ & beta & 0.500 & 0.150 & 0.386 & 0.118 & 0.388 & 0.413 & 0.121 & 0.422 & 0.387 & 0.122 & 0.334 \\
\hline$\alpha$ & normal & 0.300 & 0.050 & 0.175 & 0.011 & 0.157 & 0.214 & 0.010 & 0.212 & 0.186 & 0.009 & 0.176 \\
\hline$\zeta_{p}$ & beta & 0.500 & 0.100 & 0.822 & 0.038 & 0.878 & 0.842 & 0.034 & 0.835 & 0.916 & 0.012 & 0.916 \\
\hline$\zeta_{w}$ & beta & 0.500 & 0.100 & 0.692 & 0.042 & 0.752 & 0.783 & 0.052 & 0.769 & 0.828 & 0.034 & 0.785 \\
\hline$\Phi_{p}$ & normal & 1.250 & 0.125 & 1.321 & 0.092 & 1.203 & 1.539 & 0.066 & 1.611 & 1.337 & 0.057 & 1.334 \\
\hline$\psi$ & beta & 0.500 & 0.150 & 0.775 & 0.078 & 0.754 & 0.620 & 0.087 & 0.578 & 0.742 & 0.072 & 0.725 \\
\hline$\phi_{\pi}$ & normal & 1.500 & 0.250 & 1.400 & 0.185 & 1.223 & 1.317 & 0.245 & 1.533 & 0.880 & 0.127 & 0.867 \\
\hline$\phi_{y}$ & normal & 0.125 & 0.050 & 0.216 & 0.029 & 0.206 & 0.216 & 0.044 & 0.190 & 0.288 & 0.026 & 0.266 \\
\hline$\phi_{d y}$ & normal & 0.125 & 0.050 & 0.172 & 0.041 & 0.184 & 0.206 & 0.039 & 0.234 & 0.191 & 0.037 & 0.149 \\
\hline$\rho$ & beta & 0.750 & 0.100 & 0.819 & 0.035 & 0.808 & 0.711 & 0.044 & 0.743 & 0.644 & 0.038 & 0.643 \\
\hline$\rho_{r}$ & beta & 0.500 & 0.200 & 0.750 & 0.080 & 0.760 & 0.814 & 0.061 & 0.789 & 0.894 & 0.022 & 0.884 \\
\hline$\rho_{g}$ & beta & 0.500 & 0.200 & 0.904 & 0.029 & 0.934 & 0.971 & 0.015 & 0.975 & 0.990 & 0.005 & 0.992 \\
\hline$\rho_{z}$ & beta & 0.500 & 0.200 & 0.989 & 0.011 & 0.983 & 0.952 & 0.017 & 0.950 & 0.984 & 0.007 & 0.982 \\
\hline$\rho_{u}$ & beta & 0.500 & 0.200 & 0.844 & 0.030 & 0.871 & 0.715 & 0.090 & 0.684 & 0.887 & 0.023 & 0.859 \\
\hline$\rho_{p}$ & beta & 0.500 & 0.200 & 0.536 & 0.130 & 0.587 & 0.766 & 0.077 & 0.794 & 0.576 & 0.094 & 0.642 \\
\hline$\rho_{w}$ & beta & 0.500 & 0.200 & 0.457 & 0.088 & 0.310 & 0.691 & 0.098 & 0.709 & 0.718 & 0.095 & 0.822 \\
\hline$\rho_{i}$ & beta & 0.500 & 0.200 & 0.757 & 0.101 & 0.680 & 0.779 & 0.058 & 0.744 & 0.825 & 0.047 & 0.819 \\
\hline$\mu_{p}$ & beta & 0.500 & 0.200 & 0.507 & 0.117 & 0.548 & 0.580 & 0.140 & 0.504 & 0.521 & 0.083 & 0.575 \\
\hline$\mu_{w}$ & beta & 0.500 & 0.200 & 0.258 & 0.078 & 0.155 & 0.405 & 0.135 & 0.408 & 0.499 & 0.132 & 0.650 \\
\hline$\rho_{g z}$ & normal & 0.500 & 0.250 & 0.627 & 0.096 & 0.565 & 0.354 & 0.081 & 0.299 & 0.322 & 0.072 & 0.304 \\
\hline$\sigma_{g}$ & $\mathrm{IG}$ & 0.100 & 2.000 & 0.220 & 0.027 & 0.197 & 0.238 & 0.017 & 0.242 & 0.257 & 0.015 & 0.253 \\
\hline$\sigma_{u}$ & IG & 0.100 & 2.000 & 0.775 & 0.182 & 0.632 & 1.060 & 0.419 & 1.293 & 0.423 & 0.078 & 0.495 \\
\hline$\sigma_{z}$ & IG & 0.100 & 2.000 & 0.398 & 0.043 & 0.393 & 0.307 & 0.028 & 0.283 & 0.329 & 0.027 & 0.346 \\
\hline$\sigma_{r}$ & $\mathrm{IG}$ & 0.100 & 2.000 & 0.108 & 0.015 & 0.101 & 0.130 & 0.013 & 0.133 & 0.102 & 0.009 & 0.102 \\
\hline$\sigma_{p}$ & IG & 0.100 & 2.000 & 0.316 & 0.086 & 0.284 & 0.132 & 0.046 & 0.095 & 0.288 & 0.051 & 0.258 \\
\hline$\sigma_{w}$ & $\mathrm{IG}$ & 0.100 & 2.000 & 1.279 & 0.267 & 1.869 & 0.438 & 0.075 & 0.420 & 0.560 & 0.094 & 0.478 \\
\hline$\sigma_{i}$ & $\mathrm{IG}$ & 0.100 & 2.000 & 0.562 & 0.153 & 0.713 & 0.634 & 0.107 & 0.647 & 0.552 & 0.067 & 0.520 \\
\hline $\bar{\gamma}$ & normal & 0.440 & 0.050 & 0.341 & 0.055 & 0.418 & 0.465 & 0.024 & 0.481 & 0.427 & 0.025 & 0.431 \\
\hline $\bar{l}$ & normal & 0.000 & 2.000 & 1.605 & 0.774 & 1.213 & 2.293 & 0.640 & 2.714 & 2.401 & 0.569 & 3.011 \\
\hline $\bar{\pi}$ & gamma & 0.625 & 0.100 & 0.629 & 0.058 & 0.678 & 0.701 & 0.066 & 0.714 & 0.701 & 0.053 & 0.721 \\
\hline$\lambda$ & uniform & 0.000 & 0.700 & 0.081 & 0.062 & 0.010 & 0.090 & 0.066 & 0.103 & 0.046 & 0.036 & 0.037 \\
\hline
\end{tabular}

Table A.10: Comparison of estimation results for TANK models with a flat prior on the share $\lambda$ of H2M agents for the different data samples. 


\section{Appendix B Data}

Our measurement equations contain eight variables:

- GDP: $\ln ($ GDP/GDPDEF/CNP16OV_ma $) * 100$

- CONS: $\ln (($ PCEC-PCEDG)/GDPDEF/CNP16OV_ma)*100

- INV: $\ln (($ GPDI+PCEDG)/GDPDEF/CNP16OV_ma $) * 100$

- LAB: demeaned(ln((13*AWHNONAG*CE16OV)/CNP16OV_ma)*100)

- INFL: $\ln ($ GDPDEF $)$

- WAGE: $\ln (\mathrm{COMPNFB} / \mathrm{GDPDEF}) * 100$

- FFR: FEDFUNDS/4

- GZ: (GZspread)/4

For GDP, CONS, INV, INFL and WAGE we use the log changes in our measurement equations.

Data sources:

- GDP: GDP - Gross Domestic Product, Billions of Dollars, Quarterly, Seasonally Adjusted Annual Rate, FRED

- GDPDEF: Gross Domestic Product: Implicit Price Deflator, Index 2012=100, Quarterly, Seasonally Adjusted, FRED

- PCEC: Personal Consumption Expenditures, Billions of Dollars, Quarterly, Seasonally Adjusted Annual Rate, FRED

- PCEC: Personal Consumption Expenditures: Durable Goods, Billions of Dollars, Quarterly, Seasonally Adjusted Annual Rate, FRED

- GPDI: Gross Private Domestic Investment, Billions of Dollars, Quarterly, Seasonally Adjusted Annual Rate, FRED

- AWHNONAG: Average Weekly Hours of Production and Nonsupervisory Employees: Total private, Hours, Weekly, Seasonally Adjusted, FRED

- CE16OV: Civilian Employment Level, Thousands of Persons, Seasonally Adjusted, FRED

- CNP16OV_ma ${ }^{43}$ : trailing MA(5) of the Civilian Noninstitutional Population, Thousands of Persons, Quarterly, Not Seasonally Adjusted, FRED

- COMPNFB, Nonfarm Business Sector: Compensation Per Hour, Index 2012=100, Quarterly, Seasonally Adjusted, FRED

\footnotetext{
${ }^{43}$ As in Boehl et al. (2020), we use a trailing MA(5) of the civilian non-institutional population index to normalize GDP, its components and labor hours, instead of the index itself at it is often done. This helps us to purge our observables of jumps in the index itself that reflect artifacts in its construction.
} 
- FEDFUNDS: Effective Federal Funds Rate, Percent, FRED

- GZspread: Credit spread constructed by Gilchrist and Zakrajšek (2012), Percent, Board of Governors of the Federal Reserve System

\section{Appendix C Model Descriptions}

We build on the canonical framework developed by and, and allow for two independent extensions: hand-to-mouth consumers, that are unable to save and only consume their current-period wage income, and financial frictions in the vein of. We dub the model with only a representative agent the RANK model to distinguish it from our two-agent new Keynesian (TANK) model. The TANK model therefore features Ricardian and handto-mouth households. The model vintages including financial frictions will be referred to as financial representative agent NK model - FRANK - and FTANK respectively for the two-agent version of FRANK.

In all models, labor is differentiated by unions with monopoly power that face nominal rigidities for their wage setting process. Intermediate good producers employ labor and capital services and sell their goods to final goods firms. Final good firms are monopolistically competitive and face nominal rigidities as in . The model further allows for exogenous government spending and features a monetary authority that sets the short-term nominal interest rate according to a monetary policy rule. In TANK and FTANK, economy-wide labor supply and consumption are aggregates of the respective contributions by Ricardian and hand-to-mouth households. In FRANK and FTANK, we assume that frictionless financial intermediates collect funds from households. These funds are lent with a spread, which reflects default risk, to entrepreneurs, who use it together with their own equity to purchase physical capital. Physical capital in turn is rented out to intermediate good producers.

\section{Appendix C.1 The linearized RANK model}

This subsection briefly presents the linearized equilibrium conditions. A detailed derivation of the linearized equations is discussed e.g. in the appendix to Smets and Wouters (2007). All variables in this section are expressed as a log-deviation from their respective steady state values. The consumption Euler equation of Ricardian households is given by

$$
\begin{aligned}
c_{t}^{R}=\frac{h / \gamma}{(1+h / \gamma)} c_{t-1}^{R}+\frac{1}{1+h / \gamma} E_{t}\left[c_{t+1}^{R}\right]+ & \frac{\left(\sigma_{c}-1\right)\left(W^{h} L / C\right)}{\sigma_{c}(1+h / \gamma)}\left(l_{t}^{R}-E_{t}\left[l_{t+1}^{R}\right]\right) \\
& -\frac{(1-h / \gamma)}{(1+h / \gamma) \sigma_{c}}\left(r_{t}-E_{t}\left[\pi_{t+1}\right]+u_{t}\right),
\end{aligned}
$$

where $c_{t}^{R}$ is consumption by Ricardian agents, and $l_{t}^{R}$ is their supply of labor. Parameters $h, \sigma_{c}$ and $\sigma_{l}$ are, respectively, the degree of external habit formation in consumption, the coefficient of relative risk aversion, and the inverse of the Frisch elasticity. $\gamma$ denotes the steady-state growth rate of the economy. $r_{t}$ is the nominal interest rate, $\pi_{t}$ is the inflation rate, and $u_{t}$ is an exogenous risk premium shock, which drives a wedge between the lending/savings rate and the riskless real rate.

Equation (C.2) is the linearized relationship between investment and the relative price of capital,

$$
i_{t}=\frac{1}{1+\bar{\beta}}\left[i_{t-1}\right]+\frac{\bar{\beta}}{1+\bar{\beta}} E_{t}\left[i_{t+1}\right]+\frac{1}{(1+\bar{\beta}) \gamma^{2} S^{\prime \prime}} q_{t}+v_{i, t} .
$$


Here, $i_{t}$ denotes investment in physical capital and $q_{t}$ is the price of capital. It holds that $\bar{\beta}=\beta \gamma^{\left(1-\sigma_{c}\right)}$ where $\beta$ is the households' discount factor. Investment is subject to adjustment costs, which are governed by $S^{\prime \prime}$, the steady-state value of the second derivative of the investment adjustment cost function, and an exogenous process, $v_{i, t}$. While Smets and Wouters (2007) interpret $e_{i, t}$ as an investment specific technology disturbance, Justiniano et al. (2011) stress that this shock can as well be viewed as a reduced-form way of capturing financial frictions, as it drives a wedge between aggregate savings and aggregate investment. We henceforth refer to this disturbance as a shock on the marginal efficiency of investment (MEI).

The accumulation equation of physical capital is given by

$$
\bar{k}_{t}=(1-\delta) / \gamma \bar{k}_{t-1}+(1-(1-\delta) / \gamma) i_{t}+(1-(1-\delta) / \gamma)(1+\bar{\beta}) \gamma^{2} S^{\prime \prime} v_{i, t},
$$

where $\bar{k}$ denotes physical capital, and parameter $\delta$ is the depreciation rate. The following Equation (C.4) is the no-arbitrage condition between the rental rate of capital, $r_{t}^{k}$, and the riskless real rate:

$$
r_{t}-E_{t}\left[\pi_{t+1}\right]+u_{t}=\frac{r^{k}}{r^{k}+(1-\delta)} E_{t}\left[r_{t+1}^{k}\right]+\frac{(1-\delta)}{r^{k}+(1-\delta)} E_{t}\left[q_{t+1}\right]-q_{t} .
$$

As the use of physical capital in production is subject to utilization costs, which in turn can be expressed as a function of the rental rate on capital, the relation between the effectively used amount of capital $k_{t}$ and the physical capital stock is

$$
k_{t}=\frac{1-\psi}{\psi} r_{t}^{k}+\bar{k}_{t-1},
$$

where $\psi \in(0,1)$ is the parameter governing the costs of capital utilization. Equation (C.6) is the aggregate production function

$$
y_{t}=\Phi\left(\alpha k_{t}+(1-\alpha) l_{t}+z_{t}\right) .
$$

Intermediate good firms employ labor and capital services. Let $z_{t}$ be the exogenous process of total factor productivity. Parameter $\alpha$ is the elasticity of output with respect to capital and $\Phi$ enters the production function due to the assumption of a fixed cost in production. Real marginal costs for producing firms, $m c_{t}$, can be written as

$$
m c_{t}=w_{t}-z_{t}+\alpha\left(l_{t}-k_{t}\right) .
$$

$w_{t}$ denotes the real wage, which are set by labor unions. Furthermore, cost minimization for intermediate good producers results in condition (C.8):

$$
k_{t}=w_{t}-r_{t}^{k}+l_{t} .
$$

The aggregate resource constraint (C.9) contains an exogenous demand shifter, $g_{t}$, which comprises exogenous variations in government spending and net exports, as well as the resource costs of capital utilization:

$$
y_{t}=\frac{G}{Y} g_{t}+\frac{C}{Y} c_{t}+\frac{I}{Y} i_{t}+\frac{R^{k} K}{Y} \frac{1-\psi}{\psi} r_{t}^{k} .
$$


Final good producers are assumed to have monopoly power and face nominal rigidities as in Calvo (1983) when setting their prices. This gives rise to a New Keynesian Phillips Curve (NKPC) of the form

$$
\pi_{t}=\frac{\bar{\beta}}{1+1_{p} \bar{\beta}} E_{t} \pi_{t+1}+\frac{1_{p}}{1+1_{p} \bar{\beta}} \pi_{t-1}+\frac{\left(1-\zeta_{p} \bar{\beta}\right)\left(1-\zeta_{p}\right)}{\left(1+\bar{\beta} 1_{p}\right) \zeta_{p}\left((\Phi-1) \epsilon_{p}+1\right)} m c_{t}+v_{p, t} .
$$

Here, $\zeta_{p}$ is the probability that a firm cannot update its price in any given period. In addition to Calvo pricing, we assume partial price indexation, governed by the parameter $1_{p}$. The Phillips Curve is hence both, forward and backward looking. $\epsilon_{p}$ denotes the curvature of the Kimball (1995) aggregator for final goods. Due to the Kimball aggregator, the sensitivity of inflation to fluctuations in marginal cost is affected by the market power of firms, represented by the steady state price markup, $\Phi-1 .{ }^{44}$ Furthermore, the curvature of the Kimball aggregator affects the adjustment of prices to marginal cost as the higher $\epsilon_{p}$, the higher is the degree of strategic complementarity in price setting, dampening the price adjustment to shocks. The last term in the NKPC, $v_{p, t}$, represents exogenous fluctuations in the price markup.

While final good producers set prices on the good market, wages are set by labor unions. Unions bundle labor services from households and offer them to firms with a markup over the frictionless wage, $w_{t}^{h}$, which reads

$$
w_{t}^{h}=\frac{1}{(1-h)}\left(c_{t}-h c_{t-1}\right)+\sigma_{l} l_{t}
$$

As with price setting, we assume that the nominal rigidities in the wage setting process are of the Calvo type, and include partial wage indexation. The wage Phillips curve thus is

$$
\begin{array}{r}
w_{t}=\frac{1}{1+\bar{\beta} \gamma}\left(w_{t-1}+1_{w} \pi_{t-1}\right)+\frac{\bar{\beta} \gamma}{1+\bar{\beta} \gamma} E_{t}\left[w_{t+1}+\pi_{t+1}\right]-\frac{1+1_{w} \bar{\beta} \gamma}{1+\bar{\beta} \gamma} \pi_{t} \\
+\frac{\left(1-\zeta_{w} \bar{\beta} \gamma\right)\left(1-\zeta_{w}\right)}{(1+\bar{\beta} \gamma) \zeta_{w}\left(\left(\lambda_{w}-1\right) \epsilon_{w}+1\right)}\left(w_{t}^{h}-w_{t}\right)+v_{w, t}
\end{array}
$$

The term $w_{t}^{h}-w_{t}$ is the inverse of the wage markup. Analogous to equation (C.10), the terms $\lambda_{w}$ and $\epsilon_{w}$ are the steady state wage markup and the curvature of the Kimball aggregator for labor services, respectively. The term $v_{w, t}$ represents exogenous variations in the wage markup.

We take into account the fact that the central bank is constrained in its interest rate policy by a zero lower bound (ZLB) on the nominal interest rate. Therefore, in the linear model, it is that

$$
r_{t}=\max \left\{\bar{r}, r_{t}^{n}\right\},
$$

with $\bar{r}$ being the lower bound value. Whenever the policy rate is away from the constraint, it corresponds to the notational rate, $r_{t}^{n}$, which follows the feedback rule

$$
r_{t}^{n}=\rho r_{t-1}^{n}+(1-\rho)\left(\phi_{\pi} \pi_{t}+\phi_{y} \widetilde{y}_{t}+\phi_{d y} \Delta \widetilde{y}_{t}\right)+v_{r, t} .
$$

\footnotetext{
${ }^{44}$ Note that in equilibrium, the steady state price markup is tied to the fixed cost parameter by a zero profit condition.
} 
Here, $\widetilde{y}_{t}$ is the output gap and $\Delta \widetilde{y}_{t}=\widetilde{y}_{t}-\widetilde{y}_{t-1}$ its growth rate. Parameter $\rho$ expresses an interest rate smoothing motive by the central bank. $\phi_{\pi}, \phi_{y}$ and $\phi_{d y}$ are feedback coefficients. When the economy is away from the ZLB, the stochastic process $v_{r, t}$ represents a regular interest rate shock. When the nominal interest rate is zero, however, $v_{r, t}$ may not directly affect the level of the nominal interest rate. However, through the persistence of the stochastic process that drives $v_{r, t}$, it affects the expected path of the notational rate and can therefore alter the expected duration of the lower bound spell. It can hence be viewed as a forward guidance shock whenever the economy is at the ZLB.

Finally, the stochastic drivers in our model are the following seven processes:

$$
\begin{aligned}
u_{t} & =\rho_{u} u_{t-1}+\epsilon_{t}^{u}, \\
z_{t} & =\rho_{z} z_{t-1}+\epsilon_{t}^{z}, \\
g_{t} & =\rho_{g} g_{t-1}+\epsilon_{t}^{g}+\rho_{g z} \epsilon_{t}^{z}, \\
v_{r, t} & =\rho_{r} v_{r, t-1}+\epsilon_{t}^{r}, \\
v_{i, t} & =\rho_{i} v_{i, t-1}+\epsilon_{t}^{i}, \\
v_{p, t} & =\rho_{p} v_{p, t-1}+\epsilon_{t}^{p}-\mu_{p} \epsilon_{t-1}^{p}, \\
v_{w, t} & =\rho_{w} v_{w, t-1}+\epsilon_{t}^{w}-\mu_{w} \epsilon_{t-1}^{w},
\end{aligned}
$$

where $\epsilon_{t}^{k} \stackrel{i i d}{\sim} N\left(0, \sigma_{k}^{2}\right)$ for all $k=\{r, i, p, w\}$, and likewise for $\left\{u_{t}, z_{t}, g_{t}\right\}$.

\section{Appendix C.2 A TANK extension}

Our first extension is the addition of hand-to-mouth households to the RANK model, which thereby becomes a two-agent New Keynesian (TANK) model. We assume that, for any given reason, a share $\lambda$ of households does not have any savings technology at its disposal and therefore consumes whatever it earns from its labor services provided. ${ }^{45}$ The linearized budget constraint of hand-to-mouth consumers simply reads

$$
c_{t}^{H}=w_{t}+l_{t}^{H},
$$

with $c_{t}^{H}$ and $l_{t}^{H}$ denoting hand-to-mouth agents' consumption and labor supply. While Ricardian and hand-to-mouth consumers differ in their ability to save, we assume that they share the same preferences. Thus, the linearized labor supply equation, that would prevail in frictionless labor markets, has the same structure for hand-to-mouth consumers as it has for optimizing consumers. It is therefore given by

$$
w_{t}^{h}=\frac{1}{(1-h)}\left(c_{t}^{H}-h c_{t-1}^{H}\right)+\sigma_{l} l_{t}^{H} .
$$

We assume that hand-to-mouth agents are represented by the same labor unions as Ricardian agents. As such both types of agents earn the same wage. Aggregate consumption and labor hours can be obtained in the linearized form as

$$
c_{t}=\lambda c_{t}^{H}+(1-\lambda) c_{t}^{R},
$$

\footnotetext{
${ }^{45}$ In contrast to HANK, the TANK model does not capture uncertainty effects or time-variations of the share of constrained agents on consumption.
} 


$$
l_{t}=\lambda l_{t}^{H}+(1-\lambda) l_{t}^{R} .
$$

Note that for $\lambda$ set to zero, the TANK model nests the RANK model without hand-to-mouth consumers as a special case.

\section{Appendix C.3 Financial Frictions}

The second extension that we consider is the inclusion of frictions in financial markets. Here, we adopt the modeling choices by Del Negro et al. (2015b), who build on the work of Bernanke et al. (1999), and Christiano et al. (2014).

In this model, entrepreneurs obtain loans from frictionless financial intermediates, which in turn receive their funds from household at the riskless interest rate. In addition to the loans, entrepreneurs use their own net worth to finance the purchase of physical capital that they rent out to intermediate good producers. Entrepreneurs are subject to idiosyncratic shocks to their success in managing capital. As a consequence, their revenue might fall short of the amount needed to repay the loan, in which case they will default on their loan. In anticipation of the risk of entrepreneurs' default, financial intermediates pool their loans and charge a spread on the riskless rate to cover the expected losses arising from defaulting entrepreneurs. Therefore, in the full model, condition (C.4) in the RANK model is replaced by the two conditions

$$
\begin{aligned}
E_{t}\left[\widetilde{r}_{t+1}^{k}-r_{t}\right] & =u_{t}+\zeta_{s p, b}\left(q_{t}+\bar{k}_{t}-n_{t}\right)+\widetilde{\sigma}_{\omega, t}, \\
\widetilde{r}_{t}^{k}-\pi_{t} & =\frac{r^{k}}{r^{k}+(1-\delta)} r_{t}^{k}+\frac{(1-\delta)}{r^{k}+(1-\delta)} q_{t+1}-q_{t-1} .
\end{aligned}
$$

$\widetilde{r}_{t}^{k}$ is the nominal return on capital for entrepreneurs, $n_{t}$ denotes entrepreneurs' aggregate net worth, and $\widetilde{\sigma}_{\omega, t}$ allows for exogenous variations in the entrepreneurs' riskiness. The first condition defines the spread as a function of the entrepreneurs leverage and their riskiness, which is determined by the dispersion of the idiosyncratic shocks to entrepreneurs. Note that if the elasticity of the loan rate to the entrepreneurs' leverage, $\zeta_{s p, b}$, is set to zero, we are back to the case without financial frictions. Condition (C.27) defines the return on capital for entrepreneurs.

The evolution of aggregate entrepreneurial net worth is described by

$$
n_{t}=\zeta_{n, \widetilde{r}^{k}}\left(\widetilde{r}_{t}^{k}-\pi_{t}\right)-\zeta_{n, r}\left(r_{t-1}-\pi_{t}\right)+\zeta_{n, q k}\left(q_{t-1}+\bar{k}_{t-1}\right)+\zeta_{n, n} n_{t-1}-\frac{\zeta_{n, \sigma_{\omega}}}{\zeta_{s p, \sigma_{\omega}}} \widetilde{\sigma}_{\omega, t-1}
$$

Equation (C.28) links the accumulated stock of entrepreneurial net worth to the real return of renting out capital to firms, the riskless real rate, its capital holdings, its past net worth and variations in riskiness. The coefficients $\zeta_{n, \widetilde{r}^{k}}, \zeta_{n, r}, \zeta_{n, q k}, \zeta_{n, \sigma_{\omega}}$, and $\zeta_{s p, \sigma_{\omega}}$ are derived as in Del Negro et al. (2015b). They depend on the steady state calibration of the default rate of entrepreneurs, the distribution of entrepreneurial risk, and their survival probability.

Lastly, the evolution of exogenous variations in entrepreneurial risk, the risk shock in terms of Christiano et al. (2014), follows the process

$$
\widetilde{\sigma}_{\omega, t}=\rho_{\sigma} \widetilde{\sigma}_{\omega, t-1}+\epsilon_{\sigma, t},
$$

with $\epsilon_{\sigma, t} \stackrel{i i d}{\sim} N\left(0, \sigma_{\sigma}^{2}\right)$. In the estimation of the standard financial friction versions of the model, FRANK and FTANK, we abstain from using the risk shock, and only focus on the 
role of the financial accelerator for the transmission of other shocks. The versions FRANK-R and FTANK-R will allow for the risk shock instead of the MEI shock. In the estimation of the models on eight observables including a credit spread (FRANK-S and FTANK-S) will allow for both, the risk shock and the shock on the marginal effectively of investment.

\section{Appendix D Generalized Forecasting Error Variance Decompositions}

Tables D.11 to D.16 report the generalized forecasting error variance decomposition, constructed as in Lanne and Nyberg (2016) and sampled from the posterior. It is quite clear that risk premium shocks play a dominant role for the most variables over short and long time horizons. In the short run, fluctuations in output are primarily driven by risk premium shocks. To a lesser degree, MEI shocks play a role as well for short run fluctuations in output.

At a time horizon of four quarters, risk premium shocks and MEI shocks are the most important shocks for output. Whereas demand factors dominate the explanation of output in the last decades, supply side factors, such as fluctuations in TFP and price markups gain some importance as well at longer times horizon. Not surprisingly, the generalized forecast error variance decomposition reflects the divide between the driver of consumption and the driver of investment, that is exhibited in the historical shock decomposition. Consumption is predominantly driven by risk premium shocks, which directly hit the Euler equation of households, whereas investment is mainly driven by MEI shocks. Short-run fluctuations in prices and wages are explained by price markup shocks and wage markup shocks, respectively.

Over the medium and long run, these shocks lose in importance. Again at a time horizon of four quarters, risk premium shocks account of most of the movements in inflation, whereas MEI shocks dominate inflation in the long-run through their effect on the slowmoving capital stock. Short-term movements of the nominal interest rate are due mostly to monetary policy shocks, which represent deviations from the policy rule and translate into forward guidance shocks at the ZLB. With the extension of the time horizon it shows that the policy rate mainly reacts to movements in fundamentals, which are triggered by risk premium shocks. Thus overall, risk premium shocks are the dominant shocks for this episode.

RANK: One quarter

\begin{tabular}{rrrrrrrr}
\hline & $y$ & $c$ & $i$ & $\pi$ & $w$ & $r$ & $l$ \\
\hline$\epsilon_{g}$ & 0.117 & 0.006 & 0.000 & 0.000 & 0.000 & 0.001 & 0.138 \\
$\epsilon_{z}$ & 0.225 & 0.041 & 0.006 & 0.018 & 0.005 & 0.016 & 0.137 \\
$\epsilon_{u}$ & 0.410 & 0.775 & 0.290 & 0.044 & 0.035 & 0.137 & 0.448 \\
$\epsilon_{r}$ & 0.111 & 0.171 & 0.103 & 0.033 & 0.013 & 0.645 & 0.122 \\
$\epsilon_{i}$ & 0.130 & 0.002 & 0.598 & 0.001 & 0.001 & 0.002 & 0.152 \\
$\epsilon_{p}$ & 0.002 & 0.004 & 0.002 & 0.877 & 0.039 & 0.191 & 0.002 \\
$\epsilon_{w}$ & 0.005 & 0.001 & 0.000 & 0.027 & 0.906 & 0.009 & 0.000 \\
\hline
\end{tabular}

Table D.11 
RANK: Four quarters

\begin{tabular}{rrrrrrrr}
\hline & $y$ & $c$ & $i$ & $\pi$ & $w$ & $r$ & $l$ \\
\hline$\epsilon_{g}$ & 0.012 & 0.009 & 0.001 & 0.001 & 0.000 & 0.002 & 0.016 \\
$\epsilon_{z}$ & 0.145 & 0.099 & 0.021 & 0.074 & 0.085 & 0.016 & 0.009 \\
$\epsilon_{u}$ & 0.526 & 0.657 & 0.359 & 0.310 & 0.362 & 0.457 & 0.626 \\
$\epsilon_{r}$ & 0.211 & 0.223 & 0.178 & 0.297 & 0.192 & 0.436 & 0.255 \\
$\epsilon_{i}$ & 0.098 & 0.006 & 0.434 & 0.012 & 0.019 & 0.007 & 0.088 \\
$\epsilon_{p}$ & 0.006 & 0.005 & 0.006 & 0.237 & 0.096 & 0.074 & 0.006 \\
$\epsilon_{w}$ & 0.001 & 0.001 & 0.000 & 0.069 & 0.244 & 0.008 & 0.001 \\
\hline
\end{tabular}

Table D.12

RANK: 16 quarters

\begin{tabular}{rrrrrrrr}
\hline & $y$ & $c$ & $i$ & $\pi$ & $w$ & $r$ & $l$ \\
\hline$\epsilon_{g}$ & 0.001 & 0.017 & 0.005 & 0.003 & 0.000 & 0.002 & 0.027 \\
$\epsilon_{z}$ & 0.804 & 0.787 & 0.421 & 0.301 & 0.588 & 0.024 & 0.048 \\
$\epsilon_{u}$ & 0.049 & 0.063 & 0.071 & 0.112 & 0.144 & 0.944 & 0.122 \\
$\epsilon_{r}$ & 0.095 & 0.074 & 0.162 & 0.383 & 0.195 & 0.008 & 0.420 \\
$\epsilon_{i}$ & 0.049 & 0.057 & 0.336 & 0.163 & 0.053 & 0.018 & 0.361 \\
$\epsilon_{p}$ & 0.001 & 0.001 & 0.002 & 0.014 & 0.014 & 0.001 & 0.004 \\
$\epsilon_{w}$ & 0.001 & 0.001 & 0.003 & 0.025 & 0.006 & 0.003 & 0.019 \\
\hline
\end{tabular}

Table D.13

FRANK: One quarter

\begin{tabular}{rrrrrrrr}
\hline & $y$ & $c$ & $i$ & $\pi$ & $w$ & $r$ & $l$ \\
\hline$\epsilon_{g}$ & 0.111 & 0.007 & 0.000 & 0.000 & 0.000 & 0.001 & 0.117 \\
$\epsilon_{z}$ & 0.253 & 0.124 & 0.004 & 0.002 & 0.003 & 0.009 & 0.216 \\
$\epsilon_{u}$ & 0.295 & 0.758 & 0.082 & 0.026 & 0.016 & 0.106 & 0.312 \\
$\epsilon_{r}$ & 0.029 & 0.062 & 0.013 & 0.003 & 0.001 & 0.859 & 0.032 \\
$\epsilon_{i}$ & 0.306 & 0.035 & 0.900 & 0.023 & 0.017 & 0.005 & 0.319 \\
$\epsilon_{p}$ & 0.003 & 0.014 & 0.001 & 0.943 & 0.010 & 0.018 & 0.003 \\
$\epsilon_{w}$ & 0.003 & 0.000 & 0.000 & 0.004 & 0.952 & 0.001 & 0.000 \\
\hline
\end{tabular}

Table D.14 
FRANK: Four quarters

\begin{tabular}{rrrrrrrr}
\hline & $y$ & $c$ & $i$ & $\pi$ & $w$ & $r$ & $l$ \\
\hline$\epsilon_{g}$ & 0.011 & 0.013 & 0.000 & 0.000 & 0.000 & 0.003 & 0.016 \\
$\epsilon_{z}$ & 0.168 & 0.219 & 0.007 & 0.006 & 0.071 & 0.013 & 0.007 \\
$\epsilon_{u}$ & 0.279 & 0.655 & 0.050 & 0.093 & 0.245 & 0.500 & 0.386 \\
$\epsilon_{r}$ & 0.025 & 0.046 & 0.008 & 0.006 & 0.016 & 0.287 & 0.038 \\
$\epsilon_{i}$ & 0.513 & 0.063 & 0.933 & 0.089 & 0.383 & 0.075 & 0.550 \\
$\epsilon_{p}$ & 0.003 & 0.003 & 0.001 & 0.802 & 0.100 & 0.123 & 0.003 \\
$\epsilon_{w}$ & 0.000 & 0.001 & 0.000 & 0.005 & 0.186 & 0.001 & 0.000 \\
\hline
\end{tabular}

Table D.15

FRANK: 16 quarters

\begin{tabular}{lrrrrrrr}
\hline & $y$ & $c$ & $i$ & $\pi$ & $w$ & $r$ & $l$ \\
\hline$\epsilon_{g}$ & 0.002 & 0.011 & 0.000 & 0.003 & 0.000 & 0.002 & 0.041 \\
$\epsilon_{z}$ & 0.374 & 0.331 & 0.065 & 0.163 & 0.193 & 0.013 & 0.024 \\
$\epsilon_{u}$ & 0.031 & 0.080 & 0.017 & 0.506 & 0.122 & 0.798 & 0.212 \\
$\epsilon_{r}$ & 0.000 & 0.000 & 0.000 & 0.003 & 0.001 & 0.000 & 0.004 \\
$\epsilon_{i}$ & 0.592 & 0.578 & 0.916 & 0.295 & 0.671 & 0.185 & 0.716 \\
$\epsilon_{p}$ & 0.000 & 0.000 & 0.000 & 0.028 & 0.007 & 0.002 & 0.001 \\
$\epsilon_{w}$ & 0.000 & 0.000 & 0.001 & 0.002 & 0.005 & 0.000 & 0.001 \\
\hline
\end{tabular}

Table D.16

\section{Appendix E Normalization of historic shock decompositions for models with OBCs}

We are interested in quantifying the contribution of a each type of shock to the time series of the model variables. Such quantification is called the historic shock decomposition (HSD). Once one or several occasionally binding constraints (OBCs) are included in the model, the model is nonlinear and the HSD is generally not unique. To illustrate, imagine a deflationary MEI shock $\varepsilon_{t}^{i}$ and a risk premium shock $u_{t}$, which together cause the ZLB to bind. Assume that each, the MEI shock and the risk premium shock alone are insufficient to force the ZLB to hold. Then, the effect of $u_{t}$ conditional on the realization of $\varepsilon_{t}^{i}$ will have a different dynamic effect than just $u_{t}$ taken alone, and it is unclear which value to assign to $u_{t}$ within a HSD.

More precisely, we are interested in the series of vectors

$$
\left\{\mathbf{h}_{t, z}\right\}_{0}^{T}
$$

where $z \in\{1,2, \cdots, n\}$ is in the set of all $n$ types of shocks. $\varepsilon_{t}=\left(\varepsilon_{t}^{1}, \varepsilon_{t}^{2}, \cdots, \varepsilon_{t}^{n}\right)$ is the vector of all $n$ shocks in the model. Each $\mathbf{h}_{t, z}$ is the cumulative dynamic contribution of shock $z$ to $\mathbf{v}_{t}$. $\mathbf{h}_{t, z}$ is hence recursive. We require for each period $t$ that

$$
\sum_{z=1}^{n} \mathbf{h}_{t, z}=\mathbf{v}_{t},
$$


and at least that

$$
\left\{\mathbf{h}_{t, z}=\mathbf{0} \wedge \mathbf{h}_{t-1, z}=\mathbf{0} \Longleftrightarrow \varepsilon_{t}^{z}=0\right\} \forall z=1,2, \cdots, n
$$

i.e. that any zero shock has a zero net contribution to the HSD.

We propose a normalization method specific to models with OBCs for historic shock decomposition such that the result is independent of any ordering effects. For convenience, let us repeat Equation (7):

$$
\begin{aligned}
L_{s}\left(l, k, \mathbf{w}_{t}\right)= & \mathbf{N}^{\max \{s-l, 0\}}(\mathbf{N}+\mathbf{c b})^{\min \{l, s\}} S\left(l, k, \mathbf{w}_{t}\right) \\
& +(\mathbf{I}-\mathbf{N})^{-1}\left(\mathbf{I}-\mathbf{N}^{\max \{s-l, 0\}}\right) \mathbf{c} \bar{r} .
\end{aligned}
$$

Take as given the time series of smoothed shocks $\left\{\varepsilon_{t}\right\}_{0}^{T}$ that fully reproduces $\left\{\mathbf{v}_{t}\right\}_{0}^{T}$. This implies that we also have obtained the series of $\{l, k\}$. The law-of-motion from period $t$ to $t+1$ is then given by $L_{1}\left(l, k, \mathbf{w}_{t}\right)$. Note that $S\left(l, k, \mathbf{w}_{t}\right)$ can be decomposed in a coefficient term $\bar{S}_{v}(l, k)$, that is to be pre-multiplied to $\mathbf{w}_{t}$, and a constant term $\bar{S}_{c}(k)$ that only depends on $k$ (see Boehl, 2020b for details).

Recalling that $\mathbf{w}_{t}=\mathbf{v}_{t-1}+\boldsymbol{\Xi} \varepsilon_{t}$, we can write

$$
\begin{aligned}
\left(\mathbf{x}_{t+1}, \mathbf{v}_{t}\right)^{\boldsymbol{\top}} & = \\
L_{1}\left(l, k, \mathbf{v}_{t-1}, \varepsilon_{t}\right) & =\mathbf{N}^{\max \{1-l, 0\}}(\mathbf{N}+\mathbf{c b})^{\min \{l, 1\}} \bar{S}_{v}(l, k) \mathbf{v}_{t-1} \\
& +\mathbf{N}^{\max \{1-l, 0\}}(\mathbf{N}+\mathbf{c b})^{\min \{l, 1\}} \bar{S}_{v}(l, k) \boldsymbol{\Xi} \boldsymbol{\varepsilon}_{t} \\
& +\mathbf{N}^{\max \{1-l, 0\}}(\mathbf{N}+\mathbf{c b})^{\min \{l, 1\}} \bar{S}_{c}(k) \\
& +(\mathbf{I}-\mathbf{N})^{-1}\left(\mathbf{I}-\mathbf{N}^{\max \{1-l, 0\}}\right) \mathbf{c} \bar{r}
\end{aligned}
$$

where we are more explicit about the shocks. The first term is linear in $\mathbf{v}_{t-1}$, the second term is linear in $\varepsilon_{t}$, whereas the third and forth term are, taking as given $\{l, k\}$, vectors of constants.

Denote by $\boldsymbol{\Xi}_{z}$ the $z$-th column of $\boldsymbol{\Xi}$, which corresponds to the shock $\varepsilon_{t}^{z}$. For each $z$ we define $\mathbf{h}_{t, z}$ by the recursion

$$
\begin{aligned}
\left(\mathfrak{x}_{t+1, z}, \mathbf{h}_{t, z}\right)^{\top} & = \\
L_{1}\left(l, k, \mathbf{h}_{t-1, z}, \varepsilon_{t}^{z}\right) & =\mathbf{N}^{\max \{1-l, 0\}}(\mathbf{N}+\mathbf{c b})^{\min \{l, 1\}} \bar{S}_{v}(l, k) \mathbf{h}_{t-1, z} \\
& +\mathbf{N}^{\max \{1-l, 0\}}(\mathbf{N}+\mathbf{c b})^{\min \{l, 1\}} \bar{S}_{v}(l, k) \boldsymbol{\Xi}_{z} \varepsilon_{t}^{z} \\
& +\omega_{t, z} \mathbf{N}^{\max \{1-l, 0\}}(\mathbf{N}+\mathbf{c b})^{\min \{l, 1\}} \bar{S}_{c}(k) \\
& +\omega_{t, z}(\mathbf{I}-\mathbf{N})^{-1}\left(\mathbf{I}-\mathbf{N}^{\max \{1-l, 0\}}\right) \mathbf{c} \bar{r}
\end{aligned}
$$

where it is easy to show that Condition (E.2) is satisfied as long as $\sum_{z}^{n} \omega_{t, z}=1 \forall t{ }^{46}$

The first two terms on the RHS of (E.7) are already the recursion of $\mathbf{h}_{t, z}$ and the decomposition respectively. The two other terms are left to be split up and attributed to each shock, which - in terms of (E.7) - implies assigning the weights $\omega_{t, e}$ such that Condition (E.3) is satisfied.

\footnotetext{
${ }^{46} \mathfrak{x}_{t+1, z}$ is a by-product that we do not care about. We want $\mathbf{h}_{t, z}$.
} 
Define

$$
\omega_{t, z}=\frac{\mathbf{b N}^{\max \{1-l, 0\}}(\mathbf{N}+\mathbf{c b})^{\min \{l, 1\}} \bar{S}_{v}(l, k)\left(\mathbf{h}_{t-1, z}+\boldsymbol{\Xi}_{z} \varepsilon_{t}^{z}\right)}{\mathbf{b} \mathbf{N}^{\max \{1-l, 0\}}(\mathbf{N}+\mathbf{c b})^{\min \{l, 1\}} \bar{S}_{v}(l, k) \mathbf{w}_{t}}
$$

i.e. $\omega_{t, z}$ is proportional to the relative contribution of $\varepsilon_{t}^{z}$ to the constraint value $r_{t}$.

Intuitively, this acknowledges that the values of $\{l, k\}$ depend on the relation of the scalar $r_{t}$ relative to $\bar{r}$. The further below $r_{t}$ is of $\bar{r}$, the longer the constraint will bind, and the higher is $k$ (note that the constant term will be zero for any $l>0$ ). If the contribution of $\varepsilon_{t}^{z}$ to a negative $r_{t}$ is large, then the respective weight $\omega_{t, z}$ of the constant terms in (E.7) attributed to $\varepsilon_{t}^{z}$ will be high, and vice versa. If however $\mathbf{h}_{t-1, z}$ and $\varepsilon_{t}^{z}$ both are zero, Condition (E.3) is satisfied.

For our application with the ZLB this means that the weight of constant terms for each shock is proportional to the shock's contribution to the total level of the shadow rate. Further note that

$$
\begin{gathered}
\sum_{e} \mathbf{b} \mathbf{N}^{\max \{1-l, 0\}}(\mathbf{N}+\mathbf{c b})^{\min \{l, 1\}} \bar{S}_{v}(l, k)\left(\left[\mathbf{h}_{t-1, e} \mid \varepsilon_{t}=0\right]+\varepsilon_{e, t}\right)= \\
\mathbf{b N}^{\max \{1-l, 0\}}(\mathbf{N}+\mathbf{c b})^{\min \{l, 1\}} \bar{z}_{v}(l, k)\left(\left[\mathbf{v}_{t-1} \mid \varepsilon_{t}=0\right]+\varepsilon_{t}\right),
\end{gathered}
$$

and hence $\sum_{e} \omega_{t, e}=1$, i.e. the weights sum up to unity. 


\section{Appendix F Economic costs of the binding ZLB}
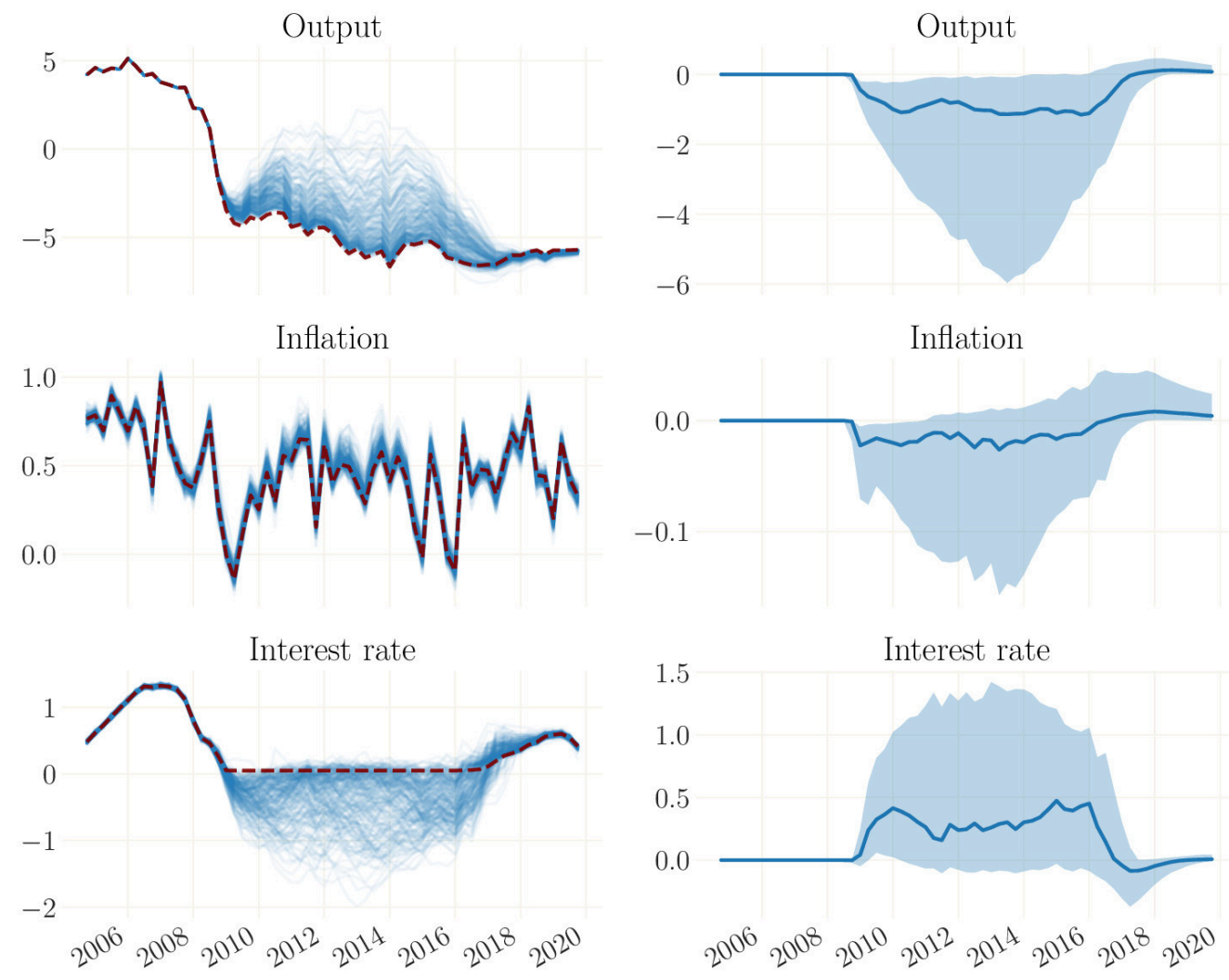

Figure F.14: RANK model estimated to 1998-2019. On the left: Counterfactual dynamics if the ZLB would not have posed a constraint to the nominal rate. On the right: Net effect of the binding ZLB.

Note: Means over 250 simulations drawn from the posterior.

As we have seen, a negative nominal interest would have been warranted by economic conditions over long parts of the sample. The binding ZLB therefore is a constraint that is economically costly. Figure F.14 illustrates these costs for the RANK model estimated on the crisis sample. The bottom panels show that without the ZLB, interest rates would have been far in negative territory, with the credible set roughly centered at around $-0.4 \%$ (1.6\% in annual terms) for most of the duration of the ZLB spell. We report that this counterfactual stimulus would have hardly increased inflation. However, there would have been economically meaningful gains in output, which would have been up to $1 \%$ higher if the ZLB would not have been binding. While our results are closely aligned to those reported by Kulish et al. (2017), they stand in contrast to findings by Gust et al. (2017), who, in particular for the Great Recession, report a deeper fall of the notational rate into negative territory. While they report output costs that are roughly similar to ours, the effects of the binding ZLB on price dynamics are far more pronounced in their framework due to their estimate of a steeper Phillips Curve (0.07 vs. 0.007 in our estimate of the RANK model). 


\section{Appendix G Challenges for the identification of forward guidance shocks}

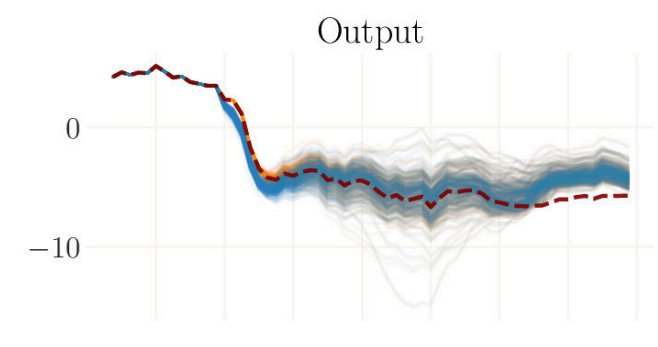

Inflation

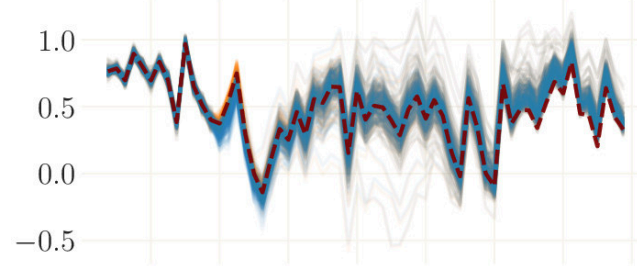

Interest rate

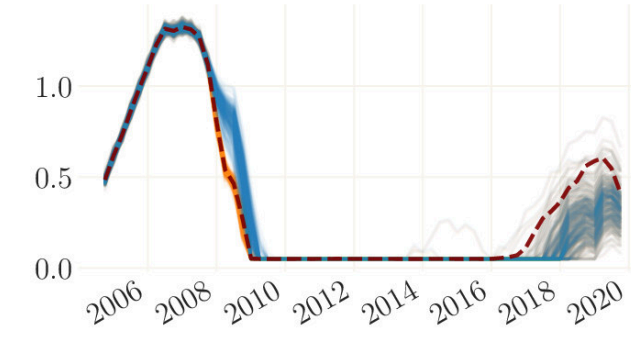

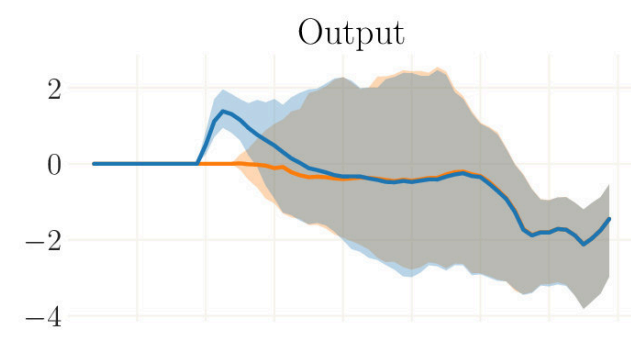

Inflation

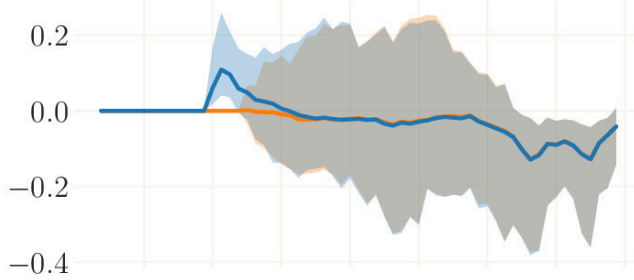

Interest rate

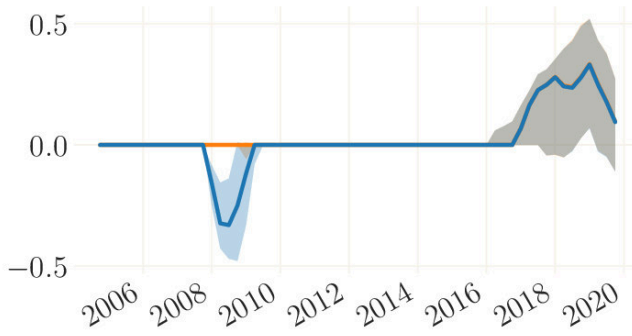

Figure G.15: RANK model estimated to 1998-2019. The net effect of monetary policy shocks. Red: mean over smoothed states. Blue: no shocks after 2007. Orange: no shocks after 2008..

Note: Means over 250 simulations drawn from the posterior.

There exist an active literature on the effects of forward guidance (Eggertsson and Woodford, 2003; Del Negro et al., 2015a; McKay and Reis, 2016).In Section 2 we report that the monetary policy shocks $\epsilon_{r}$ can be interpreted as forward guidance shocks when the economy is at the ZLB: although the actual policy rate is unaffected, the persistence of both the exogenous process and the shadow rate will prolong the expected duration of the ZLB spell, and promises lower rates even after the exit. Naturally, the nonlinear filtering procedure will also provide a series of filtered/smoothed shocks for $\epsilon_{r}$. Interpreting these shocks as forward guidance shocks, they can be used to simulate counterfactuals, and to quantify the effect of such policy.

Figure G.16 provides counterfactual simulations assuming that forward guidance shocks are absent after 2007 and 2008, respectively. The dashed red line corresponds to the mean over the actual smoothed states, i.e. including forward guidance shocks. For the blue lines, forward guidance shocks are ignored after 2007. The right hand side of the figure illustrates the net contribution of these shocks. Overall, our filtering procedure does not find any sensible forward guidance shocks during the ZLB episode. The peak in the net effect of 


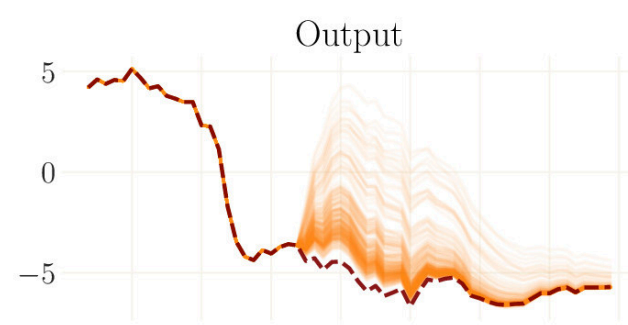

Inflation

0

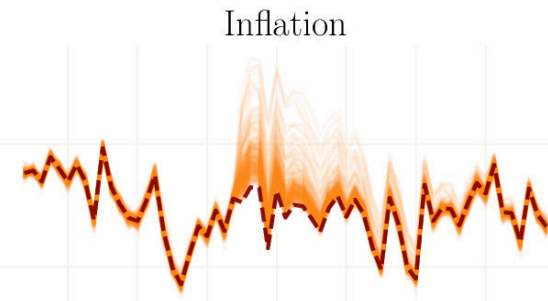

Interest rate

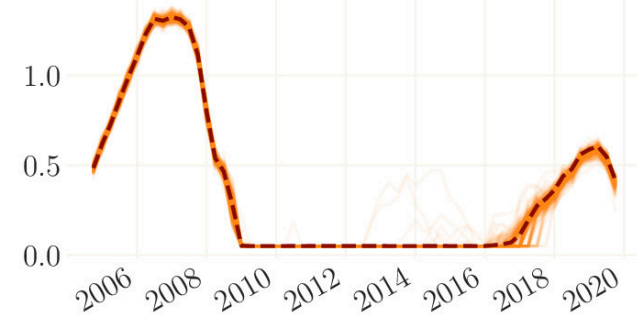

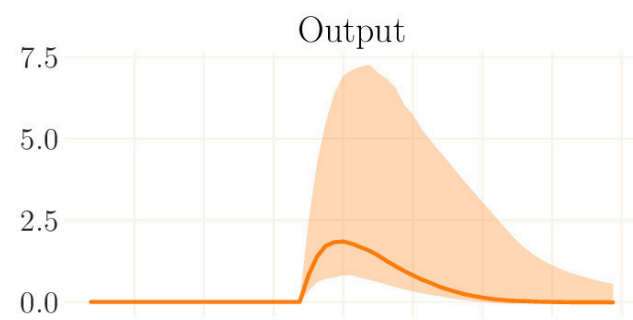

Inflation

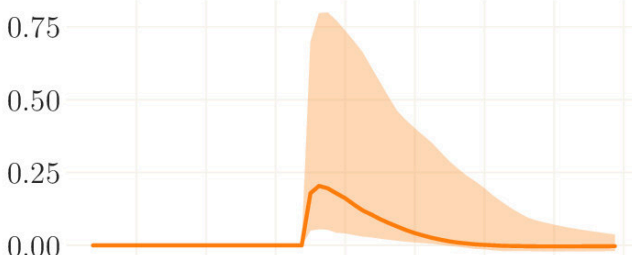

Interest rate

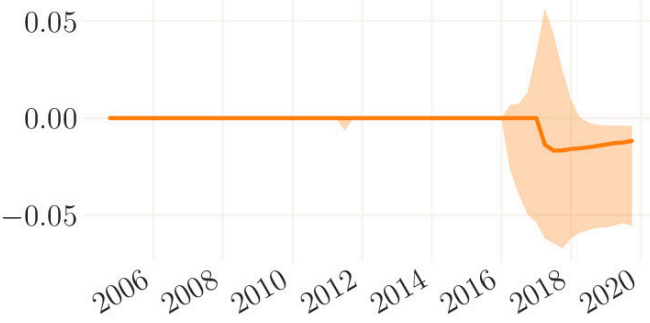

Figure G.16: RANK model estimated to $1998-2019$. The net effect of a counterfactual $1 \%$ monetary policy shock in 2010Q4 that raises the expected ZLB spell on average by 3 quarters.

Note: Means over 250 simulations drawn from the posterior.

inflation and output is almost entirely due to the early reaction of the Fed to lower rates to the ZLB, which was quicker than suggested by the policy rule. As inflation and the output gap did not yet decline, this can be instead interpreted as a reaction to the turmoil in financial markets. We find that this emergency reaction prevented a substantially deeper fall in inflation and output during the trough of the recession. Regarding the exit from ZLB, we find that the smoothed nominal interest rate series leaves the ZLB a year after the actual ZLB period ended. The very low federal fund rate in 2016 is therefore treated as having the same effects on equilibrium dynamics as a binding ZLB. This might capture uncertainty effects that could not explicitly included in our modelling approach.

Why are our estimated effects of forward guidance so weak, in particular compared to Gust et al. (2017)? As Figure G.16 shows, a counterfactual one-percent shock to the shadow rate in 2010Q4 would have extended the duration of the expected ZLB spell by about 3 quarters and would have had a considerable effect on output and inflation. These strong effects are not surprising given the results by Del Negro et al. (2015a) on the forward guidance puzzle. To address the question of what role forward guidance plays in our RANK model, note that in our model by construction the risk premium shock always appears 
together with the nominal rate. Also recall that across models the risk premium shock was one of the main, if not the main driver of the post-2008 US economic dynamics. Throughout our sample, the risk premium is positive.

A forward guidance shock will be very hard to distinguish from a negative risk premium shock. While in normal times, the risk premium and monetary policy shock are easy to identify via the response of the policy rate, this is not possible at the ZLB. Any positive forward guidance shock would require additional risk premium shocks to maintain the low level of consumption and investment. For this reason it is more likely to attribute any increase in consumption or investment to decreases in the risk premium process as these are in the nature of an stationary $\mathrm{AR}(1)$ process, and not to a positive forward guidance shock. Put differently, at the ZLB we essentially filter 6 observables with 7 structural shocks, of which two are observationally equivalent, and one of which is already identified to be at an elevated level. This explains why we are unable to identify strong forward guidance shocks.

How can this finding be interpreted in the light of the results of Gust et al. (2017) and Jones et al. (2018)? The former use the particle filter to approximate the distribution of states. This practically implies the use of considerable measurement errors for the filter. The authors set the model-implied ZLB to exactly zero, whereas we use the highest realized value of the FFR during the ZLB episode (c.f. Section 3). This means in practice that, in the absence of any measurement errors, their model-implied ZLB never actually binds. We suspect that, as a binding ZLB helps to explain the large drop in output in response to a risk premium and MEI shocks, the filter treats the actual observation of the FFR as a measurement error and assumes the actual FFR to be straight at zero. This way, the actual level of the FFR relative to the model-implied ZLB of zero enters the filtering process and potentially manifests in the finding of positive forward guidance shocks.

As for the case of Jones et al. (2018), the authors identify the ZLB durations in the estimation as in Kulish et al. (2017). In a second step they feed the estimated ZLB durations and the smoothed shock series obtained in posterior sampling into the model and use the solution method by Jones (2017) to determine the endogenous ZLB-durations. Any deviation of the spell durations identified by the posterior is then presumed to be the result from central bank communication. In the absence of any additional data input, this setup is likely to be subject to the same problem as in our model: forward guidance shocks will be hard to distinguish from risk premium shocks. However, the specific setup of the authors allows to include term premium data to the estimation. The authors argue that the term premium contains information on the future course of interest rates, and can hence be used to correctly identify forward guidance shocks via the estimated spell durations, and distinguish their effects from those of risk premium shocks. ${ }^{47}$ While we can not test whether this holds in practice, we considered as a sound argument to overcome the problems sketched in this section.

\footnotetext{
${ }^{47}$ In practice, including the term premium as an observable is also possible with our methodology. Note that we can find the expected future value in period $t+s$ of all variables via Equation (7), which could easily be linked to an observable. We abstain from doing so because we feel that the interest in the effects of forward guidance has decreased over the recent years.
} 


\section{Appendix $H$ Evolution of the natural rate}

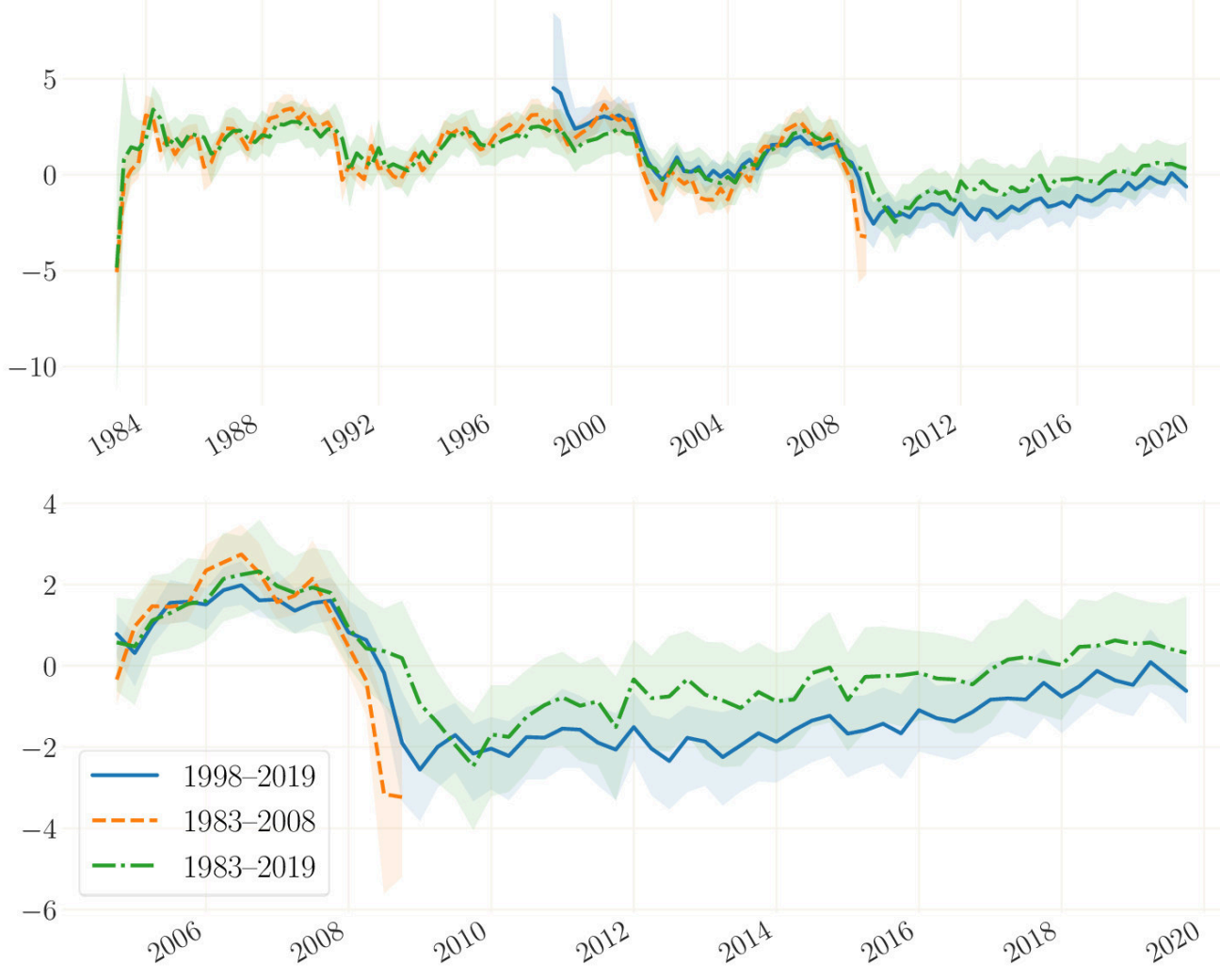

Figure H.17: RANK model estimated over different samples. Evolution of the natural rate.

Note: Means over 250 simulations drawn from the posterior.

Following Laubach and Williams (2003), an active literature has used different approaches to estimate the natural real interest rate, or ' $r$-star'. While the most prominent approach is to employ semi-structural models (see, e.g., Laubach and Williams (2003), Holston et al. (2017)), other frameworks such as VARs, VECMs and affine term structure models have been considered in this literature. In addition, Edge et al. (2008) and Neri and Gerali (2019) provide examples for the use of DSGE model in obtaining estimates of the natural rate. As a contribution to this literature, Figure H.17 displays the paths of the US natural rate that are implied by our estimates of the RANK model on several samples. It shows that our model predicts a decline of r-star far into negative territory after the Financial crisis as well as a return to positive territory at the end of the sample. This finding stands in contrasts to estimates of the natural rate according to the models by Laubach and Williams (2003) and Holston et al. (2017), which imply that r-star remained positive throughout the crisis. Apart from the considerable uncertainty surrounding estimates of $r$-star, this discrepancy is mainly due to the fact, that DSGE model estimates of the natural rate cannot capture its trend-component. However, according to semi-structural estimates, the trend-growth of output supported r-star in the financial crisis and kept it in positive 
territory. In contrast, the path of r-star in our DSGE model merely captures its cyclical components. Specifically, it reflects fluctuation of the real rate in the frictionless equilibrium around the model's steady state.

\section{Appendix I Additional historical shock decomposition of the crisis}
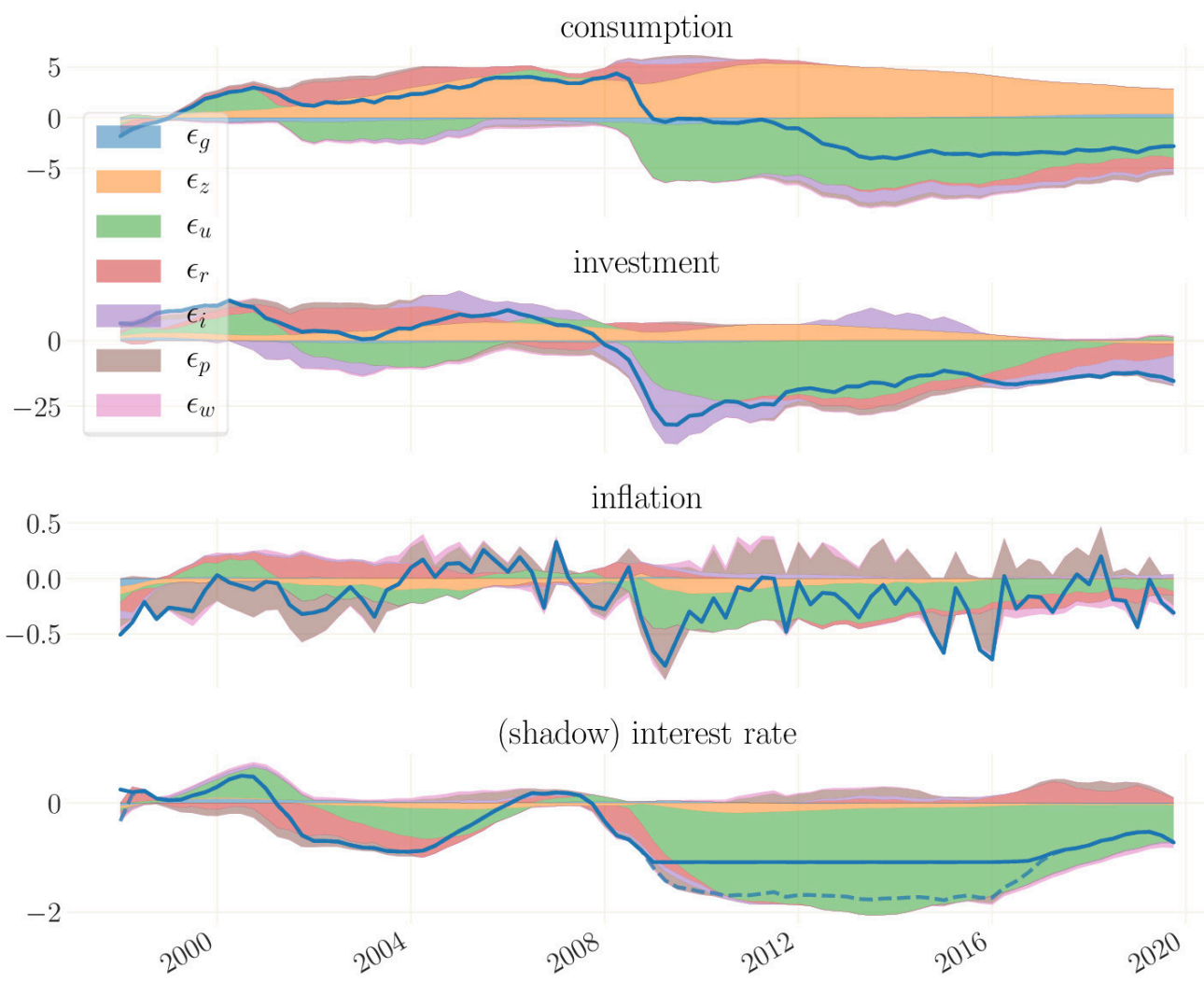

Figure I.18: TANK Model estimated to 1998-2019. Decomposition of the smoothed time series into the contribution of the different shocks.

Note: Means over 250 simulations drawn from the posterior. The contribution of each shock is normalized as in Appendix E. 


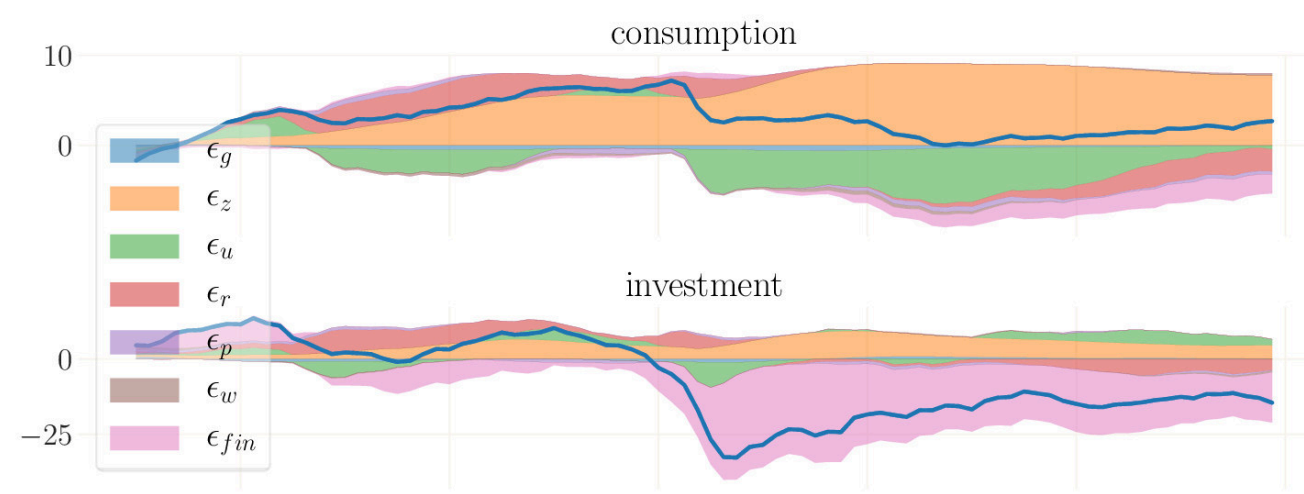

inflation

0

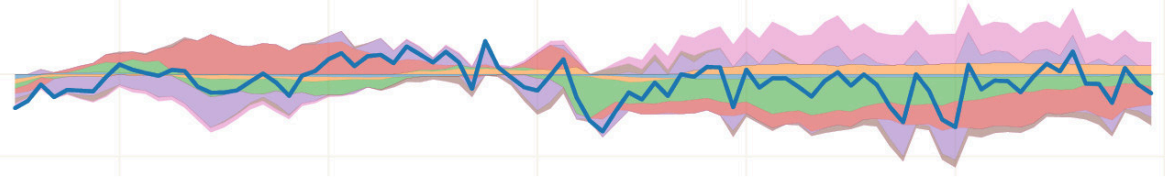

$-1$

(shadow) interest rate

0

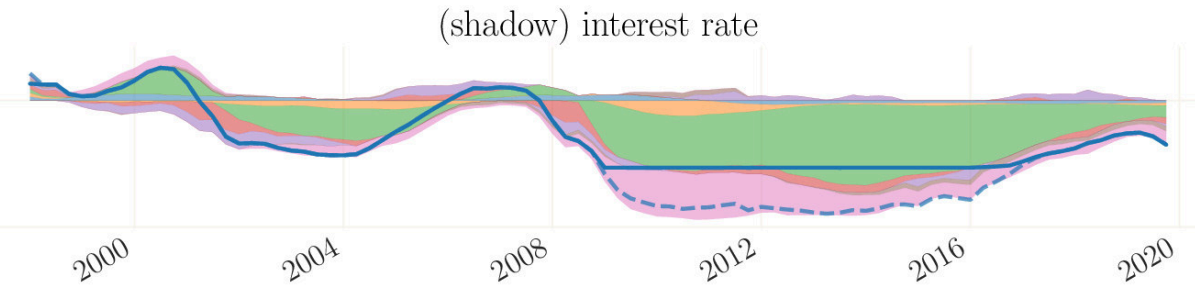

Figure I.19: FRANK-R model - with financial instead of MEI shock - estimated to 1998-2019. Decomposition of the smoothed time series into the contribution of the different shocks.

Note: Means over 250 simulations drawn from the posterior. The contribution of each shock is normalized as in Appendix E. 

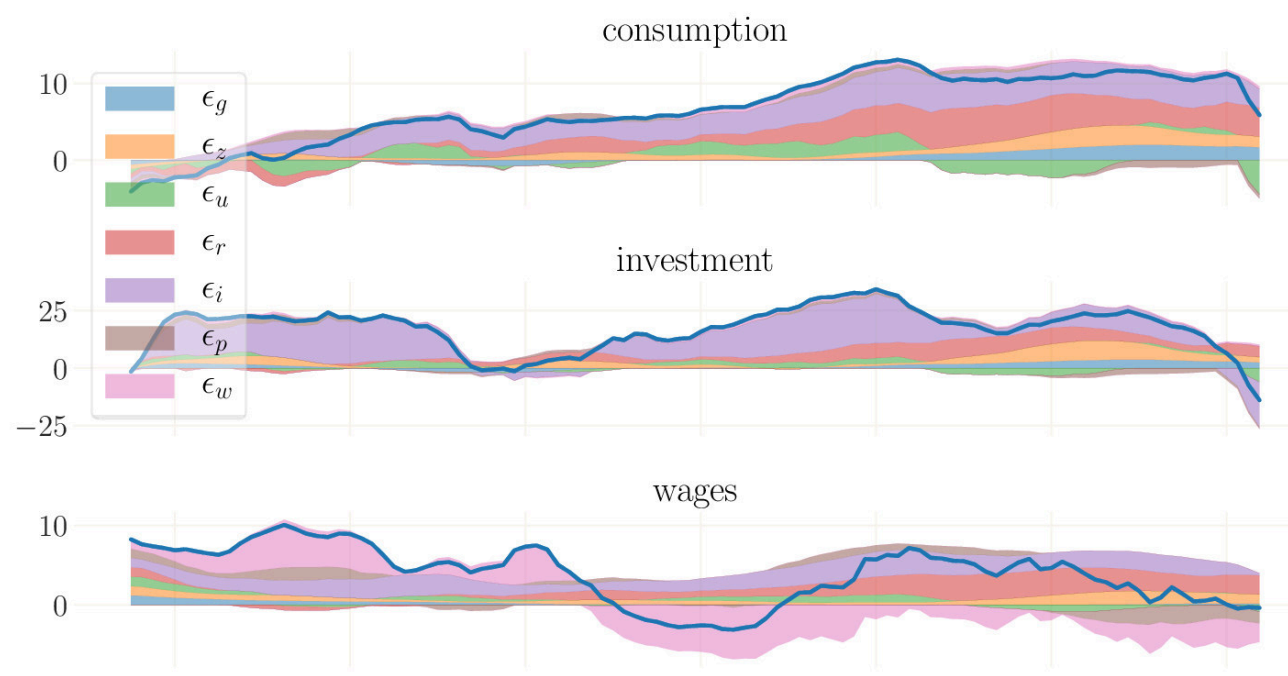

inflation
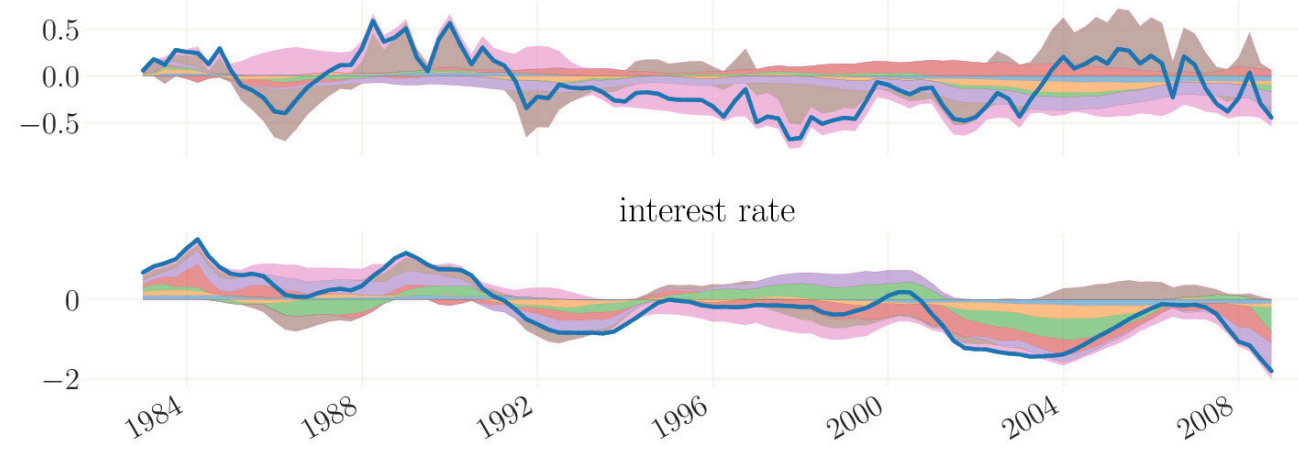

Figure I.20: RANK - estimated to 1983-2008. Decomposition of the smoothed time series into the contribution of the different shocks.

Note: Means over 250 simulations drawn from the posterior. The contribution of each shock is normalized as in Appendix E. 


\section{Appendix J Additional impulse response functions}
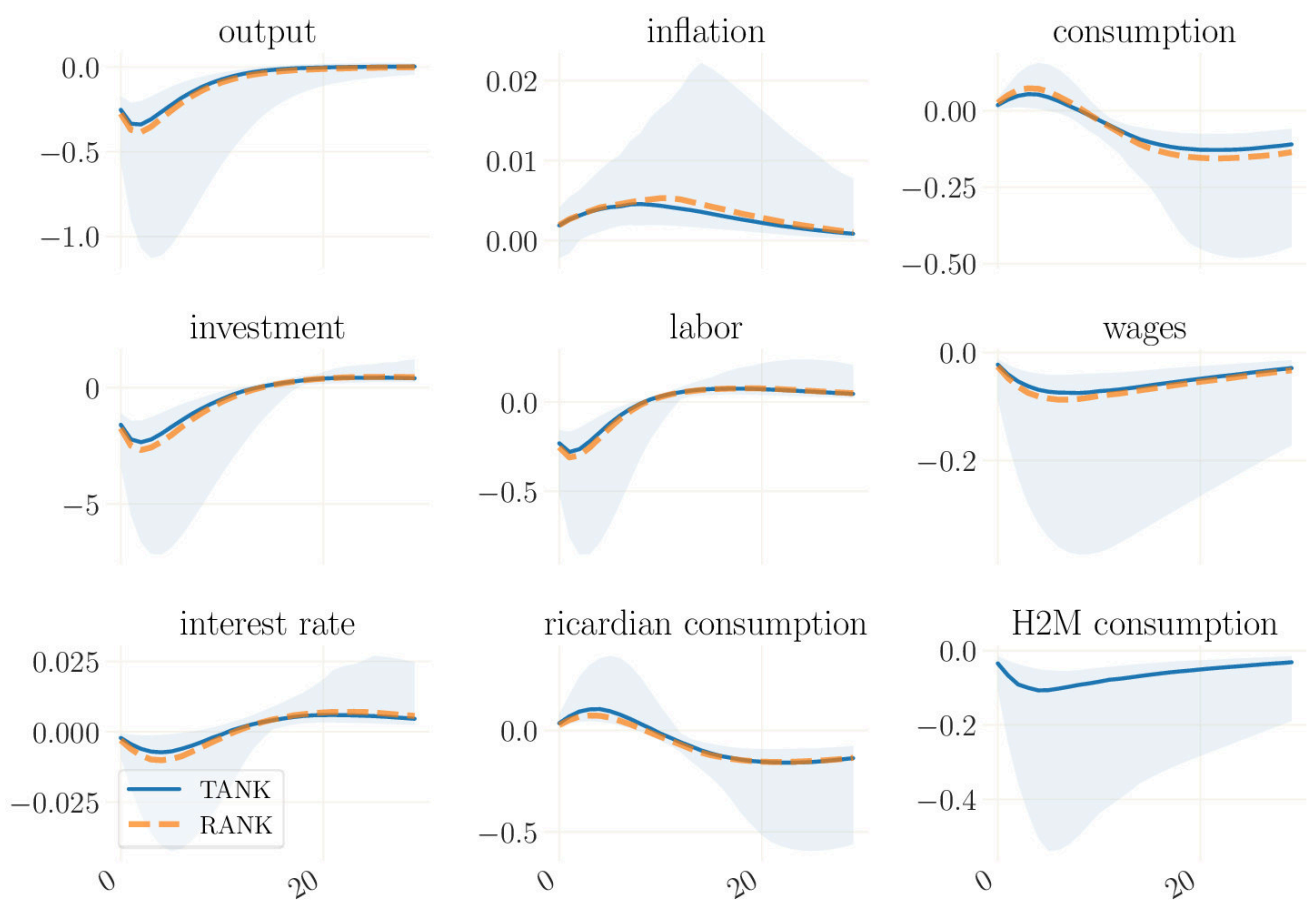

Figure J.21: IRFs to a MEI shock in TANK estimated for 1998-2019. Compared with mean IRFs to RANK. Note: Medians over 250 simulations drawn from the posterior with $90 \%$ credible set for TANK. Shock size is the posterior mean standard deviation for each model 


\section{Appendix K Exogenous processes and innovations}

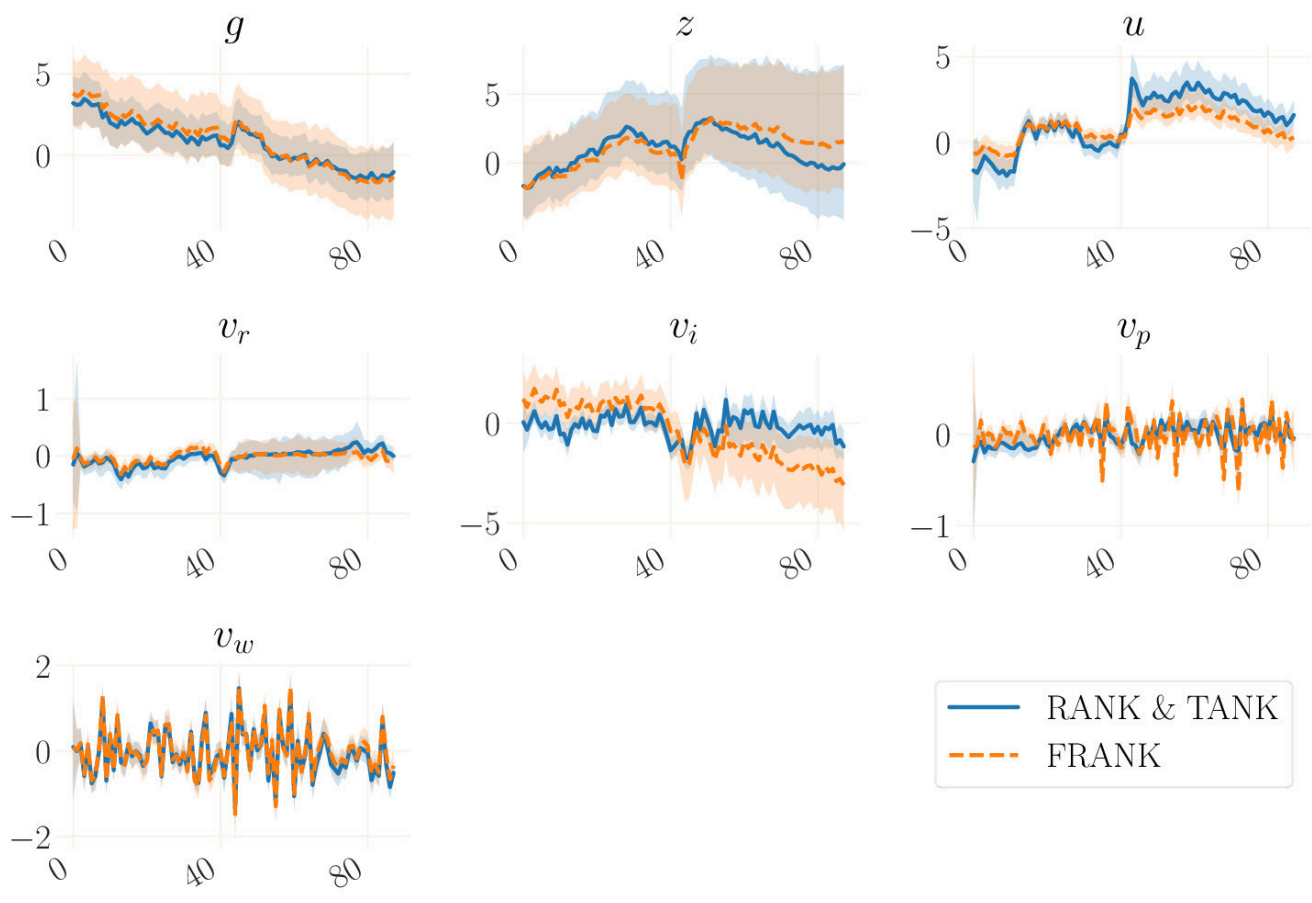

Figure K.22: Smoothened exogenous processes for the different models, sample 1998-2019. 95\% confidence intervals of 250 draws from the posterior. 

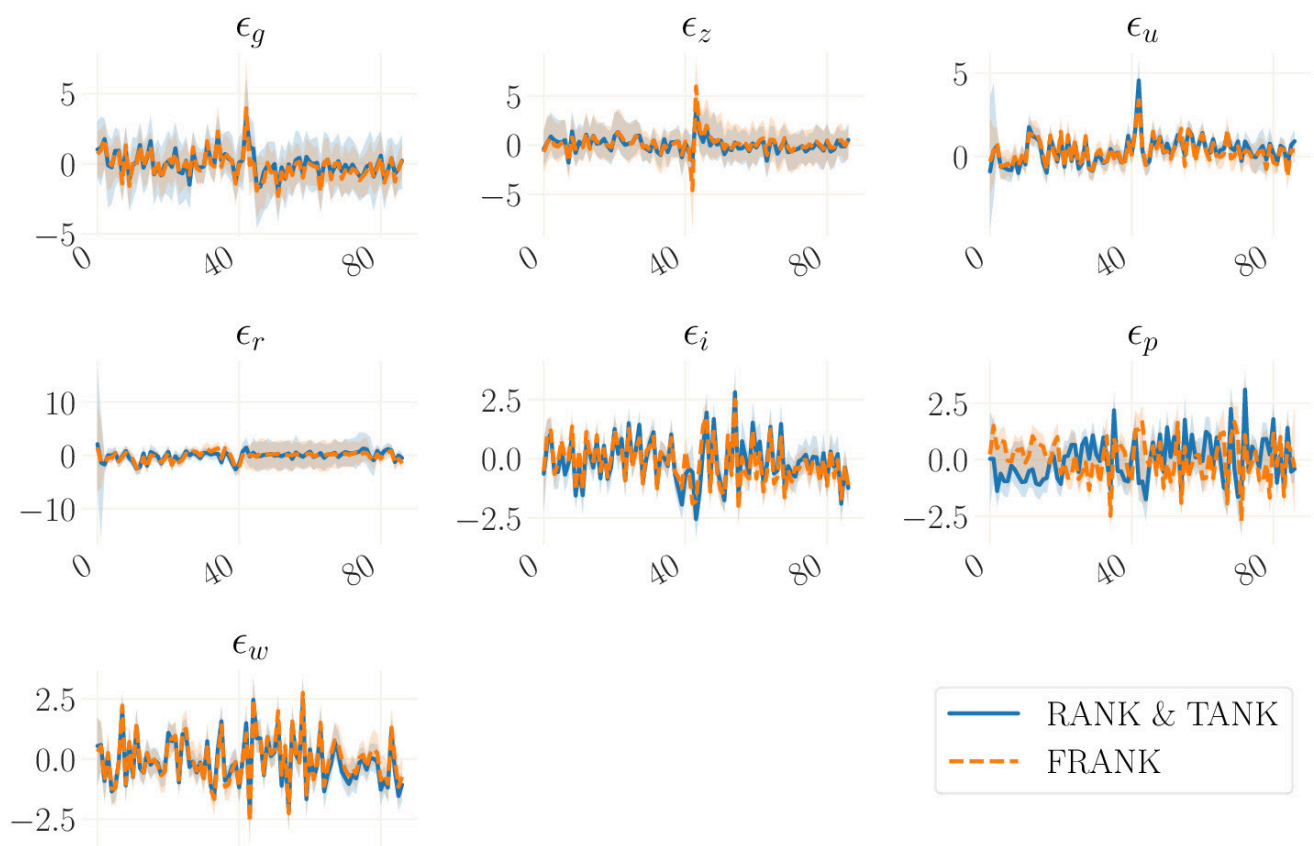

$0 \quad$ 40 $\quad$ do

Figure K.23: Smoothened innovations to exogenous processes for the different models, sample 1998-2019. Shocks are normalized to the standard deviation of the parameter draw. 95\% confidence intervals of 250 draws from the posterior. 


\section{IMFS WORKING PAPER SERIES}

\section{Recent Issues}

\begin{tabular}{|c|c|c|}
\hline $142 / 2020$ & $\begin{array}{l}\text { Gregor Boehl } \\
\text { Gavin Goy } \\
\text { Felix Strobel }\end{array}$ & $\begin{array}{l}\text { A Structural Investigation of Quantitative } \\
\text { Easing }\end{array}$ \\
\hline $141 / 2020$ & Karl-Heinz Tödter & $\begin{array}{l}\text { Ein SIRD-Modell zur Infektionsdynamik } \\
\text { mit endogener Behandlungskapazität und } \\
\text { Lehren für Corona-Statistiken }\end{array}$ \\
\hline $140 / 2020$ & $\begin{array}{l}\text { Helmut Siekmann } \\
\text { Volker Wieland }\end{array}$ & $\begin{array}{l}\text { The Ruling of the Federal Constitutional } \\
\text { Court concerning the Public Sector } \\
\text { Purchase Program: A Practical Way } \\
\text { Forward }\end{array}$ \\
\hline $139 / 2020$ & Volker Wieland & $\begin{array}{l}\text { Verfahren zum Anleihekaufprogramm der } \\
\text { EZB }\end{array}$ \\
\hline $138 / 2020$ & $\begin{array}{l}\text { Francisco Gomes } \\
\text { Michael Haliassos } \\
\text { Tarun Ramadorai }\end{array}$ & Household Finance \\
\hline $137 / 2019$ & $\begin{array}{l}\text { Martin Kliem } \\
\text { Alexander Meyer-Gohde }\end{array}$ & $\begin{array}{l}\text { (Un)expected Monetary Policy Shocks } \\
\text { and Term Premia }\end{array}$ \\
\hline $136 / 2019$ & $\begin{array}{l}\text { Luc Arrondel } \\
\text { Hector Calvo-Pardo } \\
\text { Chryssi Giannitsarou } \\
\text { Michael Haliassos }\end{array}$ & Informative Social Interactions \\
\hline $135 / 2019$ & $\begin{array}{l}\text { Tiziana Assenza } \\
\text { Alberto Cardaci } \\
\text { Domenico Delli Gatti }\end{array}$ & $\begin{array}{l}\text { Perceived wealth, cognitive sophistication } \\
\text { and behavioral inattention }\end{array}$ \\
\hline 134 / 2019 & Helmut Siekmann & $\begin{array}{l}\text { The Asset Purchase Programmes of the } \\
\text { ESCB - an interdisciplinary evaluation }\end{array}$ \\
\hline $133 / 2019$ & $\begin{array}{l}\text { Josefine Quast } \\
\text { Maik H. Wolters }\end{array}$ & $\begin{array}{l}\text { Reliable Real-time Output Gap Estimates } \\
\text { Based on a Modified Hamilton Filter }\end{array}$ \\
\hline $132 / 2019$ & $\begin{array}{l}\text { Galina Potjagailo } \\
\text { Maik Wolters }\end{array}$ & Global Financial Cycles since 1880 \\
\hline $131 / 2019$ & $\begin{array}{l}\text { Philipp Lieberknecht } \\
\text { Volker Wieland }\end{array}$ & $\begin{array}{l}\text { On the Macroeconomic and Fiscal Effects } \\
\text { of the Tax Cuts and Jobs Act }\end{array}$ \\
\hline $130 / 2019$ & Eduard Hofert & Regulating Virtual Currencies \\
\hline $129 / 2018$ & $\begin{array}{l}\text { Olga Goldfayn-Frank } \\
\text { Johannes Wohlfart }\end{array}$ & $\begin{array}{l}\text { How Do Consumers Adapt to a New } \\
\text { Environment in their Economic } \\
\text { Forecasting? Evidence from the German } \\
\text { Reunification }\end{array}$ \\
\hline
\end{tabular}


128 / $2018 \quad \begin{aligned} & \text { Christopher Roth } \\ & \text { Johannes Wohlfart }\end{aligned}$

$127 / 2018$

$126 / 2018$

$125 / 2018$

$124 / 2018$

$123 / 2018$

122 / 2018

$121 / 2018$

$120 / 2017$

$119 / 2017$

$118 / 2017$

117 / 2017

$116 / 2017$

$115 / 2017$

114 / 2017

$113 / 2017$
Helmut Siekmann

Karl-Heinz Tödter

Gerhard Ziebarth

Helmut Siekmann

Maik H. Wolters

Michael Haliassos

Thomas Jansson

Felix Strobel

Alexander Meyer-Gohde Daniel Neuhoff

Athanasios Orphanides

Gregor Boehl

Gregor Boehl

Thomas Fischer

Tobias H. Tröger

Tobias H. Tröger

Guenter W. Beck

Volker Wieland

Michael Binder

Jorge Quintana

Philipp Lieberknecht

Volker Wieland

Mewael F. Tesfaselassie Maik Wolters
How Do Expectations About the Macroeconomy Affect Personal Expectations and Behavior?

Financial Literacy Externalities

The Government Spending Multiplier,

Fiscal Stress and the Zero Lower Bound

Generalized Exogenous Processes in DSGE: A Bayesian Approach

The Boundaries of Central Bank Independence: Lessons from Unconventional Times

Zinsen, Effektivpreise und Lebenskosten

- Ein Beitrag zur Konstruktion eines intertemporalen Preisindex

Legal Tender in the Euro Area

How the Baby Boomers' Retirement Wave Distorts Model-Based Output Gap

Estimates

Die Einstandspflicht der Bundesrepublik

Deutschland für die Deutsche

Bundesbank und die Europäische

Zentralbank

Monetary Policy and Speculative Stock Markets

Can Taxation Predict US Top-Wealth Share Dynamics?

Why MREL Won't Help Much

Too Complex to Work - A Critical Assessment of the Bail-in Tool under the European Bank Recovery and Resolution Regime

How to Normalize Monetary Policy in the Euro Area

Model Uncertainty in Macroeconomics: On the Implications of Financial Frictions

The Impact of Growth on Unemployment in a Low vs. a High Inflation Environment 